
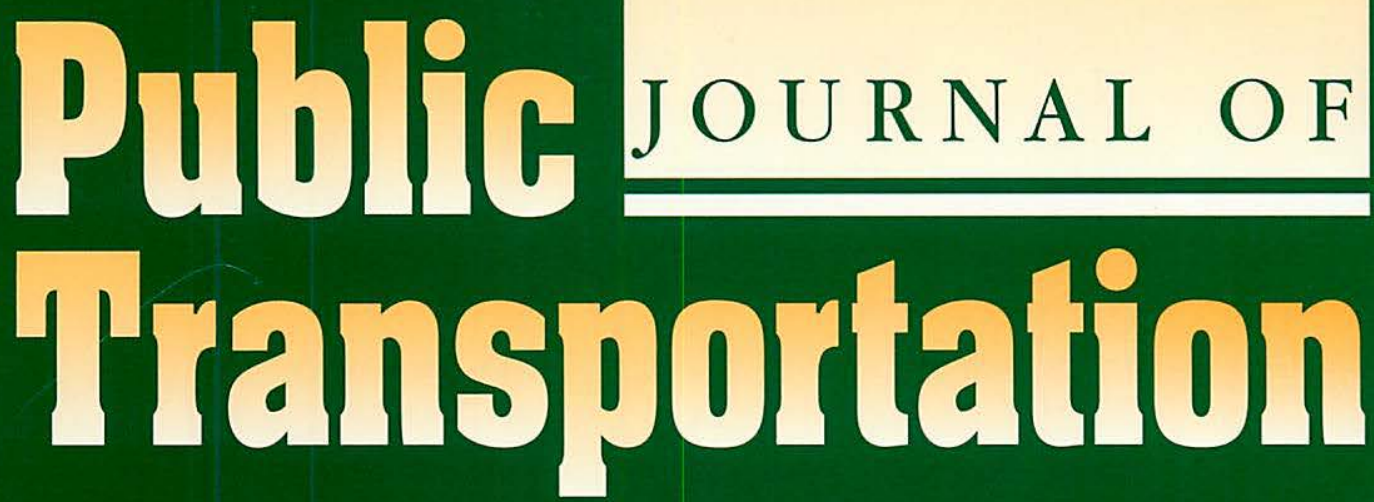

Asad J. Khattak \& Mark Hickman

Edward A. Mierzejewski

Reza Banai

man, Bo Edvardsson \& Tommy Gärling

Xuehao Chu \& Steven E. Polzin
Automatic Vehicle Location and Computer-Aided Dispatch Systems: Design and Application Considerations

A Strategic Approach to the Transportation Planning Process

Transit-Oriented Development Suitability Analysis by the Analytic Hierarchy Process and a Geographic Information System:A Prototype Procedure

Perceived Service Quality Attributes in Public Transport: Inferences from Complaints and Negative Critical Incidents

The Value of Having a Public Transit Travel Choice






\section{Public \\ JOURNAL OF \\ Transportation}

Gary L. Brosch, Editor

Patricia Henderson, Managing Editor

\section{Editorial Board}

Robert B. Cervero, Ph.D.

University of California, Berkeley

ChesterE. Colby

MKCentennial

GordonFielding, $\mathrm{PhD}$.

University of California, Irvine

DavidJ.Forkenbrock, PhD.

Universityoflowa

JoséA.Gómez-lbáñez,PhD.

HanvardUniversity
Naomi W. Ledé, Ph.D.

Texas Southern University

William W. Millar

American Public TransitAssociation

Sandra Rosenbloom, Ph.D.

University of Arizona

Lawrence Schulman

Orbital Sciences Corp.

George Smerk, D.B.A.

Indiana University

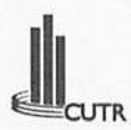

The Journal of Public Transportation (ISSN 1077-291X) is published quarterly by the Center for Urban Transportation Research (CUTR) in the College of Engineering at the University of South Florida. The contents of this document reflect the views of the authors, who are responsible for the facts and the accuracy of the information presented herein. This document is disseminated under the sponsorship of the U.S. Department of Transportation, University Research Institute Program, in the interest of information exchange. The U.S. Government assumes no liability for the contents or use thereof. Subscriptions are complimentary and may be obtained by contacting the Center for Urban Transportation Research, University of South Florida, 4202 E. Fowler Avenue, CUT 100, Tampa, FL 33620-5375, (813) 974-3120, email:phenders@cutr.eng.usf.edu. 


\section{Public sousas or Transportation}

Volume 2, No. 1, 1998

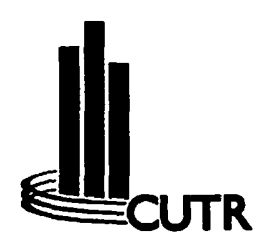

C 1998 Center for Urban Transportation Research

National Urban Transit Institute

Center for Urban Transportation Research

College of Engineering - University of South Florida

4202 E. Fowler Avenue, CUT 100, Tampa, FL 33620-5375

(813) $974-3120 \cdot \operatorname{Fax}(813) 974-5168$

E-mail:phenders@cutr.eng.usf.edu

Web Site: http://www.cutr.eng.usf.edu 


\section{Public \\ JOURNAL OF \\ Transportation}

Volume 2, No. 1, 1998

\section{Contents}

Automatic Vehicle Location and Computer-Aided Dispatch Systems:

Design and Application Considerations

AsadJ.Khattak\& Mark Hickman

A Strategic Approach to the Transportation Planning Process

EdwardA.Mierzejewsli

Transit-Oriented Development Suitability Analysis by the Analytic Hierarchy Process and a Geographic Information System:

A Prototype Procedure

RezaBanai

Perceived Service Quality Attributes in Public Transport:

Inferences from Complaints and Negative Critical Incidents

Margareta Friman, Bo Edvardsson \& Tommy Gärling

The Value of Having a Public Transit Travel Choice

Xuehao Chu \& Steven E. Polzin

"Our troubled planet can no longer afford the luxury of pursuits confined to an ivory tower. Scholarship has to prove its worth. not on its own terms, but by service to the nation and the world." - Oscar Handlin 


\title{
Automatic Vehicle Location and Computer-Aided Dispatch Systems: Design and Application Considerations
}

\author{
Asad J. Khattak \\ University of North Carolina at Chapel Hill \\ Mark Hickman \\ Texas A\&M University
}

\begin{abstract}
$\overline{\text { Abstract }}$
Automatic Vehicle Location (AVL) systems can track transit vehicles in real time. Computer-Aided Dispatch (CAD) software is used to monitor transit operations and assist management of transit operations. Together with AVL systems, CAD software can be used to replace a disabled vehicle by dispatching another vehicle, or meet fluctuating travel demand by adjusting transit headways, schedules, and routes. AVL and $C A D$ technologies can vitalize transit by directly improving on-time performance, increasing transit efficiency through providing dispatchers with location, direction and status information, and reducing operating costs through reducing dependence on transit field supervisory personnel. Direct benefits to travelers can include higher reliability of travel times and reduced stress in dealing with transit unreliability. This study explores the development, availability, and impacts of AVL/CAD technologies as reported by $A V L$ vendors and transit implementers. The study defines the key features, functions, and performance characteristics of $A V L / C A D$ technologies that can influence the level of benefits realized. The AVL/CAD implementation context is ex-
\end{abstract}


plored by examining where, when, and for what users these systems are being implemented. The results of two surveys are reported. To explore the availability of $A V L /$ $C A D$ systems, technology suppliers were surveyed. Suppliers identified the features, functions, and performance of available AVL/CAD technologies. To determine the extent of $A V L / C A D$ deployment, transit operators were surveyed regarding their experiences with $A V L / C A D$ technologies and the subsequent impacts on travelers and transit agency performance. This research provides a systematic method for evaluation of $A V L / C A D$ systems and reports the perceptions of $A V L / C A D$ vendors and transit implementers regarding available products and their impacts. The results suggest a need for better tools to characterize and quantify the impacts and benefits of AVL/ CAD systems.

\section{Introduction}

Advanced Public Transportation Systems (APTS) can increase transit efficiency, improve transit level of service, reduce costs, and temper declining transit use in the United States. A promising set of APTS technologies are Automatic Vehicle Location (AVL) systems and Computer-Aided Dispatch (CAD) software. AVL systems track transit vehicles in real time and transmit the current locations and schedule adherence information either to the driver or to a central control. CAD software integrates transit operations by giving transit dispatchers and supervisors decision support tools to manage the operating environment. Together, AVL and CAD can be used to respond quickly to transit operational problems; examples include dispatching a vehicle to replace a disabled vehicle or otherwise adjusting transit headways, schedules, and routes to improve the level of service. Integration of AVL systems with other APTS technologies can be potentially beneficial. For example, by integrating AVL with silent alarms and driver warning devices, transit security can be improved, crash propensity reduced, and response times in incident situations shortened.

Currently, many transit agencies are testing and deploying AVL/CAD technologies. The purpose of this study is to explore the available technologies and identify the possible impacts (benefits and costs) of deployment. Results from 
surveying AVL/CAD technology suppliers and transit agency implementers are reported. The first section of this paper provides a literature review of AVL/CAD technology and implementation. Based on an apparent gap in the existing literature, the second section proposes a conceptual structure to characterize both the technological attributes and the impacts of technology implementation. This structure is used in both a technology supplier survey and a transit agency survey to determine the value of AVL/CAD implementation. The survey methodology is reported in the third section, and results of the survey are described in the fourth section. Finally, conclusions on the applicability of the conceptual structure and on the current state of AVL/CAD technology are made.

\section{Background and Literature}

The research of Casey et al. (1996) has provided a recent review of AVL and CAD technologies more specifically, and recent APTS projects more broadly. Their work builds on an earlier study by Schweiger, Kihl, and Labell (1994). Casey et al. (1996) report that AVL systems are increasingly being used in transit and trucking fleets, police cars, and ambulances for computer-based vehicle tracking. They also identify at least $58 \mathrm{AVL}$ systems that are in operation, under installation, or planned in the U.S. ! ister, Schweiger and Keaveny (1995) provide an account of AVL/CAD technology (to be) deployed in Detroit, Michigan.

A detailed description of AVL technologies and a list of relevant references is provided in Khattak et al. (1993). AVL technologies include a location technology (sometimes more than one technology is used) and a communication mechanism for transmitting location data from the vehicles to a central dispatching unit. The incoming information is displayed for dispatchers on computer monitors. AVL can be integrated with other APTS technologies, such as passenger information systems, automatic passenger counters, or silent alarms. Alternative AVL technologies include (1) proximity beacon/signpost, (2) satellitebased Global Positioning System (GPS) (3) radio navigation/location, and (4) dead reckoning. Communication technologies can include two-way radio, onboard cellular telephones, and satellite communication services. AVL location 
and communication technologies may be used singly or in combination, depending on their performance and flexibility and on transit agency needs.

The current industry trends indicate that transit agencies are increasingly choosing GPS technology compared with proximity beacons. However, Casey et al. (1996) report that, at the time of their review, the proximity beacon (signpost) was the most common AVL technology in use with transit agencies. The beacons are placed along transit routes. Either the beacon or the vehicle has a unique ID. If the beacon has a unique ID, then it sends out a signal detectable by a transit vehicle fitted with a receiver. When the vehicle is asked by the central unit to report its position, it transmits the ID of the last beacon passed and the distance traveled since passing the beacon. When vehicles have unique IDs, the beacons receive signals from vehicles upon passing and transmit the information to the control center (typically via wired communication systems). This method reduces the need for reserved radio frequencies but is relatively limited in terms of locating vehicles in real-time.

Casey et al. (1996) report that, out of the 17 planned or implemented beacon systems in North America, 14 are operational; of the 40 planned or implemented satellite-based GPS systems, 10 are operational. Seven transit agencies have planned or implemented other systems (dead-reckoning, ground-based radio, or one of these supplemented by signposts or GPS), out of which 4 are currently operational. These data indicate that, while signpost systems exceed GPS systems in current operation, those in the planning stages are now installing GPS. The lower cost of GPS and its improved location accuracy (e.g., by using differential GPS) are often cited as important features guiding its selection for transit AVL systems.

To locate transit vehicles, GPS uses signals transmitted from orbiting satellites to receivers on transit vehicles. These signals are then either processed onboard the vehicle or directly transmitted to a dispatch control center. GPS performance does not degrade significantly during adverse weather or due to increasing vehicle fleet size. Access to satellite signals is provided free of charge; therefore, the major cost item is the receiver technology installed on the vehicle and 
the communication cost (to communicate the vehicle location to a control center). The disadvantage of GPS is that tall buildings, tunnels, and foliage can result in "loss of lock," i.e., loss of signals from the satellites. In such situations, supplementary systems such as dead reckoning may be used. Dead reckoning is based on calculating the vehicles' position through distance traveled and direction from an initial known position. Odometers are typically used to measure distance and a compass to is used to measure direction. Dead reckoning accumulates errors along distance traveled due to mechanical factors. Another popular method is differential GPS where a receiver is placed at a known location. The difference between the site and the GPS-measured location is used to improve locational accuracy. Differential GPS still suffers from the "loss of lock" problem. In some cases, a combination of dead reckoning and differential GPS are used.

The radio location methods are based on measuring waves propagating between vehicles and stations. However, due to wave interference from other sources such as transmission lines, the use of radio frequencies has declined. Nonetheless, Casey et al. (1996) report that, in the Los Angeles area, a private vendor has strategically placed transmitting and receiving towers and is using triangulation to determine vehicles positions (see Khattak et al. [1993] for a description of triangulation). Vehicle positions are transmitted to several subscribers (a transit agency, package delivery, ambulance service, and sanitation service), who make the system economically viable.

Once the vehicle has received its position data, the data are transmitted to a dispatch center by polling, where the dispatcher periodically requests each vehicle to identify its location. Another popular method of transmitting the data is exception reporting, where each vehicle reports its position only if it is running off-schedule or off-route. Transit agencies sometimes use a combination of periodic polling and exception reporting (Casey et al. 1996).

Computer-aided dispatch is a transit software that can perform and integrate transit operations. The key CAD functions are monitoring operations and providing decision support to respond to delays and disruptions of service. The 
decision support system may recommend service improvements such as adjustment of vehicle headways, dispatching replacement or additional vehicles, or reporting to appropriate authorities in case of incidents and on-vehicle emergencies. The AVL technology provides the necessary real-time vehicle location information to the CAD software.

In spite of this fairly good knowledge of AVL/CAD technology, there is only limited reported evidence to date on the benefits to transit agencies and travelers. Goeddel (1996) reports on the benefits of APTS technologies, including AVL/CAD systems. Goeddel evaluates the benefits of several AVL/CAD system implementations (e.g., Baltimore, Kansas City, and Toronto), where improved on-time performance, reduced layover times, and ultimate fleet reductions were possible. The author then extrapolates these benefits to all federallyfunded transit agencies to calculate the total benefit of APTS deployment in the United States. However, very few of the recent AVL/CAD implementations in the U.S. have been subsequently evaluated to determine the benefits and costeffectiveness of these technologies.

\section{Conceptual Structure}

\section{Technology Deployment}

The literature and research to date lacks a formal structure for transit technology assessment. In response, this study identified a structure to classify and investigate the availability and deployment of AVL/CAD technologies. First, the attributes of the technology are based on defining design dimensions in terms of their features, functions, and performance (Table 1). The existing literature discusses extensively the features and functions of AVL/CAD systems. Moreover, AVL technical performance may be evaluated in terms of accuracy, frequency of information updates, maintenance and flexibility in routes served, and cost. For $\mathrm{CAD}$, the important evaluation criteria are the display attributes and the content of information given to dispatchers at the operations center.

In the actual deployment, AVL/CAD technologies have application dimensions (that vary across space, time, and users). The reasons and strategies for AVL/CAD deployment are not likely to be similar among transit agencies. Some 


\begin{tabular}{|c|c|c|c|}
\hline \multicolumn{4}{|c|}{$\begin{array}{c}\text { Table } 1 \\
\text { Dimensions of AVL/CAD Features, Functions, and Performance }\end{array}$} \\
\hline \multirow[t]{2}{*}{ Technology } & \multicolumn{3}{|c|}{ Classification } \\
\hline & Features & Functions & Performance \\
\hline Dead reckoning & $\begin{array}{l}\text { Distance \& } \\
\text { direction } \\
\text { measurement } \\
\text { (odometer \& } \\
\text { compass) }\end{array}$ & Tracking & $\begin{array}{l}\text { Tracking accuracy } \\
\text { Frequency of } \\
\text { information updates }\end{array}$ \\
\hline Proximity beacon/signpost & $\begin{array}{l}\text { Signposts \& } \\
\text { vehicle transmitter }\end{array}$ & Tracking & Flexibility (route) \\
\hline Radio determination & $\begin{array}{l}\text { Radio signals } \\
\text { Vehicle to stations }\end{array}$ & Tracking & Cost \\
\hline Satellite-based GPS & $\begin{array}{l}\text { Satellites \& } \\
\text { vehicle receivers }\end{array}$ & Tracking & \\
\hline Computer-aided dispatch & $\begin{array}{l}\text { Display, platform, } \\
\text { map base }\end{array}$ & $\begin{array}{l}\text { Real-time } \\
\text { monitoring, } \\
\text { scheduling \& } \\
\text { dispatching }\end{array}$ & $\begin{array}{l}\text { Display medium } \\
\text { information } \\
\text { content }\end{array}$ \\
\hline
\end{tabular}

transit agencies may deploy AVL/CAD because of their need to replace an aging system (for instance, a radio system) and/or decisionmakers may allocate new funding to upgrade dispatching based on the perceived value of these new systems. Furthermore, the spatial, temporal, and user dimensions of AVL/CAD technologies need ti be considered carefully before deployment decisions are made. For example, the areas (particularly terrain), the populations served (commuters vs. persons with disabilities), and the frequency that transit agencies provide service on various routes are important dimensions to consider (in where, when, and for whom AVL/CAD systems are deployed). The application dimensions relevant to $\mathrm{CAD}$ are the quality and display of location information for supervisors who make operations decisions, e.g., scheduling and adjusting headways and routes. Overall, the application dimensions of space, time, and users are the 
factors that determine the impact of the technology in achieving transit system and traveler benefits.

\section{Impacts}

The impacts of deploying AVL/CAD systems are defined in terms of evaluation criteria (or evaluation dimensions) - efficiency, service quality, cost, time savings - and distribution dimensions - how these impacts are realized across space, time, and users.

\section{Evaluation Criteria}

AVL/CAD technologies can have direct, indirect, and simultaneous impacts on operators and travelers. Specifically, AVL systems are expected to have strong direct impacts on transit operators. The magnitude of direct operator impacts depends on the technology design dimensions, technology application dimensions, and the implementation context. The expected impacts are:

- improved dispatching and scheduling and, therefore, improved on-time performance;

- rapid response to service disruptions and emergencies;

- enhanced driver and passenger safety/security;

- better ability to monitor driver and vehicle performance; and

- improved planning functions including selection of routes, stops and service frequencies.

When AVL is used in conjunction with other technologies, it can reduce maintenance costs, e.g., due to quicker detection of mechanical problems on vehicles. In addition, an important but mostly indirect benefit of AVL/CAD systems to a transit agency can be increased ridership (and revenue). The direct expected traveler benefits due to AVL/CAD technologies include:

- increased transit reliability and reduced frustration with uncertain wait times;

- travel time savings and reduced uncertainty in travel times due to improved content and quality of transit information; and

- improved satisfaction with transit service. 


\section{Distribution Dimensions}

The impacts from individual AVL/CAD technologies can vary across individuals/groups both within the agency and across travelers (e.g., by location and time of travel). Some AVL/CAD technologies may influence travelers differently by design. For example, if AVL/CAD systems are implemented for ADA (Americans with Disabilities Act) service, then the impacts and benefits are targeted toward ADA-eligible individuals, such as the infirm and otherwise disabled. Alternatively, if the AVL provides real-time information on fixed route services to those with special electronic traveler information devices, the AVL/ $\mathrm{CAD}$ system benefits are targeted only to this select group.

\section{Methodology}

The literature review indicates that AVL/CAD technologies are still under development. However, their impacts, including net benefits, are still uncertain. The structure presented in the previous section describes one means of characterizing these technologies and their likely impacts. To illuminate the current experiences and impacts, AVL/CAD technology suppliers as well as transit agencies that have adopted AVL/CAD were surveyed.

The suppliers' survey obtained information about the availability of APTS technologies (Khattak et al. 1997). In this paper, the supplier responses to AVL/ $\mathrm{CAD}$ technologies are reported. Based on the conceptual structure described above, the survey inquired (from technology suppliers) about AVL design dimensions and supplier attributes. A separate transit agency questionnaire focused on AVL/CAD technology application dimensions and impacts. The transit agencies surveyed had either deployed or were planning to install AVL/CAD systems.

\section{Suppliers Survey}

A total of 40 questionnaires was received from about 250 distributed, resulting in a (relatively low) 16 percent response rate. The survey consisted of three main sections: 
- Context and background of vendor-this included the country of affiliation, years in business, number of employees, and percentage of products manufactured in the U.S.

- Technology Attributes - this identified the APTS technologies sold by the vendor (classified according to their features, functions, and performance) and the scope of their application in transit agencies.

- Impact-the expected benefits and impacts of the vendor's largestrevenue APTS technology on the performance of transit agencies and on the experience of travelers.

A copy of the survey is provided in Khattak et al. (1997).

\section{Transit Operators Survey}

In addition to the supplier survey, a total of $120 \mathrm{AVL} / \mathrm{CAD}$ questionnaires was sent out to various transit agencies operating in the U.S. and Canada that were reported in the literature as having implemented or planning to implement AVL/CAD systems. The questionnaires were directed to the management with instructions in the cover letter to consult with appropriate agency individuals if any of the answers were not known to the respondent. The transit agency survey consisted of four parts:

- Context of Transit Agency-information about the transit agency and its operating environment.

- Technology Attributes-information about the AVL/CAD technology being used by the transit agency.

- Technology Implementation-issues related to selection and implementation of their AVL/CAD technology.

- Impact-experiences of the transit agency with AVL/CAD technology.

The responses of the transit agencies are summarized according to these four parts.

To increase the response rate, a reminder letter was sent about three weeks after the initial surveys were mailed. A total of 29 responses was received, for a response rate of about 24 percent. Also, of the 29 respondents, 5 indicated that 
they had no AVL/CAD system or did not indicate the technology of their system. However, to determine perceptions regarding AVL/CAD systems, their responses to other questions, if applicable, are included in this paper. Also included are those who do not currently have AVL/CAD, but are planning to install or are presently installing these technologies.

\section{Results}

The responses of AVL/CAD vendors and transit agencies are summarized as case studies rather than a statistical sample of representative implementers. That is, the experiences in individual cases are of interest and are reported. Descriptive statistics are presented, but no statistical modeling of the data is performed.

\section{Analysis of the AVL/CAD Suppliers}

Automatic Vehicle Location Systems. Among the 40 APTS technology suppliers who responded, 18 are vending AVL systems, making it the most popular APTS system being marketed (Khattak et al. 1997). AVL features that were investigated included the tracking technology and performance (accuracy and frequency of location information update). Satellite-based AVL systems (with GPS/ NAVSTAR, GPS with dead reckoning or map matching, and differential GPS) and systems that use dead reckoning methods are most common. Six vendors use one of the above-mentioned two methods. A proximity beacon/signpost system (with sharp transmissions) is sold by three vendors. Two AVL systems use radio determination (one using certain radio frequencies and the other the Omega system).

All systems were reported to be reasonably accurate. Twelve vendors claim that their systems can track the location of a transit vehicle to less than 30 feet. Two can track the vehicle between 31 and 100 feet. One system tracks the vehicle between 101 to 200 feet and the accuracy of one system is greater than 200 feet.

The frequency of location information updates was investigated. One system updates the information continuously. Four vendors reported updating the information between 1 and 10 seconds. Two update the information every 30 
seconds, and three systems update the information every 60 seconds. Two vendors reported that they can update the information according to customer preference; and, in one system, it depends upon data loading and system configuration.

Computer-Aided Dispatch. Vendors were asked about demand-responsive CAD systems. Among the original 40 respondents, 7 vendors are involved in selling CAD systems. In terms of technical capabilities of the CAD systems for geographic referencing, only one vendor uses an Etak data base, two use TIGER, and the others use proprietary map data bases. Different functions are provided by demand-responsive CAD systems. Five vendors provide passenger trip scheduling (two based on historical information and three based on real-time information). Six vendors provide vehicle and crew scheduling, routing, and dispatching functions (three each based on historical and real-time information). Passenger account status is supplied by three systems (two based on historical and one based on real-time information). Also, passenger service monitoring and reporting, e.g., pick-ups and drop-offs, is supplied by five systems (three based on historical and one based on real-time information); and four systems provide the function of checking the ADA eligibility of passengers (two each based on historical and real-time information).

Regarding additional technology features, three demand-responsive CAD systems consider traveler preferences. One provides transit vehicle location information to travelers in real-time. Four provide advance reservations. Five systems respond to immediate requests, while four respond to standing orders. Only three systems can be linked to other sources of information, e.g., traffic or special events information. Overall, passenger trip scheduling, vehicle and crew scheduling, routing, and dispatching are considered important by the CAD suppliers.

Integration with Other APTS Technologies. Generally, AVL can be integrated with CAD and with other APTS technologies that include:

- Silent alarms -in an emergency, silent alarms can be triggered by the driver. 
- Advanced Traveler Information Systems (ATIS)-ATIS can provide:

- pre-trip information to travelers,

- in-terminal information, and

- in-vehicle real-time information.

- On-board sensors and logic/control unit-vehicle performance such as engine temperature, engine oil pressure, and other engine conditions are monitored and they are flagged if out of limits.

- Traffic signal priority-the system automatically performs this function.

- Automatic passenger counters.

- Automated fare payment systems.

- Annunciation systems and "next stop" destination signs.

The vendors reported that, on average, about 7 different APTS technologies can be integrated with either AVL or CAD systems (including mutual AVL/CAD integration). APTS technologies mentioned by the vendors that can be integrated with AVL/CAD include in-vehicle, pre-trip and en-route information systems; automatic passenger counters; and signal priority systems. Most AVL/CAD technologies seem to offer substantial flexibility in integration with other systems.

Companies were asked to list APTS technologies that are currently integrated or "bundled" with their latest system. On average, about four additional APTS technologies are integrated with the AVL package.

\section{Analysis of the Transit Operators Survey: Demand for AVL/CAD Systems}

Several questions in the transit operator survey asked about the operating environment for the transit agency. A majority of the survey responses were from transit agencies operating in urban areas: 18 of the 29 respondents were from large urban areas, five from small urban areas, and one from a suburban area. Five respondents either did not indicate the type of operating area or operated in more than one environment.

When asked to rank their agency's objectives and goals, most agencies indicated that providing safe transportation was their highest priority followed by 
providing reliable transportation, and then providing economical transportation. By counting the ranks given by respondents to each goal, they can be grouped into the following categories:

- High Priority - provide safe, reliable and economical transportation.

- Medium Priority-improve transit accessibility, convenience/comfort, and mobility for special groups (e.g., handicapped and lower income individuals).

- Low Priority-relieve traffic congestion, coordinate with other transportation modes, and minimize environmental impacts.

Technology Design Dimensions. A majority of the respondents (13 agencies) indicated satellite-based GPS system as their main vehicle tracking method. Proximity/signpost technology was the second most used technology (5 agencies). Standard two-way radio was the main communication technology (15 agencies), followed by trunked radio (4 agencies). Two respondents indicated that they use a satellite system and dead reckoning, and one respondent indicated using dead reckoning and proximity beacons for tracking vehicles. One respondent reported using cellular phone and trunked radio for communication. This may reflect transit agencies' need to supplement the primary AVL technology when topographic variations reduce tracking accuracy.

As expected, satellite-based GPS technology has been deployed relatively recently (6 GPS systems were deployed within 1 year and another 6 between 15 years) compared to proximity beacon/signpost technologies ( 2 such systems were deployed between 1-5 years ago, and another 2 more than 5 years ago). These findings are consistent with Casey et al. (1996).

AVL systems' ability to locate vehicles disaggregated by tracking system type was examined. One satellite-based GPS system was reported to track vehicles within 30 feet, 6 could track vehicles between 30-100 feet, and another 5 between 101-200 feet. Two agencies reported that their proximity beacon/sign post technology could track vehicles within 30-100 feet, and 1 agency each between 101-200 and greater than 200 feet. There is significant variation in the locational accuracy of AVL systems as perceived by the users. Interestingly (but 
not surprisingly), the AVL positional accuracy claimed by vendors is higher than that reported by the transit agencies (the users).

Technology Application Dimensions. Within the transit agency survey, the objective of one section was to determine the factors influencing AVL/CAD installation decisions. These factors were classified into the categories listed below. Each agency was asked to indicate the degree to which each of the following factors influenced system selection:

- opportunity-based conditions, i.e., based on unique opportunities;

- need-based conditions, i.e., based on existing and/or pressing agency needs;

- $\quad$ operating the system, i.e., the capabilities and impacts of the technology; and

- maintaining the system, i.e., the capabilities of the agency to maintain the technology.

A five-point Likert scale ranging from "strongly agree" to "strongly disagree" was used to seek responses. The salient opportunity-based conditions promoting AVL/CAD implementation were, first, that a member in the organization pushed for adoption, and second, that financial assistance was easy to secure. The need to replace (or upgrade) the existing radio/dispatching system and the need to expand the agency's services and capabilities were reported to be the critical need-based considerations leading to AVL/CAD system adoption. In operating the system, key requirements in procuring AVL/CAD were whether the system effectively identifies vehicles and monitors schedule adherence. Other important considerations included the requirements that the AVL/CAD system effectively monitored drivers' performance, monitored vehicle location, effectively supported dispatching decisions, allowed employees to adjust easily to the new operating procedures, and gave consistently accurate information. Relatively less important considerations were effectively monitoring vehicle conditions, monitoring in-vehicle security, directing en-route operations, and monitoring passenger loads. The important maintenance considerations were whether the suppliers are in business and whether they continue to provide system components and technical support. 
AVL/CAD Impacts. Agencies reported their perceived benefits and experiences with the AVL/CAD systems (or expected benefits, if the system was planned/under installation). The survey also contained questions about actual performance before and after AVL/CAD implementation. Most agencies did not have or did not provide quantitative measures of system performance, both before and after implementing an AVL/CAD system. (The questions included criteria such as operating costs, revenue, percentage of vehicles adhering to schedules, and response times to breakdowns and crimes.) Therefore, the responses to questions about "before and after" impacts are not reported.

In response to the question, "Has the AVL/CAD system been a valuable investment?", 17 out of 28 agencies said yes, 5 said that they did not know, 1 was uncertain, and the rest did not respond (none said no). These responses should be interpreted with caution because, to some extent, the positive responses might represent justification bias, i.e., having committed to the AVL/CAD system, respondents may find justification for their agencies' decisions.

AVL/CAD intra-organizational impacts are summarized in Table 2. Within this table, overall benefits of the AVL/CAD system are ranked based on the average scores, which were computed as follows: Strongly Agree $=3$, Agree $=2$, Disagree $=1$, Strongly Disagree $=0$. (Note that this scale is ordinal, and the truly permissible statistic for central tendency is the mode.) The "don't knows" were not included in the calculation. The survey inquired about how various individuals in the agency had responded to the implementation of AVL/CAD. Our $a-$ priori expectations were that the more technology-literate members of the agency would respond favorably to the new technology, while those less familiar with computers, electronics, and technology would be less receptive to the AVL/CAD system. Largely true to these expectations, those who responded positively included general managers, boards of directors, planners, schedulers and analysts, dispatchers, phone operators/customer service agents, on-street supervisors, ride or trip checkers, maintenance staff, information system managers, and drivers (in that order).

Table 3 indicates the general agreement reported by implementers in certain classes of benefits to the transit agency who responded to the question, 
Table 2

Level of Agreement of Transit Agency Staff Experiencing a Positive Reaction to AVL/CAD Implementation

\begin{tabular}{|c|c|c|c|c|c|c|}
\hline \multirow[b]{2}{*}{ Group } & \multicolumn{6}{|c|}{ Number of Agencies } \\
\hline & $\begin{array}{c}\text { Strongly } \\
\text { Agree }\end{array}$ & Agree & Disagree & $\begin{array}{l}\text { Strongly } \\
\text { Disagree }\end{array}$ & $\begin{array}{l}\text { Don't } \\
\text { Know }\end{array}$ & $\begin{array}{l}\text { Avg. } \\
\text { Score }\end{array}$ \\
\hline General Managers & 13 & 8 & - & - & 2 & 2.62 \\
\hline Boards of Directors & 9 & 5 & 1 & - & 6 & 2.53 \\
\hline Planners/Schedulers/Analysts & 11 & 10 & 1 & - & 1 & 2.45 \\
\hline Dispatchers & 7 & 11 & - & - & 4 & 2.39 \\
\hline \multicolumn{7}{|l|}{ Phone Operators/ } \\
\hline Customer Svc Agents & 4 & 14 & - & - & 4 & 2.22 \\
\hline On-Street Supervisors & 7 & 6 & 4 & - & 6 & 2.18 \\
\hline Ride or Trip Checkers & 3 & 4 & 2 & - & 9 & 2.11 \\
\hline Maintenance Staff & 4 & 11 & 3 & - & 3 & 2.06 \\
\hline Information System Managers & 5 & 9 & 2 & 1 & 2 & 2.06 \\
\hline Drivers of Transit Vehicles & 4 & 11 & 4 & - & 4 & 2.00 \\
\hline
\end{tabular}

"Describe the benefits you expect from your AVL/CAD system." As noted in the table, most respondents believe that the AVL/CAD improves their ability to monitor vehicle location; improves schedule adherence; enhances security for bus drivers and passengers; improves the ability to respond to breakdowns, accidents and schedule adjustments; improves the ability to monitor driver performance; improves ability to respond to crimes or other security incidents; and, improves the ability to direct en-route vehicles. Much less confidence was placed in AVL/ 
Table 3

Expected Benefits from AVL

Number of Agencies

Benefit

\begin{tabular}{|c|c|c|c|c|}
\hline $\begin{array}{c}\text { Strongly } \\
\text { Agree }\end{array}$ & Agree & Disagree & $\begin{array}{l}\text { Strongly } \\
\text { Disagree }\end{array}$ & $\begin{array}{l}\text { Do } \\
\text { Kn }\end{array}$ \\
\hline
\end{tabular}

Improve ability to

monitor vehicle location

23

2

2.92

Improve schedule adherence

20

5

2.8

Enhance security for bus

drivers and passengers

17

8

Improve ability to respond to breakdown, accidents, schedule adjustment, etc.

8

Improve ability to monitor driver's performance

Improve ability to respond to crimes or other security incidents

Improve ability to direct

en-route vehicles

12

11

1

Improve coordination with other transportation modes

Reduce labor hours

(e.g. on-strect supervisor)

$5 \quad 13$

13

2

Reduce number of vehicles as a result of better planning

$\begin{array}{lllll}8 & 5 & 1 & 3 & 2.09\end{array}$

$\begin{array}{llllll}7 & 8 & 6 & 1 & 3 & 1.95\end{array}$

CAD technologies in improving coordination with other travel modes, reducing labor hours (e.g., on-street supervision), and reducing the number of vehicles as a result of better planning.

APTS Integration. As their AVL/CAD systems are currently installed, 24 agencies indicated that they also have silent alarms; 22 indicated that they have 
on-board computers; and 14 indicated that they have mobile data terminals. A cross tabulation of these systems by AVL tracking system type is presented in Table 4. This indicates that integration of APTS technologies is taking place at several transit agencies. However, when combined with the results of the vendor survey, it appears that much of the responsibility for integration falls directly on the transit operator. That is, they either integrate these systems themselves and/ or contract out with system integrators. This finding is in contract to AVL/CAD technologies coming as part of an integrated bundle of APTS technologies from a single vendor.

\begin{tabular}{|lccc|}
\hline \multicolumn{4}{c|}{$\begin{array}{c}\text { Table } 4 \\
\text { Other APTS Technologies That Can Be Integrated with } \\
\text { Vendors' Current Tracking System }\end{array}$} \\
\hline \multicolumn{1}{c}{$\begin{array}{c}\text { Tracking } \\
\text { System }\end{array}$} & \multicolumn{3}{c|}{ Number of Agencies } \\
\cline { 2 - 4 } & $\begin{array}{c}\text { Silent } \\
\text { Alarms }\end{array}$ & $\begin{array}{c}\text { On-Board } \\
\text { Computers }\end{array}$ & $\begin{array}{c}\text { Mobile Data } \\
\text { Terminals }\end{array}$ \\
\hline Dead Reckoning & - & - & - \\
Proximity Beacon/Signpost & 5 & 5 & 1 \\
Radio & 1 & - & - \\
Satellite-Based GPS & 11 & 11 & 9 \\
Other (Signpost and Odometer) & 1 & 1 & 1 \\
\hline
\end{tabular}

With respect to the possibility of upgrading their existing system (adding a system), 6 agencies indicated that they can upgrade their system with on-board computers or with silent alarms, and 5 agencies indicated that they can upgrade their system with mobile data terminals. Moreover, a majority of the transit agencies indicated that they have integrated Automatic Vehicle Identification systems and on-board computers with their current AVL/CAD system. Of the systems currently not installed, automatic passenger counters were chosen most 
often by transit agencies as the system they would like to add to their existing system.

Transit agencies were asked to report which of the following APTS technologies are currently integrated with their AVL/CAD system: pre-trip information to travelers, in-terminal information, in-vehicle real-time information, onboard computers, vehicle performance, traffic signal priority, automatic passenger counters, and automated fare payment systems. Respondents were then asked to "Describe the total benefits of these combinations in terms of those accruing to the operator and those accruing to the traveler." Tables 5 and 6 present a summary of perceived total operator and traveler benefits from integrating AVL/ CAD systems with other APTS technologies. The perceived benefits of such integration, in order of highest to lowest benefit, are:

- improved ability to monitor vehicle location;

- enhanced security for drivers;

- improved schedule adherence;

- improved ability to respond to crimes and security concerns;

- improved ability to monitor driver's performance;

- improved ability to respond to breakdowns and accidents;

- improved ability to direct en route vehicles;

- reduced labor hours;

- improved coordination with other transportation modes; and

- reduced number of vehicles as a result of better planning.

The ranking of expected benefits from integration largely mirror those reported for AVL systems alone. However, in comparing the results from Table 3 (AVL systems alone) and Table 5 (AVL systems integrated with other APTS technologies), it appears that transit operators perceive higher incremental benefits from AVL implementation alone than they do from system integration. This result, while perhaps not surprising, suggests that, at this early stage of $\mathrm{AVL} /$ CAD deployment, operators do not perceive a significantly higher value of system integration in the AVL/CAD context. 


\section{Table 5}

\section{Level of Agreement Regarding Transit Agency's Benefits from AVL/CAD Integration with Other APTS Technologies}

\section{Number of Agencies}

\begin{tabular}{|c|c|c|c|c|c|c|}
\hline Benefit & $\begin{array}{c}\text { Strongly } \\
\text { Agree }\end{array}$ & Agree & Disagree & $\begin{array}{l}\text { Strongly } \\
\text { Disagree }\end{array}$ & $\begin{array}{l}\text { Don't } \\
\text { Know }\end{array}$ & $\begin{array}{l}\text { Avg. } \\
\text { Score }\end{array}$ \\
\hline Improved ability to monitor location & n 16 & 6 & - & - & 1 & 2.73 \\
\hline Enhanced security for drivers & 14 & 9 & - & - & 1 & 2.61 \\
\hline Improved schedule adherence & 12 & 11 & - & - & 1 & 2.52 \\
\hline $\begin{array}{l}\text { Improved ability to respond to } \\
\text { crimes and other security incidents }\end{array}$ & 11 & 12 & - & - & 1 & 2.48 \\
\hline $\begin{array}{l}\text { Improved ability to monitor } \\
\text { driver's performance }\end{array}$ & 7 & 14 & 1 & - & 2 & 2.27 \\
\hline $\begin{array}{l}\text { Improved ability to respond to } \\
\text { breakdown, accidents, etc. }\end{array}$ & 7 & 15 & 1 & - & 1 & 2.26 \\
\hline $\begin{array}{l}\text { Improved ability to direct } \\
\text { en-route vehicles }\end{array}$ & 6 & 15 & 1 & - & 2 & 2.23 \\
\hline Reduced labor hours & 2 & 16 & 3 & - & 3 & 1.95 \\
\hline $\begin{array}{l}\text { Improved coordination with } \\
\text { other transportation modes }\end{array}$ & 2 & 15 & 3 & - & 4 & 1.95 \\
\hline $\begin{array}{l}\text { Reduced number of vehicles } \\
\text { as a result of better planning }\end{array}$ & 5 & 8 & 7 & 1 & 3 & 1.81 \\
\hline
\end{tabular}

Table 6 shows that the important traveler benefits as perceived by the transit agencies implementing AVL/CAD systems include enhanced security for passengers, improved ability to make connecting services, and, to a lesser extent, reduced wait times. It is generally not true that transit agencies expect to be able to reduce walking distances to stops and stations through use of AVL/CAD systems. Overall, a majority of the agencies expressed that AVL/CAD technologies 


\section{Table 6}

Level of Agreement Regarding Traveler Benefits from

AVL/CAD Integration with other APTS Technologies

\section{Number of Agencies}

\begin{tabular}{lcccccc}
\hline \multicolumn{1}{c}{ Benefit } & $\begin{array}{c}\text { Strongly } \\
\text { Agree }\end{array}$ & Agree & Disagree & $\begin{array}{c}\text { Strongly } \\
\text { Disagree }\end{array}$ & $\begin{array}{c}\text { Don't } \\
\text { Know }\end{array}$ & $\begin{array}{c}\text { Avg. } \\
\text { Score }\end{array}$ \\
\hline $\begin{array}{l}\text { Enhanced security for passengers } \\
\begin{array}{l}\text { Improved ability to make } \\
\text { connecting services }\end{array}\end{array}$ & 9 & 13 & 1 & - & 1 & 2.35 \\
$\begin{array}{l}\text { Reduced wait times } \\
\begin{array}{l}\text { Reduced walk distance to } \\
\text { stops / stations }\end{array}\end{array}$ & 3 & 16 & 2 & - & 2 & 2.09 \\
\hline
\end{tabular}

were performing their main functions and that it was a valuable investment. There is higher uncertainty about whether the AVL/CAD was providing quantifiable benefits to both the agency and travelers. Respondents' lack of response to questions about quantitative "before and after" benefits underscores the need for better tools to characterize and quantify the impacts and benefits of AVL/CAD systems.

\section{Summary and Conclusions}

In this research, a conceptual structure for analyzing AVL/CAD technologies was proposed. The structure was used to explore the design and technical application dimensions of technologies; the structure also identifies the impacts/ benefits of these technologies in specific contexts.

AVL/CAD technologies can be defined by their design and application dimensions. The design dimensions are technology features, functions and performance. The technology application dimensions include the conditions of implementation, integration with other technologies, and the spatial, temporal, and 
user attributes, indicating where, when, and for whom the technology is implemented.

Technology deployment takes place in an implementation context. For example, the service network structure and density, number of vehicles, duration of peak flows and types of travelers served can influence AVL/CAD impacts. The operator impacts can be measured in terms of efficiency and costs, while the traveler impacts are measured in terms of transit service improvements. These impacts also have "distribution" dimensions; that is, the impacts of the AVL/ CAD system can depend on the scope of technology implementation.

The structure developed in the study was used to explore the AVL/CAD commercial availability (supply) and deployment (demand). A survey of vendors showed that satellite-based GPS and proximity beacon/signpost AVL/CAD technologies are popular with both the vendors and transit agencies; GPS technology is being widely deployed in transit agencies. Moreover, transit agencies reported a substantial number of APTS technologies that can be integrated with AVL/CAD.

The AVL/CAD survey of potential and current transit implementers indicated that those who responded positively to the implementation included general managers, boards of directors, planners, schedulers and analysts, dispatchers, phone operators/customer service agents, on-street supervisors, ride or trip checkers, maintenance staff, information system managers, and drivers (in that order). The perceived benefits were the improved ability to monitor vehicle location, improved schedule adherence, and enhanced security for bus drivers and passengers. It is not clear whether many transit agencies believe that AVL/CAD systems reduce costs (i.e., by reducing labor hours or vehicle hours). Furthermore, there was evidence that AVL/CAD implementation decisions are made as longer-term upgrades and/or investments. There is a need for more quantitative evidence about AVL/CAD impacts on transit operators and travelers. This research indicates that there may be considerable questions raised about the overall cost-effectiveness of such systems from the perspective of transit implementers. It is also telling that the AVL/CAD systems are liked most by the white-collar 
workers and relatively less by the people who are working day-to-day with the system and with the public (i.e., people on the "front line").

Although limited insight was gained in this paper from studying potential traveler impacts from the transit implementer's perspective, there is a strong need to evaluate traveler benefits. Research should be directed at:

- evaluating objectively-measured benefits to transit users in terms of travel-time reliability, reduced uncertainty, information on waiting and transfer times, and reduced travel time;

- user-perceived benefits measured in terms of the above criteria and reduced stress;

- changes in ridership (if any) due to improved level-of-service; and

- marketing of the benefits (if any) to attract non-users to transit.

While AVL/CAD suppliers and implementers perceive significant benefits, there is a need to synthesize the experiences of transit agencies (see Casey and Collura 1994). Importantly, there is a need to identify APTS technologies that can be mixed to provide the correct balance between operator effectiveness and customer satisfaction. The correct mix will also depend on transit agency objectives and operating environment. In future research, it will be interesting to evaluate how the perceived impacts of APTS technologies depend on the design dimensions, application dimensions, and the implementation context.

Individually, APTS technologies may be of limited value, but, collectively, they may significantly enhance transit system performance and attract travelers. While operators perceived significant benefits from AVL/CAD implementation, they did not perceive significant additional benefits from system integration. However, the issue of APTS integration may be critical to the long-term success of these new technologies. More research is needed to explore the benefits of system integration. *

\section{References}

Casey, R., and J. Collura. 1994. Advanced public transportation systems: Evaluation guidelines. Federal Transit Administration, U.S. Department of Transportation, FTA-MA-26-0007-94-2, Washington, D.C. 
Casey, R., L. Labell, R. Holmstrom, J. LoVecchio, C. Schweiger, and T. Sheehan. 1996. Advanced public transportation systems: The state of the art. Update '96. U.S. Department of Transportation, Federal Transit Administration, FTA-MA-26-700796-1, January.

Goeddel, D. 1996. Benefits assessment of advanced public transportation systems (APTS). Federal Transit Administration (FTA), Volpe Report Number: DOT-TSCFTA-96-07, FHWA-JPO-96-0031.

Khattak, A., H. Noeimi, H. Al-Deek, and R. Hall. 1993. Advanced public transportation systems: A taxonomy and commercial availability. Partners in Advanced Transit and Highways (PATH) Research Report UCB-ITS-PRR-93-9, Institute of Transportation Studies, University of California at Berkeley, California.

Khattak, A., H. Noeimi, and H. Al-Deek. 1996. A taxonomy for advanced public transportation systems. Journal of Public Transportation (1)1: 39-64.

Khattak, A., M. Hickman, P. Gould, and T. Paramsothy. 1997. Advanced public transportation systems: A taxonomy, commercial availability and deployment: Phase II. Partners in Advanced Transit and Highways (PATH) Research Report UCBITS-PRR-97-16, Institute of Transportation Studies, University of California at Berkeley, California.

Lister, M., C. Schweiger and I. Keaveny. 1995. Getting smarter with ITS: Improved paratransit operations using integrated scheduling and dispatch and automatic vehicle location at SMART. Preprint 95128, ITS America, 1995 Annual Conference, Washington, D.C.

Schweiger, C., M. Kihl, and L. Labell. 1994. Advanced public transportation systems: The state of the art. Update '94. Final report prepared for Federal Transit Administration (DOT-T-94-09), Volpe National Transportation Systems Center, Cambridge, Massachusetts.

\section{Acknowledgment}

Funding for this study was provided by the California Department of Transportation through the California PATH Program. We appreciate the support of Mr. Cliff Loveland and Ms. Vicki Cobb at Caltrans. Mr. Pierce Gould and Dr. Thananjeyan Paramsothy at the University of California-Berkeley greatly helped with successfully completing the project. We are also grateful to Dr. Stein Weissenberger for his support during the project. 


\section{About the Authors}

DR. ASAD J. KHATTAK is the Director of Transportation Specialization with the Department of City and Regional Planning at the University of North Carolina at Chapel Hill.

Dr. Mark Hickman is Assistant Professor with the Department of Civil Engineering at Texas A\&M University. 


\title{
A Strategic Approach to the Transportation Planning Process
}

\author{
Edward A. Mierzejewski \\ University of South Florida
}

\begin{abstract}
The underlying premise of the urban transportation planning process is that we can forecast the future. The process typically develops 20-year forecasts of traffic volumes on each link of the transportation network. Planners then attempt to devise a master plan that represents an optimal solution for the forecasted conditions. The reality is that we cannot predict the future. Imponderable and unpredictable events will shape the future in ways we cannot hope to anticipate. In addition, social and political bias is a strong contributor to errors in anticipating future events and to our willingness to deal with uncertainty. This paper identifies possible remedies for dealing with uncertainty and bias, including better analytical methods, better process methods, and methods to counter bias. An evaluation of various remedies is performed and practical measures that can be applied to the urban transportation planning process are identified. Finally, specific recommended modifications to the urban transportation planning process are outlined.
\end{abstract}

\section{A World of Change, Uncertainty, and Bias}

"It's tough to tell the future."

So begins a report distributed by the Florida Department of Transportation (1994) as background for the 2020 Florida Transportation Plan. It goes on to note: 
Analyzing historical and current trends to forecast conditions 20 or more years into the future has been compared to throwing darts at a moving board under a strobe light. The dynamic nature of social, economic, and political activities in the United States and Florida creates too many uncertainties for foolproof forecasting.

Twenty-five years earlier, Manheim (1979) noted, "We live in a world of rapid change." He identified three dimensions of change that are relevant to transportation systems: change in demand, change in technology, and change in values. We might also note a world of uncertainty-not only is change occurring, but it is occurring in ways that we cannot anticipate. Others have cited the uncertainty in future availability of resources (Neumann and Pecknold 1973) and in estimating costs (Wachs 1986; Pickrell 1990).

In addition to the objective fact of our inability to accurately predict the future, a major feature of urban transportation planning is the social and political bias that is evident in technical analyses. Recognition of uncertainty is routinely suppressed, bold assertions are made about future conditions, and forecasts are intentionally manipulated to promote politically-motivated conclusions. These features are particularly evident in the planning of large-scale transit guideway investments.

\section{The Urban Transportation Planning Technical Process}

Planning for urban transportation systems involves the application and analysis of technically complex simulation models within a highly political decisionmaking environment. The conventional process involves development of 20-year forecasts of socio-economic variables, such as population and employment, disaggregated into hundreds of traffic analysis zones of the typical metropolitan area. Based on the 20-year socio-economic forecasts, a series of sequential models are used to develop detailed forecasts of demands on the future transportation network. 


\section{Reality: Change Cannot Be Predicted with Certainty}

The underlying premise of the urban transportation planning process is that we can forecast the future. The reality is that the models are highly imprecise, the inputs to the models are impossible to predict, and the forecasted results are almost sure to miss the mark.

\section{Sources of Uncertainty in Transportation Planning Models}

Lowe and Richards (1983) identified three sources of error in transportation planning models: specification, calibration, and error in exogenous inputs. Limitations in the precision of the transportation planning models caused by specification and calibration error pale in comparison to the uncertainty of forecasting exogenous inputs. How precise can we be in forecasting social and economic factors 20 years into the future?

Look ahead 20 years into the future and imagine what the United States will be like. Specifically, try to estimate the nation's population and employment 20 years from now. Don't forget to account for factors such as future wars, major recessions, the reliability of crude oil supplies, U.S. immigration policy, and future fertility and death rates.

Now think about what Florida's share of your national estimate will be 20 years in the future. Don't forget to account for the future fall of Castro, the political situation in Haiti, future national retirement locational preferences, potential development moratoria, and supplies of potable water.

Now that you have addressed all these factors and are confident with your estimates of U.S. and Florida's population and employment, think about what an individual county with Florida, e.g. Hillsborough County's, share will be 20 years from now. Be sure to account for factors such as the status of rebuilding the Tampa Interstate, the commercial success of the Florida Aquarium, competition by Orlando for tourists, and major corporate relocations. Now, allocate the Hillsborough County share across 800 traffic analysis zones.

Seems like a pretty hopeless exercise, doesn't it? Yet, this is exactly what we do, every time we prepare a long range plan for an urbanized area. Moreover, 
advocates of major capital investments routinely claim to be able to estimate traffic volumes or transit ridership 20 years into the future on individual links of a hypothetical transportation network. We develop plans as if we could take a rifle shot 20 years into the future and predict the precise magnitude and distribution of activities within a region. The reality is quite different-more like a shotgun blast.

\section{Examples of Forecast Performance}

It can be instructive to review examples of the past performance of transportation forecasts to see just how accurate our forecasts have been. The examples presented in the following sections show that the track record of forecasts are not very reassuring.

Tampa Urban Area Transportation Study. In 1970, a comprehensive urban area transportation study was undertaken for Tampa, which developed traffic forecasts for the year 1985 (Barr and Dunlop 1970). A comparison of the actual 1985 traffic volumes was made with those forecasts made in 1970. Of 87 different links for which it was possible to compare actual 1985 traffic counts with those forecasted in 1970 , the errors ranged from -78 percent to +281 percent, with an average absolute link error of 57 percent. Moreover, these forecasts were for a 15-year period-insufficient by today's standards.

Tampa CBD Employment Forecasts. During the early- to mid-1980s, several forecasts were prepared of future employment in the Tampa central business district (CBD). As illustrated in Figure 1, forecasts were done for a downtown people mover (DPM) study, for a central business district development of regional impact (CBD DRI), and for several other conditions. Forecasts done in the early 1980 s projected CBD employment to be at 75,000 to 80,000 by the year 2000. In the mid-1980s, new forecasts were made. By then, it was clear that CBD employment was not on track to 80,000 by the year 2000 ; instead, it was forecast that employment would be in the 55,000 range by the year 2000 , but would still be approaching 90,000 by the year 2010 . The reality is that, in the years since 1980, employment in the Tampa CBD has been fairly flat, falling in the $28,000-30,000$ range in 1998 . The range of forecasts and the actual perfor- 


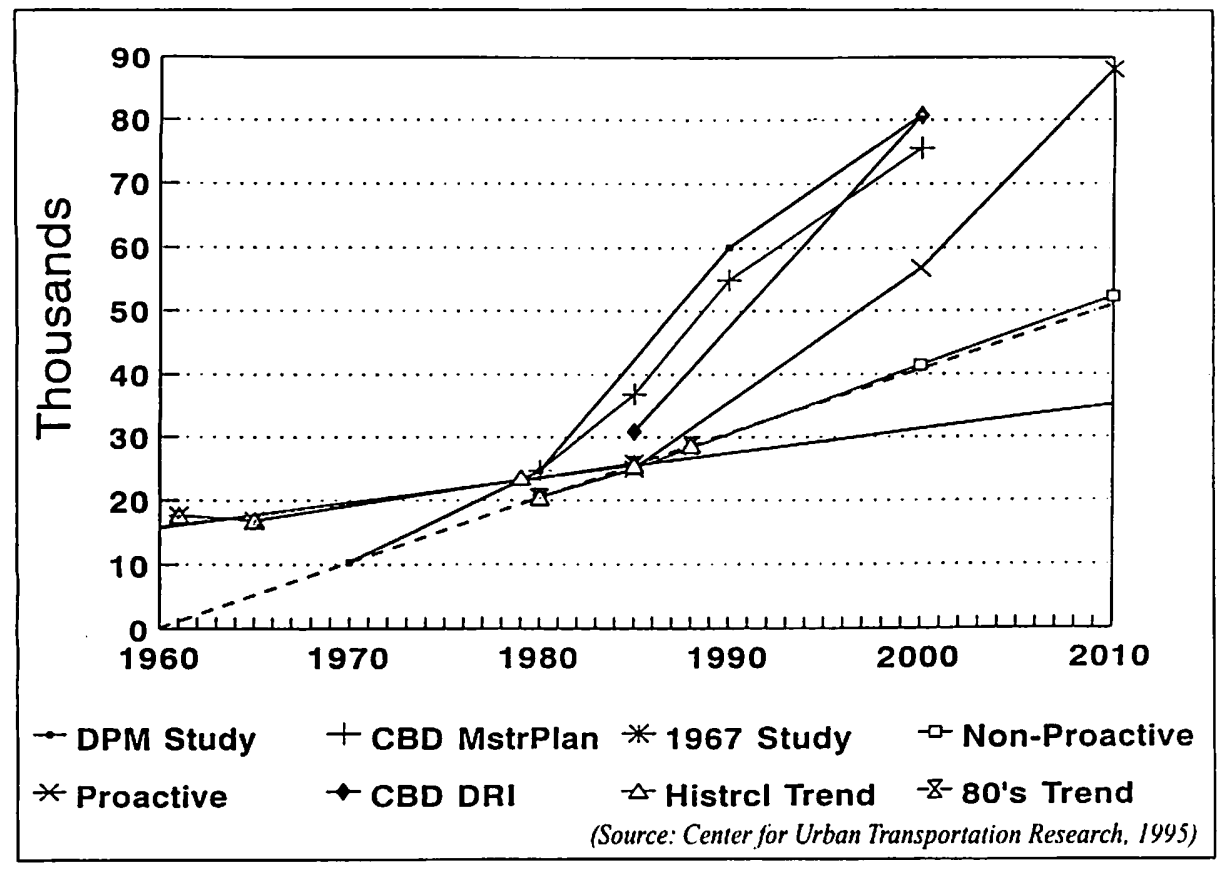

Figure 1. Tampa CBD employment forecasts.

mance demonstrate the extreme volatility of these model inputs, which, regrettably, have been used as the basis for major capital facility planning in the region, including a downtown people mover system, a rail transit system, and a massive freeway construction program.

Interstate Highway Estimates. An analysis of forecasts of traffic on urban interstates reported that traffic was overestimated by 21 percent and 24 percent, respectively, for three- and seven-year forecast periods (Pell and Meyberg 1983). The authors of the study concluded that ". . . one of the most damning practical criticisms [of the urban transportation planning process] is that the forecasts produced ... are incorrect."

British Case Studies. The Transport and Road Research Laboratory published a report (Mackinder and Evans 1981) in which forecasts from 44 British urban transportation studies undertaken between 1962 and 1971 were compared 
with actual occurrences. On average, population was overestimated by 20 percent and highway and public transit trips by 30 to 35 percent. If one were to measure the errors in forecasting the incremental change in various parameters, the results would be much worse: average forecasted population growth was three times the observed growth, while forecasts of the growth in total person trips were more than six times the observed growth.

Guideway Transit Case Studies. Pickrell (1990) examined the accuracy of forecasts for eight U.S. cities that invested in rail transit projects. Forecasts of ridership and costs that were the basis of local decisions to implement these systems were compared with the actual costs and ridership experienced. Ridership estimates were found to be consistently overestimated, while costs were consistently underestimated. The study noted that decisions to implement these major capital investments were made based on very small forecasted differences in performance between alternatives, whereas the actual performance of the selected alternatives were substantially different from the forecasts.

\section{Misinterpretation and Outright Bias} in Individual and Group Decisionmaking

The preceding section dealt with uncertainty and error primarily with respect to the inability of models to replicate observed conditions. This section deals with our inability to interpret data correctly, and even more importantly, the pervasiveness of outright bias in the decisionmaking process.

\section{Common Errors in Individual Perception}

Perhaps the poor performance of transportation planning models should not be surprising, since our individual intuitive judgments regarding cause and effect are often flawed. In their best-selling book, In Search of Excellence, Peters and Waterman (1984) cite the work of psychologists Tversky and Kahneman (1974), and conclude that "... people reason intuitively. They reason with simple decision rules, which is a simple way of saying that, in this complex world, they trust their gut." Unfortunately, gut feelings are not necessarily valid. 
Most people attempt to discriminate much more than their knowledge warrants (Behn and Vaupel 1982). Perhaps the most significant example of individual misperception is the comparative ease with which we can come up with after-the-fact explanations for events that we failed to predict (Fischoff 1977; Behn and Vaupel 1982; Hogarth 1987; Dawes 1988). When we reflect on a historical occurrence, we search for reasons why it was entirely predictable, even though before the event itself the evidence was very confusing.

\section{Socio-Political Bias in Forecasting and Decisionmaking}

Given the difficulty we have as individuals, can it be any wonder that group decisions are even more confounding? Such errors are even more difficult to deal with, because they demonstrate not only our lack of individual ability to deal objectively with information but also with the bias introduced by conflicting values. As observed by Ascher (1978), forecasts that underscore a priority that is out of political favor are likely to be ignored, whereas forecasts that support politically favorable positions are likely to be embraced.

Reliance on Myth and Metaphor. In his provocative analysis of the decision to build a rail transit system in Los Angeles, Jonathan Richmond (1995) describes the process whereby myths are constructed through images, symbols, and metaphors, which provide compelling messages on what is good and bad in our world. He believes that a central feature of myth development is the focus on a technology that can serve as the center of attention, one of simplicity and certainty. Technology serves as a symbol; rather than deal with the complex myriad problems that need to be solved, technology allows us to focus on the "easy fix" to all of our problems.

Making Forecasts Support Our Preconceptions. Too often our forecasts reflect what we desire, rather than what is likely to occur. As noted by the U.S. Department of Transportation and the Environmental Protection Agency, forecasted distributions of regional population and employment are often an erroneous input to the transportation planning models because of the influence of political compromise, rather than technical expertise (U.S. DOT 1993). Human 
nature being what it is, we are more willing to entertain evidence that supports our view of the world and are resistant to contradictory evidence (Hogarth 1987).

Ethics and Bias of Advocacy in Forecasting. Wachs (1986) relates tinkering with forecasts to the issue of professional ethics. He notes one study in which the models predicted "insufficient" rail ridership. To correct this situation, assumed highway speeds were reduced from $45 \mathrm{mph}$ to a "more realistic" $30 \mathrm{mph}$. This simple assumption substantially increased the forecast of rail ridership. He notes that most of the forecasts used in planning of U.S. rail transit systems are statements of advocacy, rather than unbiased estimates.

\section{Recommended Changes to the Urban Transportation Planning Process}

Our inability to control uncertainty dictates substantial changes in the way we do urban transportation planning. The assumption of a rational decisionmaking process that underlies current transportation practice does not exist. Rather, what has been observed is a technical process that is incapable of forecasting conditions 20 years into the future and a political process that systematically and deliberately contrives forecasts to justify preconceptions of decisionmakers.

In spite of uncertainty, we need to plan for the future and to move proactively toward the attainment of valued goals. Moreover, we can adopt planning practices that reduce bias in our decisionmaking process.

This section presents strategies considered to be most suitable for application to urban transportation planning, along with specific actions needed to incorporate them into the process.

\section{Define a Strategic Vision}

The transportation planning process should begin by articulating a strategic vision. This would best be accomplished as part of a comprehensive strategic planning process. We need to be able to articulate a vision of what we want our community to be "when it grows up."

The vision need not be a dramatic departure from the past. On the other hand, the vision might call for sweeping changes to the character of the area. The vision will need to incorporate land use, community development, protection of 
natural resources, and transportation. The vision will necessarily be strategic-it will incorporate the general desired features but will not rigidly define precise details, as these must be responsive to the unknowable future.

\section{Highlight Uncertainties through Strategic Planning}

Strengths, Weaknesses, Opportunities, and Threats. Once a strategic vision has been articulated, the recommended process would undertake a classical strategic planning approach that identifies strengths, weaknesses, opportunities, and threats to reaching the desired vision. This activity represents a radical departure from traditional planning practice, which evaluates all available information to estimate a single expected value for each variable. The product of the strategic planning process should be an identification of all conceivable risks and a proposed action for dealing with them.

Highlight Uncertainties. A critical element of a new process should be the articulation of all assumptions and all uncertainties associated with forecasting future conditions. This practice will require a new awareness on the part of professional staff of the importance of assumptions in the analytical process. However, it is vitally important that decisionmakers and the community be made fully aware of the uncertainties, particularly critical inputs to the transportation planning models: population, labor force, and employment.

Scenario Analysis/Ranges of Assumptions. The strategic planning process should explicitly consider specific ranges of assumptions, as captured in alternative scenarios of the future. In spite of best available projections, what is the chance that study area population, labor force or employment will be 10 percent higher or lower than the best guess estimate? Twenty percent higher? Errors of this magnitude need to be expected and anticipated.

\section{Promote Fexibility}

Once we admit the reality of uncertainty, flexibility becomes very important. In a future that holds unanticipated surprises, we need to place a high value on retaining future options.

Right-of-Way Protection. One measure that could be implemented to preserve future options and to emphasize flexibility is the early acquisition of trans- 
portation rights of way. While right-of-way preservation presents difficult political challenges, the benefits make it worthwhile.

Build-Later. The concept of a "build-later" alternative, as advocated by Chu and Polzin (1996), is recommended to be included in major investment studies. In contrast to current practice, in which end-states 20 or more years into the future are the basis for decisions today, the build-later alternative would result in the inclusion of major investment timing as an explicit analysis factor.

\section{Plan for Incremental Implementation}

Much of the research presented in this paper points toward the desirability of incremental implementation of major projects. One of the most controversial categories of transportation investments is the implementation of major fixed guideway transit projects, such as rail rapid transit systems. Risks and uncertainties, particularly as they relate to future ridership and costs, have often made it impossible to muster the necessary political support to implement such systems, which are typically represented in the form of optimistic assessments of outcomes 20 to 50 years into the future.

Can it be any surprise that elected officials are reluctant to commit to systems that will involve massive present costs in return for uncertain future benefits? Because we make only grandiose plans, all we have to show is plans, while we might actually implement something one step at a time. Such an approach might begin by offering express bus service using makeshift park-and-ride lots. As demand increases, permanent and perhaps more ideally-located park-andride facilities can be constructed.

As warranted by demand, dedicated high occupancy vehicle (HOV) facilities can be implemented or preferential bus treatments can be devised that allow buses to circumvent specific high congestion delay points. As each of these actions is taken, based on affirmation in the form of ridership, political support for the next increment of investment will build. Ultimately, the addition of a guideway transit system can be justified, with the park-and-ride infrastructure already in place. 
Place Greater Emphasis on the Short Run. Uncertainty increases with duration-not a major revelation, but, surprisingly, a fact that is frequently ignored. Regrettably, a condition of federal participation in projects has been assurance that improvements meet anticipated traffic levels 20 years following opening of the project. Moreover, this requirement will almost always negate the potential of systems and demand management actions as alternatives to major capital improvements.

The focus of transportation planning on the 20-year horizon needs to be changed; instead, more emphasis should be placed on current deficiencies, and on the five-year horizon. Rather than focus on the development of a static plan for 20 years into the future, a dynamic process is recommended that identifies improvement needs in five-year increments. Initially, as suggested by Pickrell (1990), alternative actions for coping with immediate deficiencies should be evaluated. Following this, forecasts would be made of conditions at five-year increments into the future. The emphasis should be on selecting a good short term plan, to meet the needs of the initial five-year period, with a sequence of improvements identified for each subsequent increment. In contrast to the current process, which is predicated on optimizing the response to a highly uncertain 20-year forecast, the recommended process is focused on optimizing responses in a shorter, five-year time frame, with an eye on the long term.

Alternatives that Can be Implemented in Usable Modules. An example was provided of an alternative approach to the implementation of guideway transit systems. Rather than focusing on a system justified with forecasts of demand decades into the future, the alternative approach called for incremental implementation beginning with temporary park-and-ride lots, transitioning to HOV, ultimately resulting in guideway transit, if warranted.

A modal alternative that merits much more consideration is that of exclusive busway systems. A major advantage of a busway system is that, if properly staged, even small increments provide notable operational advantages. Each increment offers improved levels of service for the bus system, contrasted with rail guideway alternatives, for which a substantial portion of the system must be 
completed in order to achieve any benefits. A recent paper by Martinelli (1994) provides ample evidence of the benefits afforded by busways. He notes that the busway combines the flexibility of a bus to go anywhere with the line haul characteristics of fixed guideway transit services, at substantially lower cost. The Ottawa and Pittsburgh exclusive busway systems are cited as examples of operational efficiency, the former carrying 210,000 passengers daily.

A key feature of the busway alternative is that it can be implemented in increments, each of which provides measurable benefits. An important implication of uncertainty is that technologies that can be implemented in usable increments have an advantage.

\section{Promote Objectivity}

While the urban transportation planning process cannot (and should not) remove politics from decisionmaking, the process should promote the separation of politics from forecasting and impact analysis. The role-indeed, the ethical responsibility of the transportation planner should be to provide objective analysis in a public forum that allows elected decisionmakers to make informed political tradeoffs. As those with experience in the process will attest, this is easier said than done. The specific recommendations of this and the next major section are designed to promote objectivity so that political tradeoffs are made based on our best available technical analysis.

Incorporate Independent Peer Reviews. All of us have experienced instances in which our close day-to-day participation in a project has blinded us to factors that are evident to outsiders. It is easy to get so involved in a project that we "cannot see the forest for the trees."

It is recommended that the preparation of regional transportation plans, major corridor analyses, and major activity center studies incorporate a new task, an outside professional peer review. Effective peer reviews can serve as a check on basic input assumptions, technical procedures, demand forecasts, cost estimates, and the whole range of socio-political bias. Part of the task of the peer review would be to document uncertainties and assumptions (explicit and implied). 
The benefits of a peer review process can best be ensured if the peer panel is sponsored by an organization with a measure of independence from the study being reviewed. In the case of projects involving large sums of federal dollars, it might be appropriate if the cognizant federal agency assembles and retains a peer panel from outside the geographic region. At the state level, it might be appropriate for the state department of transportation to retain an outside peer panel as a condition of expending large sums of state dollars.

Separate Planning from Implementation. One of the most obvious factors working against objective development of capital improvements is conflict of interest of agencies and firms with a vested interest in capital intensive solutions. In Florida, we have seen the creation of regional commuter rail authorities charged with studying and implementing commuter rail systems. What happens if objective study shows that a rail system is unwarranted? There is merit to the classical separation of regional planning and project implementation, as it requires implementing agencies to have the endorsement of the metropolitan planning organization as a condition of project implementation. This requirement promotes comprehensive analysis of alternatives.

Regrettably, we cannot always rely on professional consultants to evaluate objectively the feasibility of major capital projects when they have millions of dollars in design fees riding on a favorable decision. It is recommended that, when consulting firms are retained for technical assistance in evaluating alternatives, conflict-of-interest considerations should dictate that firms involved in the planning analysis be prohibited from a major role in the design contracts. While many consulting firms have a high degree of ethics and can be relied upon to exercise objective judgment without regard to future contracts, the motivations for bias are too strong to overlook.

\section{Place the Consequences of Risk with Decisionmakers}

When the bulk of the cost burden of major capital investments for a given locality is borne by others, there is little incentive to make careful decisions on resource commitments. This is particularly true of discretionary projects, and in the current vernacular, "demonstration projects," which translate to political ear- 
marking. An intelligent resource allocation system should be one in which the risks of aecepting optimistic forecasts of demand, cost, etc., are borne by the group making implementation decisions. A number of specific measures can support this recommendation.

Broad Formula Grants. One measure that ISTEA promoted was to reduce the number of categorical limitations on application of federal funds. There is considerable merit to the allocation of federal and state support by means of broad formula grants that allow substantial local discretion as to which specific projects are undertaken, without regard to categorical limitations and differences in matching ratios. To the extent that local officials are required to allocate fixed funding amounts, the consequences of poor decisions would rest more squarely on local shoulders. If local decisions were poor, local areas would suffer, with no hope of state or federal bailout.

Another alternative, suggested by Polzin (1995), would limit the federal commitment to major transit capital investments to a fixed amount per passenger carried, thereby placing the risks of optimistic demand and cost estimates squarely on the shoulders of local decisionmakers.

Increase Local Funding Responsibilities. Another measure is to reduce federal support for local transportation investments, placing more of the funding burden on state and local agencies, which, in turn, are more dependent on local sources of tax support. Though the relative merits of shifting more responsibility for funding to the state and local level will be evaluated in the political arena, there can be little doubt that placing funding responsibility at the same level at which implementation decisions are made will hold local officials much more accountable for rational decisionmaking.

\section{Closing}

Uncertainty is pervasive in all of our planning activities. Yet, we plan as if we could take a snapshot 20 years into the future and devise an optimal solution to that snapshot. We ignore and even disguise the limitations of our methods and fail to develop contingencies for the uncertainties that may arise. 
It is believed that the implementation of the approaches outlined in this paper will allow us to recognize uncertainty, yet not be paralyzed by it; to move proactively toward the attainment of valued societal objectives, yet be prepared for the changes we cannot predict.

\section{References}

Ascher, W. 1978. Forecasting: An appraisal for policymakers and planners. Baltimore, MD: The Johns Hopkins University Press.

Barr, Dunlop \& Associates, Inc. 1970. Tampa urban area transportation study: A summary report. Prepared for the Florida Department of Transportation.

Behn, R. D., and J. W. Vaupel. 1982. Quick analysis for busy decision-makers. New York: Basic Books, Inc.

Center for Urban Transportation Research. 1995. State transportation policy initiative: A new strategic urban transportation planning process. Tampa: University of South Florida.

Chu, X., and S. E. Polzin. 1996. Considering build-later as an alternative in major investment analyses. Transportation Research Board 75th Annual Meeting, Washington, D.C., preprint.

Dawes, R. M. 1988. Rational choice in an uncertain world. New York: Harcourt Brace Jovanovich.

Fischoff, B. 1977. Perceived informativeness of facts. Journal of Experimental Psychology: Human Perceptions and Performance 3(2): 349-358.

Florida Department of Transportation. 1994. Trends and conditions, 2020 Florida transportation plan.

Hogarth, R. M. 1987. Judgment and choice: The psychology of decision, Second Edition. New York: John Wiley \& Sons.

Lowe, S. and M. G. Richards. 1983. Systematic sensitivity testing in project appraisala method of identifying the uncertainty of transportation forecasts. Proceedings, 10th Transportation Planning Colloquium. Delft, The Netherlands: 3-12.

Mackinder, I.H., and S. E. Evans. 1981. The predictive sccuracy of British transport studies in urban areas. Transport and Road Research Laboratory Supplementary Report 699. Crowthorne, Berkshire, England. 
Manheim, M. L. 1979. Fundamentals of transportation systems analysis. Cambridge, MA: The MIT Press.

Martinelli, D. R. 1994. A systematic review of busways. Harley O. Staggers National Transportation Center, West Virginia University.

Mierzejewski, E. A. 1996. An assessment of uncertainty and bias: Recommended modifications to the urban transportation planning process. Unpublished doctoral dissertation, University of South Florida.

Neumann, L. A., and W. Pecknold. 1973. Application of the time-staged strategic approach to systems planning. Highway Research Record 435: 20.

Pell, C. M., and A. H. Meyberg. 1983. The estimation and use of uncertain forecasts in urban transportation planning. Proceedings, 10th Transportation Planning Colloquium. Delft, The Netherlands: 15-27.

Peters, T. J., and R. H. Waterman, Jr. 1984). In search of excellence: Lessons from America's best-run companies. New York: Warner Books.

Pickrell, D. H. 1990. Urban rail transit projects: Forecast versus actual ridership and costs. U.S. Department of Transportation.

Polzin, S. E. 1995. Private communications. Center for Urban Transportation Research. Richmond, J. 1995. Transport of delight: The mythical conception of rail transit in Los Angeles. Working Paper ITS-WP-95-10. Institute of Transportation Studies, the University of Sydney.

Tversky, A., and D. Kahneman. 1974. Judgment under uncertainty: Heuristics and biases. Science 185: 1124-1131.

U.S. Department of Transportation and Environmental Protection Agency. 1993. Clean air through transportation: Challenges in meeting national air quality standards.

Wachs, M. 1986. Technique vs. advocacy in forecasting: A study of rail rapid transit. Urban Resources 4(1): 22-30.

\section{About the Author}

Edward A. Mierzejewski, Ph.D., P.E., is Deputy Director for Engineering at the Center for Urban Transportation Research at the University of South Florida in Tampa. 


\title{
Transit-Oriented Development Suitability Analysis by the Analytic Hierarchy Process and a Geographic Information System: A Prototype Procedure
}

\author{
Reza Banai \\ The University of Memphis
}

\begin{abstract}
A prototype procedure is illustrated to assess the suitability of land use around proposed light rail transit stations of a metropolitan area, with an example of a focus on one station area land use pattern. Transit oriented development (TOD) guidelines provide the criteria for an assessment. The procedure for assessment is facilitated by a geographic information system (GIS), and the Analytic Hierarchy Process (AHP), a multicriteria methodology that is increasingly employed in conjunction with geographic information systems. The weights of the criteria are determined through paired comparisons (relative measurement), and a ratings intensity scale is used to determine the scores of land units (absolute measurement). This flexibility in measurement is helpful in situations where land use criteria, such as TOD guidelines, as suitability factors and with certain desirable thresholds of intensity are known, but must be considered strategically and adaptively, responsive to local priorities and site-specific conditions. The scores of land uses on a scale of zero to 100 percent are determined, which indicate the degrees of the suitability of a transit station area as a potential
\end{abstract}


TOD. As well, the proportions suggest changes that target particular parcels-individually and as a group-so as to bring about a desirable mix of the public, core/ employment, and housing uses for an urban TOD. This prototype application highlights the versatile properties of the AHP, particularly when used in the specific context of a development paradigm (TOD) in conjunction with a geographic information system that has not been previously addressed in the literature on applications.

\section{Introduction}

A view of ecology as a whole system encompasses not only the natural but also the built environment. The physical form that human settlement must take, then, is integral to the debates about sustainability and ecology, the balance of the natural and human-made systems. A recent contribution cognizant of a holistic view of ecology is provided by Calthorpe (1993) in his exemplary book, The Next American Metropolis, subtitled Ecology, Community, and the American Dream. Sustainable communities have a physical form that support public transit. A transit-oriented development (TOD) is defined by an average distance of 2000 feet (10-minute walk) from a transit stop, with retail, commercial, and office uses that are centrally located. TODs accommodate a mix of retail, office, residential, and public uses. The spatial configuration of a TOD thus caters to its residents and employees, whether they travel by transit, car, bicycle, or on foot (Figure 1).

Calthorpe (1993) defines three types of TODs - urban, neighborhood, and "secondary areas." The three types of settlement pattern follow a similar principle which defines spatial configuration in relation to a pedestrian scale and which promotes the diversity or mix of uses-commercial, residential, and public. Arguably, they are "new" types in the sense of a contrast with single-use zoning, with a bias in favor of a single mode of transportation-the automobile-which, in part, contributes to urban and suburban sprawl. In contrast to urban sprawl, evident since around the late 1940s in the U.S. and contentiously characterized as inhumane, resource intensive, formless and increasingly deemed as unsustainable, TODs have a more compact, rather than limitless, form. With 


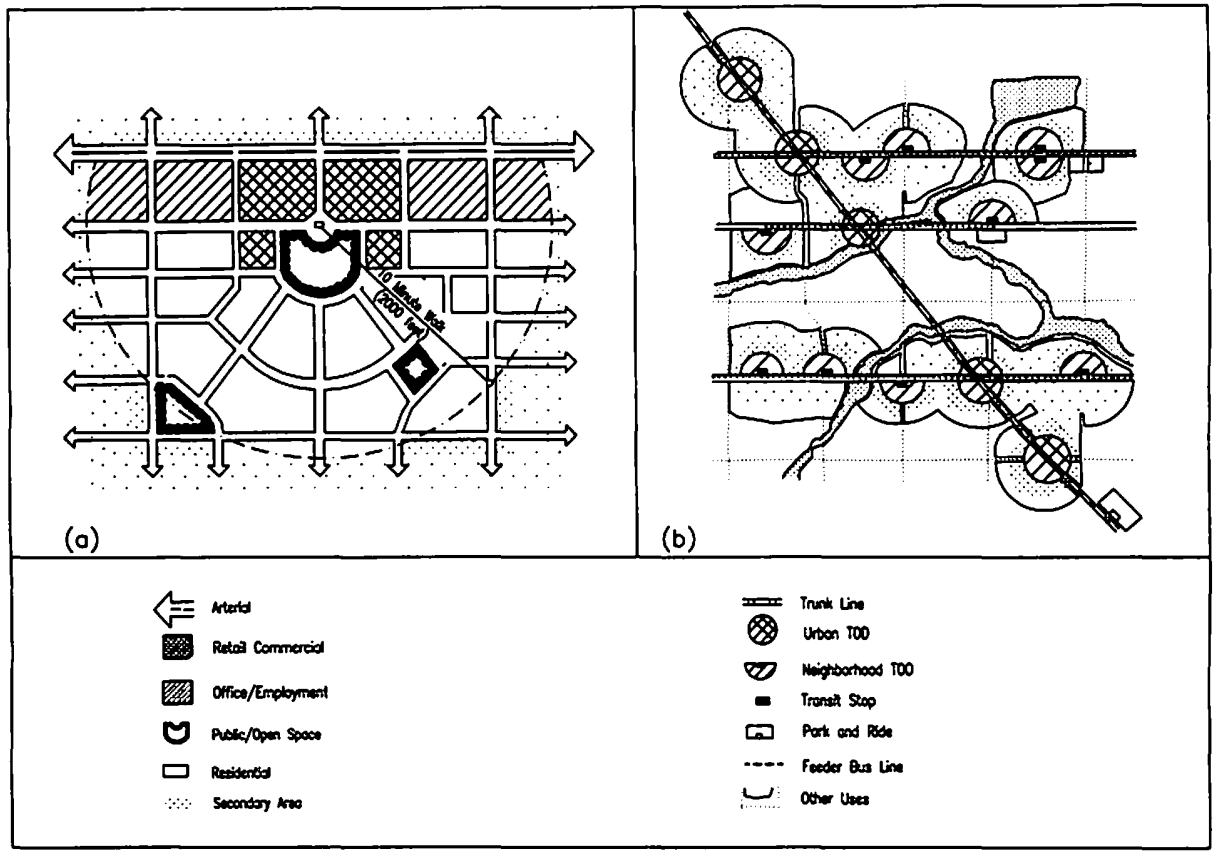

Source: Modified from Calthorpe (1993).

Figure 1. (a) Transit-oriented development (TOD);

(b) Regional location of TODs in relation to circulation.

their mix of uses as well as transportation modes and places in which to live and work, TODs provide alternatives to suburban sprawl.

A set of principles guide the physical form of TODs, whether in new growth areas or in "infill," redevelopment. The principles address a combination of social, spatial, economic, ecological, and organizational goals conducive to the (re)creation of transit-oriented developments. The principles serve as a backdrop for the specification of a set of design guidelines. The design guidelines address both the general and the specific-for example, the proportion of TOD areas devoted to public, employment, and housing uses; the density of housing; the location of civic buildings; parking and circulation; and general configuration of buildings (see Calthorpe 1993 for details).

The guidelines are not seen as a "universal model," however, thereby making adaptation of them in response to the conditions specific to a locality or a 
region plausible (Calthorpe 1993: 52; see also 42). Judicious appraisal, adoption, or modification of the guidelines involve an assessment of the conditions specific to a site that is commensurate with the small, spatial size of a TOD area (2000 feet radius from a transit station). A procedure that aids in the assessment of the relative importance of TOD guidelines as criteria as well as in the ratings of the site parcels relative to the criteria is outlined in the next section. This procedure uses the analytic hierarchy process, which is increasingly applied as a multicriteria methodology of site assessment in conjunction with geographical information systems. The properties of the AHP that make it particularly appropriate in the specific context of a development paradigm (TOD) and a GIS are highlighted.

The AHP is a robust multicriteria methodology in situations involving factor diversity. This AHP property is particularly useful since TOD guidelines specify a combination of qualitative and quantitative factors. Furthermore, the weights of the criteria are determined by means of paired comparisons. This property is of particular relevance in situations where the relative importance of site suitability factors must be determined in context rather than assumed on the basis of general models or previous empirical studies. Even TOD guidelines, as Calthorpe (1993) emphasizes, are better thought of when considered in context rather than universally applied. The AHP aids in the (re)formulation of TOD guidelines in context with a process of weighing the multiple criteria for site assessment. Above all, land use/transportation planning epitomizes planning in the face of the uncertainties of the economic, demographic, and political environment. The expert planning team encounters the uncertainties of the decisions of other participantsthe present and future residents of a community, the developer, the financier, the politician. Furthermore, values and circumstances change, and decisions are made in the face of limited information. In contrast to other multicriteria methods, the AHP provides a measure to gauge the consistency of value judgments of the decisionmakers in the process of deciding the relative importance of the criteria. Thus, the AHP provides an alternative to the commonly-used methods, particularly useful in decisionmaking under conditions of limited information and un- 
certainty, where the inconsistency in judging the relative importance of the criteria in a site suitability analysis can be both detected and improved. ${ }^{\prime}$

The method of paired comparisons of factors with reciprocal matrices (relative measurement) is unique to the AHP. However, the ratings of the alternatives when standards are known is performed in the AHP (absolute measurement) similar to other multicriteria methods. Both relative and absolute scales of the AHP were used with a geographical information system to develop a prototype procedure to assess TOD suitability. Focus was on an area within 2000 feet radius of a proposed light rail transit station. The focused site is located in an area that is designated as an "urban center," characterized by mixed residential, commercial, office, and governmental uses, internally-oriented design and higher densities, and a variety of services in close proximity to the service population (Memphis 2000 Policy Plan 1981). This concept of an urban center suggests an affinity with the concept of an urban TOD. Thus, an impetus is provided for the development of a procedure for an assessment of the focused site as an urban TOD as well as an urban center. This prototype procedure is intended as a contribution to the planners' "tool kit" in situations (such as in planning for a TOD) which, as Calthorpe notes, involve "areas larger than single parcels but smaller than those typically covered in community plans" (Calthorpe 1993:51).

\section{Transit Oriented Development Suitability Analysis: An Application of the Analytic Hierarchy Process with a Geographical Information System}

\section{Problem Context}

A recent study conducted for the local transit authority in the city of Memphis (Tennessee) has identified the locations of light rail (LRT) stations along the already existing railroad lines (Figure $3 \mathrm{c}$ ). Ridership, travel time, station spacing, and proximity to concentrations of shopping and employment activity were among the factors considered in the proposed location of LRT stations. The study itself notes, however, that the final decision on the location of stations is contingent upon station area land use, access plans, and station designs. Each transit station location may thus be considered as a catalyst for station area de- 
velopment or redevelopment (infill), as well as for enhanced transit accessibility.

Given the preliminary location of LRT stations, station area land use suitability was then to be determined. Certain properties or factors that make a place transit-friendly are known in the literature (for example, see Cervero 1993; Bernick and Cervero 1997; Ewing et al. 1997). As also noted above in Calthorpe's transit-oriented development guidelines, certain desirable thresholds are considered if places are to sustain an orientation to transit. For example, accessibility as a factor is considered with a threshold of a maximum of 2000 feet or (10-minute walk) from the surrounding housing to the transit station. At distances beyondfor example, 3,000 feet from the station-more people use a bus rather than walk to the transit station. (For a comparison of the different thresholds and mode shares, see Bernick and Cervero 1997.) Moderate-to-high density is also a suitability factor in TOD. Furthermore, land use mix, in contrast to single-use designation is considered not only as a factor in promoting transit use but also in enhancing the sustainability of TOD itself, as a "balanced" place that contains employment, shopping, and living activities. Since TODs cater to vehicular traffic as well as pedestrian movement, the circulation network is both continuous and hierarchically-differentiated to promote efficiency and safety of circulation.

The determination of the suitability of a station area land use as a potential TOD, it turns out, is a particular case of a more general problem of land use/site evaluation involving multiple factors as criteria. In the section that follows, one method - the AHP - among a class of multicriteria evaluation methods is illustrated as a prototype procedure to assess transit-oriented development suitability analysis within a GIS.

\section{TOD Suitability Analysis by the AHP with GIS}

Since its inception in the 1970s by Saaty (1977), and despite its wide-ranging disciplinary applications (e.g., see Zahedi 1986; Saaty and Vargas 1987), the AHP has relatively recently received attention as a multicriteria land evaluation/ site assessment method, particularly in conjunction with geographical information systems. (e.g., see Banai 1989, 1993; Xiang and Whitley 1993; Malczewski 
1996; Lin et al. 1997). (See Saaty [1992] for detailed exposition of the theory, applications, and extensions of the AHP method. For a brief introduction, particularly in the GIS context, see Banai [1993]). The basic AHP properties are outlined thus:

(a) Hierarchical Structure. The systemic concept of a hierarchy is used to structure a multicriteria evaluation problem. The criteria, the subcriteria (if any), and the alternatives are represented at the various levels of a typical AHP hierarchy of interrelated of factors. The factors at each lower level are compared with respect to the factors at the higher level of the hierarchy. First, the relative importance of the criteria is determined, followed next by the importance of the subcriteria, and finally down to the lowest level in the hierarchy in which the alternatives are rated.

(b) Paired Factor Comparison. At the core of the AHP is a systematic procedure for determining the relative importance of factors through their paired comparisons and by using a ratio scale. The weights of $n$ factors, $A_{1}, A_{2}, \ldots, A_{n}$ are denoted by a vector

$$
\mathrm{w}=\left(\mathrm{w}_{1}, \mathrm{w}_{2}, \ldots, \mathrm{w}_{\mathrm{n}}\right)
$$

Paired comparisons of the factors are performed in a matrix

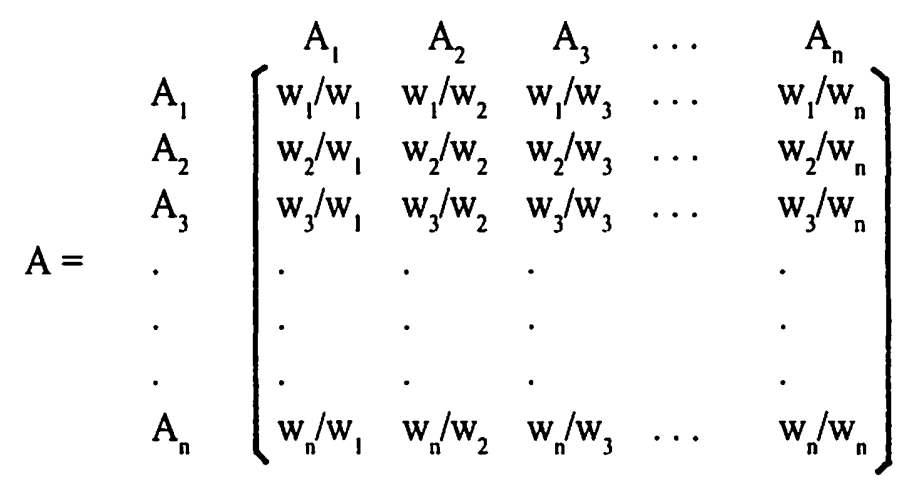


The matrix A is reciprocal $\left(a_{i j}=1 / a_{j j}\right)$, consistent $\left(a_{i j}=a_{i k} / a_{j k}\right)$, and all its diagonal entries are one $\left(a_{i i}=1\right)$. The coefficients (or entries) of $A$ give the relative magnitudes of the $n$ factors $\left(a_{i j}=w_{i} / w_{j}\right)$ when the vector of weights $w=$ $\left(\mathrm{w}_{1}, \mathrm{w}_{2}, \ldots, \mathrm{w}_{\mathrm{n}}\right)$ is known. However, if the weights are not known, they can be recovered by solving the well-known characteristic value problem. That is A is (post) multiplied by $\mathrm{w}$ and the result is stated in proportion to $\mathrm{w}$ itself, with $\mathrm{n}$ as a scalar.

$$
\mathrm{A} \cdot \mathrm{w}=\mathrm{n} \cdot \mathrm{w}
$$

Since A has unit rank (there is only one independent row of A), all of its characteristic values $\lambda_{\mathrm{i}}(\mathrm{i}=1 \ldots, \mathrm{n})$ are zero except one which Saaty $(1980)$ has denoted by $\lambda_{\text {max }} \neq \lambda_{i}=0$. The system $A \cdot \mathrm{w}=\mathrm{n} \cdot \mathrm{w}$ is stated in the form

$$
\mathrm{A} \cdot \mathrm{w}=\lambda_{\max } \cdot \mathrm{w}
$$

The weights of the factors compared pairwise in matrix A are thus determined by the normalized principal characteristic vector of $A$. The vector of weights $\mathrm{w}$ is recovered from any column of $\mathrm{A}$. A unique solution is obtained upon normalization of the columns of $A$ (each $w_{i}$ entry is divided by the column total $\Sigma w_{i}$. for $\mathrm{i}=1, \ldots, \mathrm{n})$.

c. Calculus of Consistency. When the vector of weights $w$ is known, matrix $A$ is consistent. That is, $a_{i j} \cdot a_{j k}=a_{i k}$.

However, when $w$ is unknown and the coefficients of $A$ are estimates of the relative weights, then the condition of consistency may not hold. That is, $a_{i j} \cdot a_{j k}$ $\neq \mathrm{a}_{\mathrm{ik}}$. A small perturbation in the values of the coefficients of $A$ implies a small perturbation in $\lambda_{\max }$. When $A$ is consistent, $\lambda_{\max }=n$. But, in general, $\lambda_{\max } \geq n$ (Saaty, 1980). The closer the value of $\lambda_{\max }$ is to $n$, the more consistent are the estimated coefficients of $A$ and therefore the better the estimated solution vector w. Hence, deviation from consistency is measured by an index:

$$
\mathrm{CI}=\left(\lambda_{\max }-\mathrm{n}\right) /(\mathrm{n}-1) .
$$


This value is compared with its average value for a randomly-generated reciprocal matrix of the same size as A. The comparison indicates whether the ratio estimates in the pariwise comparison matrix $\mathrm{A}$ are closer to being logically consistent or are closer to being random (Saaty 1980). Saaty has suggested an upper limit of 10 percent as a measure of good consistency. When this 0.10 threshhold is exceeded, the ratio estimates are revised to improve consistency. Thus, a procedure is provided that offers a gauge on consistency of judgment when violated in multicriteria evaluation in the face of limited information, data imperfection, factor diversity, and uncertainty.

(c) Synthesis. Once the relative weights of the factors at the various levels of the hierarchy-from the criteria to the alternatives-are determined, the results are aggregated in a weighted summation procedure in which the scores of the alternatives are computed.

The AHP was used interactively with a geographic information system (GIS) (a) to determine the relative importance of TOD suitability factors as criteria, (b) to analyze ratings of groups of land parcels with thematic maps of spatial data, and, finally, (c) to display the composite criteria-weighted ratings score of TOD land use suitability.

In the site study, ArcCAD (ESRI, Inc., Redlands, $C A$ ) was used for analysis of GIS data and thematic maps, AutoCAD (Autodesk, Inc., San Rafael, CA) was used as the drawing editor for the maps, and Expert Choice (1988, Decision Support Software, Inc., McLean, VA)was used for multicriteria assessment, utilizing the Analytic Hierarchy Process. The GIS information included parcel boundaries, census tract information (1996 Tiger/line files), road and street centerlines, zoning, and building outlines (local public utility company). The parcel data (shape files) were the most utilized in the assessment of land use suitability. This GIS data source provided the (city and county) tax assessors' use occupancy codes, which were useful for identifying and grouping land uses. The parcels were grouped (by use occupancy codes) as suggested by the TOD guidelines, as public, core/employment, and housing. After ratings were derived from Expert Choice, the resulting weights were then re-entered with the GIS data for map evaluation. Figure 2 illustrates the GIS data and software utilization. 


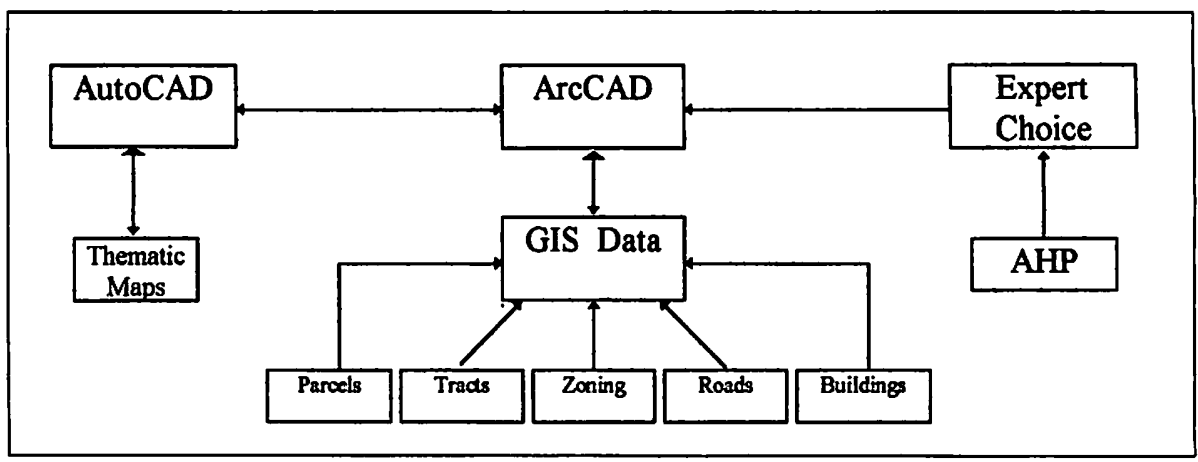

Figure 2. GIS data and software application for TOD suitability analysis.

Within the ArcCAD environment, GIS information is organized by multiple themes. In this example, parcel information was grouped by like use occupancy codes into themes such as public, core/employment, and housing. This information was then queried, clipped, buffered, and analyzed to determine total areas, and proximities.

As noted above, because situations and circumstances vary, TOD criteria should be considered judiciously, responsive to the conditions specific to a locality. If the TOD criteria (suitability factors) are not to be considered as fixed, universally held standards, then the relative importance of the criteria must be devised responsive to the local circumstances and in accordance with locally determined "standards." The AHP's logic of pairwise comparison (relative measurement) aids in the derivation of the relative weights of the suitability factors.

Once the relative importance of the context-dependent criteria is determined, the next step involves the ratings of the land uses to assess suitability for TOD. The AHP's logic of absolute measurement aids in this process of determining the relative merit of land uses given the TOD criteria. With the combined steps, the versatile properties of the AHP are used in a situation that involves multicriteria evaluation with both relative and absolute scales of measurement. This flexibility of the AHP, particularly in situations where land use guidelines, such as TOD (criteria), as suitability factors and with certain desirable, albeit modifiable, thresh- 
olds are known, is not highlighted in the literature on the application of the AHP as a site suitability technique with a geographical information system.

\section{Deriving the Relative Weights of TOD Suitability Factors}

A hierarchy is constructed in which four suitability factors and their subfactors are specified (Figure 3a). The alternatives as urban and neighborhood TODs, and secondary areas, comprising three land use groupings (public, core/ employment, and housing) are specified at the final branchings of this hierarchy.

The choice of the four suitability factors is strategic. It represents a realistic scenario in which a group of decisionmakers, having considered a general set of suitability factors, focus upon those that are deemed critical to a particular site. Not only, then, do the decisionmakers "narrow-down" the suitability factors to those which are particularly critical to the conditions of a given site, but they also see fit to discern their relative importance, rather than to assume that factors are equally important at any location. In effect, the decisionmakers set out to derive local "standards" from the general TOD criteria. An example of a procedure that aids in this type of suitability analysis and decisionmaking follows.

The four suitability factors are compared pairwise in a matrix (Table 1) by using the AHP scale (see p. 57).

Regarding the entries in the first row, the reciprocal value $(1 / 3)$ indicates that Density (column factor) is moderately more important than MixUse (row factor). Also in the first row, MixUse is given a value (2) in the mid-point of the scale of equal and moderate importance, in comparison with RoadNet. MixUse and ProxStat are considered as equally important (1).

Considered alone, density — particularly moderate to high density—is a factor deemed essential to a transit-supportive development. Considered together with the mix of uses, however, density is given a "moderately" greater importance (3). Why is density given only a "moderately" greater importance than the mix of uses, if moderate-to-high density is essential to a transit-supportive development? Because the "balance," e.g., with respect to jobs-housing, that an appropriate mix of land uses in a development provides is desirable in itself, whether or not transit is available. In the spirit of the guidelines, a TOD is not only a 


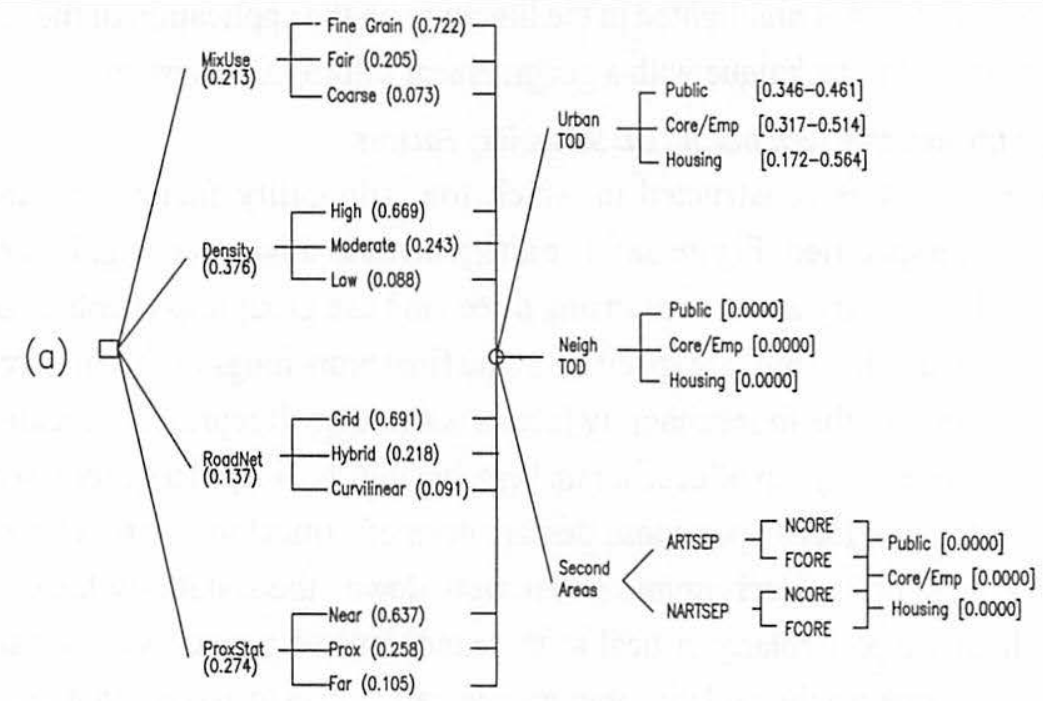

(b)
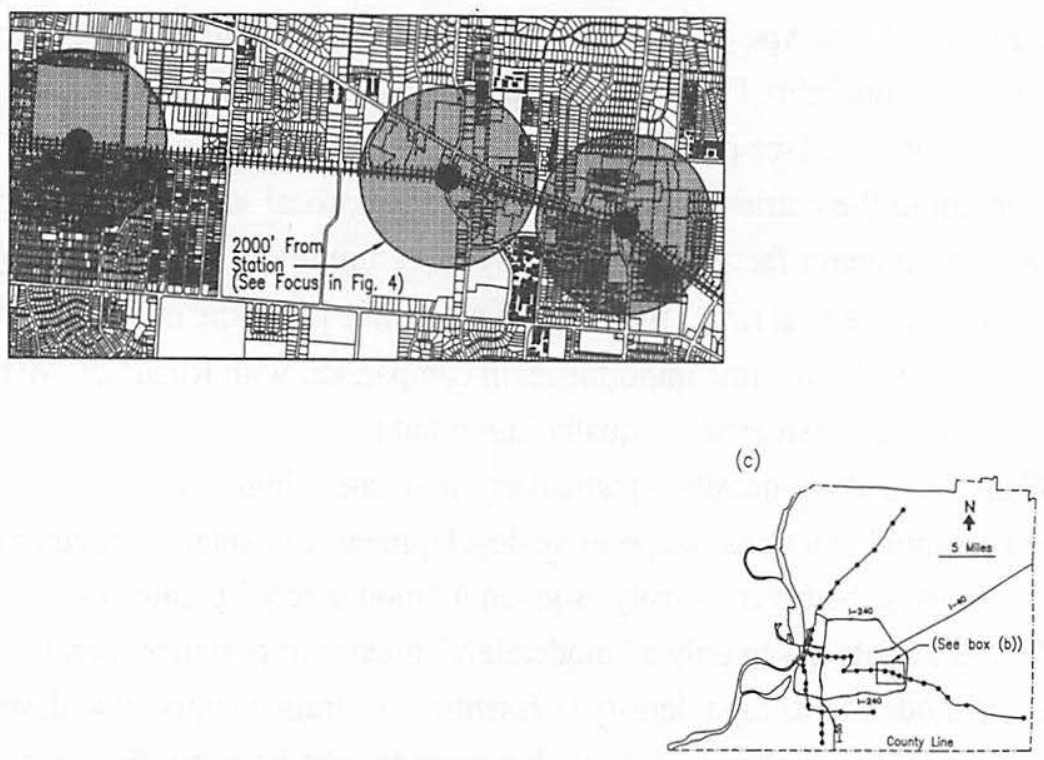

Figure 3. (a) A hierarchy for TOD land suitability analysis of a station area; (b) proposed transit stations; (c) regional LRT lines and stations. 


\section{The AHP Scale: Definition and Explanation}

Equal importance-the two activities contribute equally to the objective

Moderate importance-experience and judgment slightly favor one activity over another

Essential or strong importance-experience and judgment strongly favor one activity over another

Demonstrated importance-an activity is strongly

favored and its dominance is demonstrated in practice

Extreme importance-the evidence favoring one activity over another is of the highest possible order of affirmation

Intermediate values between the two adjacent judgments-compromise is needed.

If an activity $i$ has one of the above numbers assigned to it when compared with activity $j$, then $j$ has the reciprocal value when compared with $i$. above numbers

*The scale 1.1. 1.2, ... 1.9, or an even finer one, can be used to compare elements that are close together or are near equal in importance; similarly from 2.0 to 2.9, etc. (Source: Saaty1987)

transit-supportive development but is also a balanced or finer-grained development. Hence, also, the usefulness of a multicriteria logic of the AHP with paired comparisons of the TOD suitability factors is suggested. The comparisons of the remaining factors follow a similar logic of multicriteria evaluation.

It should be noted that once the upper (or lower) diagonal entries are assigned values in the matrix in Table 1, the lower (or upper) entries are determined reciprocally, without the use of further judgment. Also note that all the diagonal entries are unity, when a factor is compared to itself. The relative weights of the factors (bounded on a scale from zero to 100 percent) are determined by 
Table 1

Deriving Relative Weights of the TOD Suitability Factors

\begin{tabular}{lccccc}
$\begin{array}{l}\text { Suitability } \\
\text { Factor }^{*}\end{array}$ & MixUse & Density & RoadNet & ProxStat & Weight \\
\hline MixUse & 1 & $1 / 3$ & 2 & 1 & 0.213 \\
Density & 3 & 1 & 2 & 1 & 0.376 \\
RoadNet & $1 / 2$ & $1 / 2$ & 1 & $1 / 2$ & 0.137 \\
ProxStat & 1 & 1 & 2 & 1 & 0.274 \\
Consistency & & & & & \\
Index (C.I.) $=0.057$ & & & & & \\
\hline
\end{tabular}

(a) MixUse: The mix of public, corelemployment, and housing uses in the site, distinguished further by the subfactor, fine grain, fair, and coarse (see Fig. 3a). Density: The density of land uses in the site, distinguished by high, moderate and low densities of uses. RoadNet: The road pattern in the transit station area, distinguished by a grid or a curvilinear network of streets, or by a combination, hybrid. ProxStat: The proximity of the public. core/employment, and housing to the transit station, further differentiated by near, proximate, and far (Fig. 3a).

the normalized principal characteristic vector of this matrix. The relative weights of the suitability factors are shown in the right margin of the matrix in Table 1. In a descending order of relative importance, the factors are Density (0.376), ProxStat (0.274), MixUse (0.213), and RoadNet (0.137). Note also that the consistency index value of 5.7 percent is well within the 10 percent range of an acceptable limit, which indicates good consistency in the matrix of ratio estimates of the relative weights of the suitability factors.

At the second branchings of the hierarchy (Figure 3a) the relative importance of subfactors is determined. The subfactors indicate a gradation of the main factors. Through paired comparisons, the "grade" of "membership" of the subfactors is determined. The use of the terminology of fuzzy set logic is deliberate. For example with respect to MixUse, even a "coarse" land use mix is considered for suitability, albeit with a much lower priority $(0.073)$, in compari- 
son to a "fair" (0.205), and to the highly desirable "fine grain" $(0.722)$ land use pattern. The paired comparisons of the subfactors and their relative weights (or grades of membership) are given in Table 2. These comparisons provide examples of how preferences are revealed as the suitability factors are differentiated.

Next, the ratings of the land uses in the site are determined. The ratings are then weighted by the relative importance of the suitability factors (above), and thus the final scores for the various units of land use are determined.

Table 2

Paired Comparisons of the Subfactors

\begin{tabular}{lccccccccc}
\hline MixUse & Fine & Fair & Coarse & Wt. & Density & High & Mod. & Low & Wt. \\
Fine & 1 & 5 & 7 & 0.722 & High & 1 & 3 & 7 & 0.669 \\
Fair & $1 / 5$ & 1 & 4 & 0.205 & Moderate & $1 / 3$ & 1 & 3 & 0.243 \\
Coarse & $1 / 7$ & $1 / 4$ & 1 & 0.073 & Low & $1 / 7$ & $1 / 3$ & 1 & 0.088 \\
C.I. $=0.107$ & & & & & C.I. $=0.006$ & & & &
\end{tabular}

RoadNet Grid Hybrid Curv. Wt. ProxStat Near Prox. Far Wt.

$\begin{array}{lccccccccc}\text { Grid } & 1 & 4 & 6 & 0.691 & \text { Near } & 1 & 3 & 5 & 0.637 \\ \text { Hybrid } & 1 / 4 & 1 & 3 & 0.218 & \text { Prox. } & 1 / 3 & 1 & 3 & 0.258 \\ \text { Curvilinear } & 1 / 6 & 1 / 3 & 1 & 0.091 & \text { Far } & 1 / 5 & 1 / 3 & 1 & 0.105 \\ \text { C.I. }=0.046 & & & & & \text { C.I. }=0.033 & & & & \end{array}$

\section{Rationale for Site Ratings}

Mix Use-The mix of land uses, as derived by the AHP, is ranked second among our four criteria with a weight of 0.213. As Calthorpe (1993: 63) states, "TODs must be mixed-use and contain a minimum amount of public, core commercial and residential uses." The mix of uses provides preferred thresholds to consider when evaluating TOD land uses. The preferred range of ideal mix of uses for an urban TOD is shown in Table 3, compared to the actual mix of uses determined for our site.

The amount of public land use is approximately three times that of the preferred, while the core/employment is in the middle of the preferred range. The 
percentage of residential land use is only 8 percent, which falls short of the preferred range of 20-60 percent. This suggests that some of the public land uses could be readjusted or converted to housing to bring the overall land uses within the suggested range.

The subfactors of this criterion were defined as "fine grain" with a weight of 0.722 , "fair" with a weight of 0.205 , and "coarse" with a weight of 0.073 . These subfactors indicate how each occupancy code group contributes to a desirable overall mix of uses. A "fine" rating indicates that the proportion of land use types is comparable to those found in the TOD guidelines. The goal of this is to maintain balance between the different land use groups to achieve a sustainable mix of uses.

\begin{tabular}{|lclc|}
\hline \multicolumn{4}{|c|}{ Table 3} \\
Preferred vs. Observed Mix of Uses \\
\hline Preferred Mix of Use & Urban TOD & Actual Mix of Use & Site \\
\hline Public & $5-15 \%$ & Public & $47 \%$ \\
Core/Employment & $30-70 \%$ & Core/Employment & $45 \%$ \\
Housing & $20-60 \%$ & Housing & $8 \%$ \\
\hline
\end{tabular}

Two public uses-parks and churches-dominate the site area (Figure 4). These uses comprise 47 percent of the total land area. Large-scale regional parks are more desirable in a TOD's secondary area rather than in its primary area, which accommodates a number of small scale parks as open spaces (recall Figure 1). The regional park extends beyond the 2,000 ft. radius and into the "secondary area." Park/open space land was given a rating of "fair" due to a disproportionate use of land within a TOD area. Within the core/employment area, department stores, strip shopping, restaurants, fast food places, and service stations dominate and justify a "coarse" rating. The presence of two supermarkets, and a few banks are more proportional to the amount of land use mix; therefore, 
a rating of "fair" was given. The amount of land area occupied by the mix of offices, and their distribution helped them attain a rating of "fine." As for the housing component of land use mixes, which totaled only 8 percent of the given area, the single family and duplex uses were assigned a rating of "coarse." The lack of sufficient proportions of these two uses was seen as detrimental to the area. The planned-unit-developments and condominiums ranked higher since they occupied more area in proportion to that of the other groups. However, again as with other two groups making up the category, the amount of land use is below the mix of uses as suggested by the TOD guidelines and was assigned "fair" rating.

Density-Density, with a weight of 0.376 , was determined to be the most important of the four criteria. The number of dwelling units per acre (du/ac) is an indicator of density. The ideal urban TOD as described by Calthorpe has an average residential density of $18 \mathrm{du} / \mathrm{ac}$. The gradation of the subfactors includes ratings above and below this average threshold of density. The subfactor choices of density are "high," with a weight of 0.669 , "moderate," with a weight of 0.243 , and "low," with a weight of 0.088 . Each land use unit (occupancy code group) is thus rated for contribution to the overall density of the area as an urban TOD. Due to the large area and few public buildings, park/vacant land was rated as "low." In contrast, the religious/institutional land uses were given a "high" rating due to the size of the buildings relative to the area of land they occupy (floor area ratio).

The core/employment land uses such as banks, strip shopping, supermarkets, restaurants, fast food places, and service stations were assigned a rating of "low" due to the predominance of parking lots and characteristically low density one-story buildings. Department stores and office land uses were given a rating of "moderate" due to the larger multistory mall and Sears department store. The presence of several multistory office buildings in this area helps to increase the overall density, supportive of transit-oriented development, and therefore these were assigned "moderate" rating. The housing land uses of duplex and single family were both assigned "low" ratings. Calthorpe assigns single family homes 


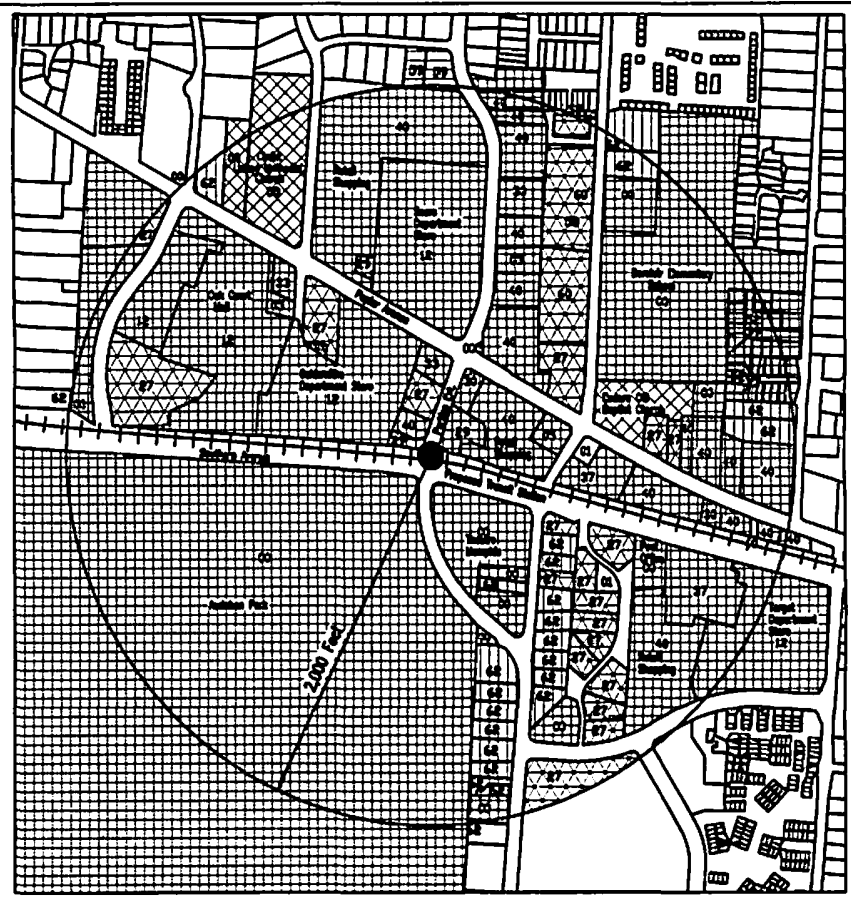

\begin{tabular}{|c|c|c|c|c|c|c|}
\hline & & & Mixuse & Density & RoodNet & ProxStot \\
\hline P & F Perk/Nocont Lond $(00)$ & [osut] & Foir & Low & Grid & Near \\
\hline & Religious(08) & [avis] & Fair & High & Grid & Prox \\
\hline •/Employment & 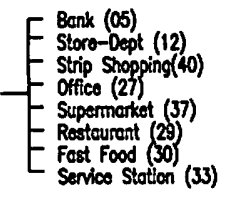 & 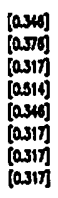 & $\begin{array}{l}\text { Foir } \\
\text { Coorse } \\
\text { Coorse } \\
\text { Fine } \\
\text { foir } \\
\text { Coorse } \\
\text { Coorse } \\
\text { Cocrse }\end{array}$ & $\begin{array}{l}\text { Low } \\
\text { Noderate } \\
\text { Low } \\
\text { Moderete } \\
\text { Low } \\
\text { Low } \\
\text { Low } \\
\text { Low }\end{array}$ & $\begin{array}{l}\text { Grid } \\
\text { Grid } \\
\text { Grid } \\
\text { Grid } \\
\text { Grid } \\
\text { Grid } \\
\text { Grid } \\
\text { Grid }\end{array}$ & $\begin{array}{l}\text { Near } \\
\text { Neor } \\
\text { Neor } \\
\text { Neor } \\
\text { Neor } \\
\text { Neor } \\
\text { Near } \\
\text { Necr }\end{array}$ \\
\hline Hous & 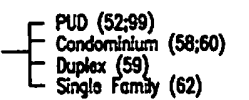 &  & $\begin{array}{l}\text { Fair } \\
\text { Foir } \\
\text { Cocrse } \\
\text { Cocrse }\end{array}$ & $\begin{array}{l}\text { Moderote } \\
\text { High } \\
\text { Low } \\
\text { Low }\end{array}$ & $\begin{array}{l}\text { Grid } \\
\text { Grid } \\
\text { Grid } \\
\text { Grid }\end{array}$ & $\begin{array}{l}\text { Prox } \\
\text { Near } \\
\text { For } \\
\text { Prox }\end{array}$ \\
\hline
\end{tabular}

Land Use Suitability Rotings:

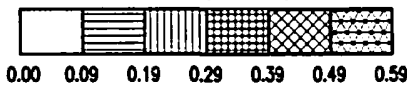

Source: Occupancy codes (in paremthese's) from public domain GIS (1996).

Figure 4. Land use suitability ratings for an urban TOD. 
a density of 7-10 du/ac, and duplexes 10-14 du/ac. This is, again, due to their low density, which is preferred in secondary-area developments. The planned unit developments (mainly townhouses) were assigned a "moderate" rating due to their higher residential densities, which average 18-29 du/ac. The condominiums in the area, particularly the 12-story one on Perkins, with a density of 40-65 du/ac, received "high" rating.

RoadNet-The road network criterion, which is assigned an overall weight of 0.137 (the lowest of the four) is based on the traffic circulation system found within each use occupancy code group of parcels for that land use. The three choices of ratings are "grid" $(0.691)$, "hybrid" $(0.218)$, and "curvilinear" $(0.091)$. A "grid" rating means that the overall street pattern exhibits parallel lines of travel, with a regular, continuous network of arterial and collector streets, preferably with an axial orientation to the transit station. The "hybrid" rating is a combination of some grid pattern and curvilinear streets. The "curvilinear" rating is reserved for street patterns, which do not allow a continuous or through traffic flow, similar to those found in suburban residential neighborhoods with many coves and dead-end streets.

The street pattern for each occupancy code and the overall transit station area itself is a grid. The main arterial streets (Poplar Avenue and Perkins/Perkins Extended) (Figure 4) both pass through or near the proposed transit stop and serve as collector streets from outlying residential areas. Therefore, each use occupancy code was assigned a rating of "grid" with a weight of $(0.095)$.

ProxStat-The proximity to transit station criterion, which is assigned a weight of 0.274 (the second highest of the four), is simply based on the overall distance of each group of parcels with the same use occupancy code from the proposed transit stop. The choices of ratings for this criteria are "near" $(0.637)$, "proximate" (0.258) and "far" (0.105).

The majority of use occupancy code groups, such as park/vacant land, bank, department store, strip shopping, office, supermarket, fast food place, service station, and condominium were assigned a rating of "near" because of the close proximity and equality of distributions around the proposed transit stop. The 
groups of religious, PUDs, and single-family were assigned a rating of "proximate." The two large church parcels are located on the north side of the proposed transit stop, approximately 1,000 feet to $1,800 \mathrm{ft}$. away, respectively. The planned unit developments are located within the $2,000 \mathrm{ft}$. radius, which, by TOD definition, justify a "proximate" rating. The duplexes are located just outside the north side of the 2,000 foot radius boundary, resulting in a "far" rating.

\section{Conclusion}

The AHP-GIS procedure illustrated here facilitates small area suitability assessment beyond individual parcels and at a scale of "district" rather than metropolitan-wide comprehensive planning. The detailed, micro investigation of the smaller area or district plan, however, provides input into the larger comprehensive plan of which it is a part. By identifying and grouping land parcels into units of the public, core/employment, and housing land uses, the composition of the area as a whole is determined for suitability as a transit-oriented development. The holistic perspective is particularly important to a concept of a "balanced" TOD, if followed through methodologically. The AHP aids in such an investigation of the appropriate proportion and composition of a TOD.

By using four criteria as an illustration, the suitability of the various units of land use, which constitute the still larger units of public, core/employment, and housing, is determined. It turns out that certain land uses fare favorably when the area as a whole is viewed as a TOD (see Figure 4). For example, among the uses with highest scores include religious uses $(0.481)$, office $(0.514)$, and condominium (0.584) within public, core/employment, and housing groups, respectively. The ranges of the final scores by the three categories (see also Figure 2a, urban TOD branching) indicate only housing $(0.172-0.567)$, with a low score in the range, lagging behind those of the public $(0.346-0.461)$ and core/employment $(0.317-0.514)$. As noted above, conversion or redevelopment of land (for example, vacant) into residential uses could result in a more favorable score of housing in a transit-oriented development.

One can allow for even greater complexity by increasing the number of levels or factors in a decisionmaking hierarchy. The participants (e.g., experts, 
developers, publics, politicians) are identified explicitly. Thereby, the different priorities that different participants attach to the TOD suitability factors as criteria are accounted for. A possible scenario in which the weightings of the criteria result in an outcome that favors one party more than another may be examined. The AHP predictions of such an outcome could inform the parties involved and thus provide a basis so as to arrive at a collectively desirable decision outcome. ${ }^{2}$

This prototype analysis provides only a stepping stone for further investigation. For example, the use of census GIS data is helpful to determine areas of growth or decline. These areas can be analyzed to determine suitability for new, in-fill, or redevelopment TODs. New trunk line and station locations might be considered, based on the interpretation of rapid population growth and zoning changes in suburban areas, particularly in relation to new regional malls and activity centers, which have burgeoned recently. Joint consideration of transit spacing and station area (TOD) criteria could justify alternative transit station locations other than those currently proposed along the existing truck lines (based on transit functional requirement and regional distribution of activity centers). GIS themes can be developed quickly to show transit, bus routes, stops, or proposed road design changes as thematic maps. The socioeconomic (e.g., income, auto ownership), demographic (e.g., population characteristics, density), and physiographic profiles of the region can be mapped thematically with available GIS census data to facilitate both the depiction and analysis of land use/transportation. nexus. The AHP aids in such a GIS analysis to fine-tune public policy priorities for future transit-oriented developments in the region.

\section{Endnotes}

' The AHP is widely applied and therefore has also received both critical and constructive consideration of its properties. The issues regard the scale, treatment of objectivity, procedures for aggregation of weights, and methods of ranking alternatives. For a survey of applications and areas of methodological extensions, see e.g., Zahedi (1986) and Forman (1993) for a lucid discussion of "facts and fictions" about the AHP. 
${ }^{2}$ For a historical account of a transport planning process from the perspectives of different participants or "actors," see Hall (1980), especially Chapter 3, "London's Motorways."

\section{References}

Banai, R. 1993. Fuzziness in geographical information systems: Contributions from the analytic hierarchy process. International Journal of Geographical Information Systems (7)4: 315-329.

Banai, K. R. 1989. A new method for site suitability analysis: The analytic hierarchy process. Environmental Management 13: 685-693.

Bernick, M., and R. Cervero R. 1997. Transit villages in the 21st century. New York: McGraw-Hill.

Calthorpe, P. 1993. The next American metropolis: Ecology, community and the American dream. New York: Princeton Architectural Press.

Cervero R. 1993. Transit-supportive development in the United States: Experiences and prospects. Washington, D.C.: Federal Transit Administration.

Ewing, R., B. Mackey, and B. Sewell. 1997. Transit-oriented development in Florida. Land Development (10)2: 31-35.

Forman, E. H. 1993. Facts and fictions about the analytic hierarchy process. Mathematical and Computer Modelling (17)4/5: 19-26.

Hall, P. 1980. Great planning disasters. California: Univ. of California Press.

Lin H., Q. Wan, X. Li, J. Chen, and Y. Kong. 1997. GIS-based multicriteria evaluation for investment environment. Environment and Planning B: Planning and Design 24: $403-414$.

Malczewski, J. 1996. A GIS-based approach to multiple criteria group decision-making. International Journal of Geographical Information Systems (10)8: 955-971.

Saaty, T. L. 1992. Multicriteria decision making-the analytic hierarchy process. Pittsburgh, PA: RWS Publications.

Saaty, R.W. 1987 The analytic hierarchy process-what it is and how it is used. Mathematical Modelling (9)3-5: 161-176.

Saaty, R.W., and L. G. Vargas (eds.) 1987. The analytic hierarchy process: Theoretical developments and some applications. Mathematical Modelling (9)3-5.

Saaty, T. L. 1980. The analytic hierarchy process. New York: McGraw-Hill. 
Saaty, T. L. 1977. A scaling method for priorities in hierarchical structures. Journal of Mathematical Psychology 15: 234-281.

Xiang, W. N., and D. L. Whitley. 1994. Weighting land suitability factors by the PLUS method. Environment and Planning B: Planning and Design 21: 273-304.

Zahedi, F. 1986. The analytic hierarchy process: A survey of the method and its applications. Interfaces (16)4: 96-108.

\section{Acknowledgment}

The author would like to thank John Lancaster for research assistance. The comments of the reviewers on an earlier version of this paper are gratefully acknowledged.

\section{About the Author}

Reza Banal, Ph.D., is a Professor of City and Regional Planning at the University of Memphis in Tennessee. 


\title{
Perceived Service Quality Attributes in Public Transport: Inferences from Complaints and Negative Critical Incidents
}

\author{
Margareta Friman \\ Bo Edvardsson \\ University of Karlstad, Sweden \\ Tommy Gärling \\ Göteborg University, Sweden
}

$\overline{\text { Abstract }}$

A sample of 200 complaints filed to a public transport company and 210 negative critical incidents (NCIs) obtained from on-board interviews were analyzed with the purpose of inferring perceived service quality (PSQ) attributes of public transport. The most frequent complaints and NCIs concerned employee behavior and punctuality, followed by missing or inaccurate information and inadequate planning. In a follow-up mail survey, a representative sample of 997 respondents reported if they remembered having experienced prototypical NCIs constructed on the basis of the complaints. Confirming the validity of the inferred PSQ attributes, all NCIs were reported to have been experienced by at least some respondents. NCIs related to employee behavior were, however, less frequently remembered, whereas those related to vehicle design and space, punchuality, and traffic planning were more frequently re- 
membered. Taken together, the results suggest that PSQ attributes in public transport refer to employee behavior, reliability, and simplicity. Finally, inferences made from customer complaints and negative critical incidents are shown to extend our knowledge of perceived service quality attributes in public transport.

\section{Introduction}

The problem currently facing public transport operators is that although travel demand steadily increases, the demand for public transport declines (Benister 1992) due to increased automobile use. Andreassen (1995) feels that transport operators often make the mistake of mass marketing a standard service to a heterogeneous market. Changing the marketing strategy in a desirable direction requires a focus on how customers' perceptions are related to characteristics of the service. However, research on public transport has tended to emphasize the technical aspects of the service (e.g., vehicle and facility design), leaving out psychological and social aspects that may be more important (Everett and Watson 1987). It has, therefore, been argued that transportation systems need to be considered from a behavioral perspective rather than from an exclusively technological view (Hartgen 1981). Knowledge of perceived quality of public transport services may be essential if the service is to become more attractive to consumers who have other alternatives (e.g., automobile). Such knowledge gained from behavioral service-quality research will guide the formulation of strategies that can influence customers' travel choices and satisfaction.

The focus of this article is perceived service quality of public transport services (i.e., buses and streetcars). Specifically, the aim is to empirically examine whether previous findings concerning perceived service quality (PSQ) attributes generalize to public transport services. More than 30 studies during the last 10 years of customer PSQ were examined in a recent review (Edvardsson 1996) showing that how the employees treat the customers, reliability of the service, simplicity (e.g., clearness and accessibility of information), and recovery when something goes wrong are significant factors. The hypothesis of this 
study is that these factors are also important in public transport, although it is realized that there may be differences between different types of services (Lovelock 1983).

A public transport service may be characterized by means of objective attributes or performance measures (e.g., travel time, cost, and frequency of service). A distinction can also be made between episodes, critical incidents, and PSQ (see Figure 1). An episode refers to a trip or part of a trip, such as walking to a bus stop or buying a ticket. The customer may evaluate any such episode as positive or negative when it differs from a norm or expectation (Strandvik 1994). Such episodes, which may be either positive or negative, are labeled critical incidents (Flanagan 1954). It may be assumed that PSQ, to some extent, depends on the number of positive or negative critical incidents which are remembered

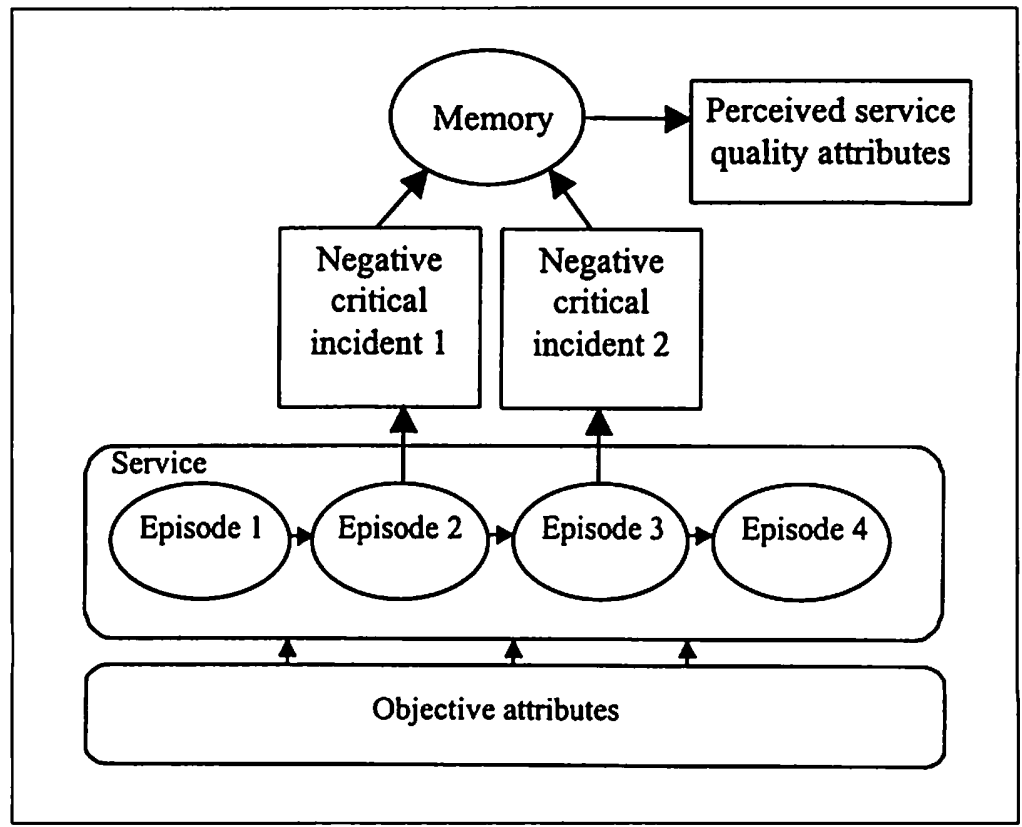

Figure 1. Hypothetical relationships between objective attributes of public transport services, episodes, and negative critical incidents encountered by consumers, and perceived service quality attributes. 
(e.g., Folkes 1994; Johns and Tyas 1997). In the case of public transport services, negative critical incidents (NCIs) may have more impact, since, in contrast to some other services (e.g., restaurants, entertainment), avoiding dissatisfaction may be more important that attaining satisfaction. An example is that delays lead to perceiving the service as unreliable. However, a bus or streetcar that is on time may go unnoticed. Another example is that remembering episodes when staff is not helpful may cause the impression of non-professional staff, whereas the reverse has no influence. Of course, in neither example are the perceptions necessarily correct. Still, if many NCIs are investigated, inferences may be possible to make about how service quality is perceived.

The assumption that PSQ attributes depend on negative critical incidents makes it appropriate to use the critical incident technique (CIT) for obtaining information about perceived service quality attributes. CIT refers to " . . a procedure for gathering certain important facts concerning behavior in defined situations ..." (Flanagan 1954: 335). Some criteria have been stated for defining a critical incident (e.g., Flanagan 1954; Youngdahl and Kellogg 1996). For instance, it has been suggested that a critical incident should involve specific actions and be extremely unsatisfactory or satisfactory. The description must also provide sufficient details. Studies of critical incidents in service research have been conducted focusing either on customers' or employees' perceptions. For instance, Bitner, Booms, and Ttreault (1990) reported the results of several studies of service quality in airlines, hotels, and restaurants were the CIT was used. Both satisfactory and dissatisfactory specific events and behaviors were included. The technique has also been used to analyze only negative critical incidents in, for example, high technology services (Edvardsson 1988), banks (Olsen 1992), and automobile services (Stauss 1992).

Information about critical incidents may be obtained in different ways. In early CIT.studies, it was common to ask experts to describe critical incidents they had experienced. As the popularity of CIT increased (Stauss 1993), a variety of methods of eliciting critical incidents were employed, including, for instance, personal interviews, focus group interviews, and questionnaires. An un- 
obtrusive method of obtaining NCIs may be to use archival customer-complaint data. Cadotte and Turgeon (1988), who analyzed the content of complaints as well as compliments, found that in general complaints contain extremely unsatisfactory experiences. Thus, it seems reasonable to assume that complaints are similar to NCIs. In the first study reported here, access was given to a database compiled by a public transport company. A sample of the filed complaints was categorized and counted.

Only a small number of customers complain when they have had a negative experience with a service (Day et al. 1981) (see note 4). Those who do may furthermore differ importantly from other customers. To guard against such potential reporting biases, in the second study a sample of customers was asked to report NCIs in face-to-face interviews.

The aim of the CIT is to obtain a detailed, comprehensive description of the critical incidents as they are experienced (Olsen 1992). In order to extract meaningful information from such descriptions, they must be categorized. Categorization of critical incidents consists of (1) developing knowledge of the area to be investigated, (2) developing guiding principles for distinguishing critical from other incidents, (3) developing categories as well as rules defining inclusion, and (4) actually categorizing the incidents. Depending on aim and purpose, categorization can either be inductive or deductive. In any case, the categorization may be unreliable. However, Andersson and Nilsson (1964), who tested whether groups of students would categorize incidents differently than the researcher, showed that, even if the students placed a critical incident in a different category at the lowest level, agreement was usually satisfactory at superordinate levels. Together, the methodological studies reported by Andersson and Nilsson (1964) and others (e.g., Ronan and Latham 1974) suggest that categorization may, in fact, be satisfactorily reliable. Still, it is advisable to include checks of reliability in any single study.

The aim of the third study was partly to validate the categories in the preceding studies and partly to assess the frequency of negative critical incidents in a representative sample. On the basis of the complaints, a set of prototypical 
descriptions of NCIs was prepared. In a mail questionnaire, these descriptions were presented to respondents who indicated for each whether or not they remembered having experienced a similar event.

The present research thus aims at examining the hyposthesis, based on previous findings in different service industries (Edvardsson 1996), that the following are important PSQ attributes in public transport: employee behavior, reliability, simplicity, and recovery. If PSQ attributes are related to negative critical incidents, it is appropriate to use the CIT. Descriptions of NCIs may be obtained from complaints, interviews, or survey questionnaires. All these techniques were used in different studies to combine their relative strengths and weaknesses. The following three sections present the results. In the last section, the main findings are summarized and discussed.

\section{Complaints}

\section{Data Set}

The public transport company in Gothenburg, Sweden invites customers to make complaints by phone, postcard, letter, or fax. Two hundred' such complaints were collected from their database, consisting of approximately 3,000 complaints obtained during the last 12 months (an average of approximately 250 complaints each month). A few complaints were screened since they were not possible to read or did not include sufficient information. Of the remaining complaints in the database, 15 to 17 were randomly chosen from each month.

\section{Analyses and Results}

The selected complaints were categorized independently by two judges according to an inductive procedure where the categories were developed on the basis of the descriptions. After reading all complaints, the descriptions were grouped by the judges in categories based on similarity. The grouping was changed and refined until the descriptions in a category were more similar to each other than to descriptions in any other category. Agreement between the judges was almost complete; the disagreements were resolved by discussion. 


\section{Table 1}

\section{Frequencies of Categorization of Incidents Obtained from Complaints}

\begin{tabular}{|c|c|c|c|}
\hline Superordinate Group & Main Category & Freque & \\
\hline \multirow[t]{4}{*}{ Treatment and Action } & Uncomfortable driving & 47 & \\
\hline & Unsafe driving & 17 & \\
\hline & Driver failed to stop & 15 & \\
\hline & Bad treatment by other employee & 5 & $(\Sigma 84)$ \\
\hline \multirow[t]{3}{*}{ Punctuality } & Early departure & 15 & \\
\hline & Late departure & 15 & \\
\hline & Canceled trip without notice & 11 & $(\Sigma 41)$ \\
\hline \multirow[t]{3}{*}{ Information } & $\begin{array}{l}\text { Arrival and departure times } \\
\text { (including delays) }\end{array}$ & 21 & \\
\hline & Destination & 6 & \\
\hline & Tickets and their validity & 5 & $(\Sigma 32)$ \\
\hline \multirow[t]{2}{*}{ Technical Malfunctioning } & Vehicle & 1 & \\
\hline & Equipment & 8 & $(\Sigma 9)$ \\
\hline \multirow[t]{3}{*}{ Vehicle Design and Space } & Crowding & 5 & \\
\hline & Discomfort & 5 & \\
\hline & Embarking and disembarking & 2 & $(\Sigma 12)$ \\
\hline \multirow[t]{2}{*}{ Traffic Planning } & Fare structure & 9 & \\
\hline & Scheduling & 5 & $(\Sigma 14)$ \\
\hline \multirow[t]{3}{*}{ Other. } & Retailer & 2 & \\
\hline & Injury & 1 & \\
\hline & Bus stop & 5 & $(\Sigma 8)$ \\
\hline
\end{tabular}

Table 1 displays the frequencies in each category. Common features formed the basis for labeling them. As can be seen, the categories fall into a number of superordinate groups. By far, most complaints referred to how customers are treated by staff and whether or not staff takes appropriate actions (Treatment and 
Action). Examples include unsafe and uncomfortable driving. Some complaints in this group also pertain to interaction with other staff.

The second most frequent category, Punctuality, mainly referred to complaints about early or late departures. A few were complaints about trips canceled without notice.

Almost equally frequent were complaints about inaccurate or missing information (Information) about arrival or departure times and destinations. In addition, complaints were filed about confusing ticket information. Such information is provided by the driver or other staff on request but is also available in timetables. The information appeared to be particularly confusing concerning traffic changes.

Three remaining groups, together accounting for 17 percent of the complaints, referred to malfunctioning of loudspeakers or reading lights (Technical Malfunctioning); crowding, discomfort, or difficulties in embarking and disembarking the vehicle (in particular, by handicapped or parents with baby carriages) (Vehicle Design and Space); and fare structure and scheduling (Traffic Planning).

A last category (Other) included complaints that could not be classified to the other categories. Two concerned dissatisfaction with retailers (in Sweden, tickets are frequently sold in drugstores). Injuries during travel were reported on one occasion. More frequently, complaints were filed about lack of protection against weather conditions at bus stops, either due to design features or limited open hours.

\section{On-Board Interviews}

\section{Procedure}

During a week at randomly selected times of the day, two trained interviewers approached adult customers of both genders traveling on buses and street cars in Gothenburg. Ninety agreed to be interviewed, which was close to a 100 percent response rate. They were asked to attempt to remember an episode in their contacts with the public transport company during the past year that they 
perceived as negative or unpleasant. Respondents were then asked to describe the episode in as much detail as possible. Each was encouraged to report three such episodes, but a majority reported only one or two. Only a few respondents reported incomplete or inappropriate information. Altogether 210 usable NCIs were reported.

\section{Results}

Again, two judges ${ }^{2}$ independently categorized the descriptions of the $\mathrm{NCIs}$ following the procedure for complaints. As can be seen in Table 2, the results are similar to complaints (Table 1). The categories differ slightly, although it is possible to form the same superordinate groups. New NCIs include traffic accident, bus running out of fuel, and traveler vomiting. Also, Treatment and Action and Punctuality are the most frequent superordinate groups, although the order is reversed, in that more NCIs were classified in the second rather than in the first category. Furthermore, Traffic Planning is a more frequent category.

\section{Mail Survey}

\section{Procedure}

A set of descriptions to be included in a questionnaire was selected on the basis of the complaint data. Prototypical exemplars were construed corresponding to the superordinate groups described in Table 1. Eighteen descriptions were selected and modified in several pretests in which different student samples were recruited. The descriptions, which were included in the survey questionnaire, are given in the Appendix. As can be seen, some of the main categories were represented by several descriptions, whereas others were only represented by a single description.

In the questionnaire, the descriptions were presented side by side, two on each page. Instructions explained that the descriptions referred to episodes that had occurred to passengers of buses or streetcars in the area where the respondents were living. Respondents were asked to read each description and to answer a number of questions. ${ }^{3}$ These included whether respondents had never, a few times, occasionally, or regularly experienced a similar incident; whether they 
Table 2

Frequencies of Categorization of Incidents Obtained from On-Board Interviews

\begin{tabular}{|c|c|c|c|}
\hline Subordinate Group & Main Category & Freque & \\
\hline \multirow[t]{4}{*}{ Treatment and Action } & Uncomfortable driving & 21 & \\
\hline & Unsafe driving & 11 & \\
\hline & Driver failed to stop & 15 & \\
\hline & Bad treatment by other employee & 3 & $(\Sigma 50)$ \\
\hline \multirow[t]{3}{*}{ Punctuality } & Early departure & 45 & \\
\hline & Late departure & 5 & \\
\hline & Canceled trip without notice & 14 & $(\Sigma 64)$ \\
\hline \multirow[t]{3}{*}{ Information } & $\begin{array}{l}\text { Arrival and departure times } \\
\text { (including delays) }\end{array}$ & 17 & \\
\hline & Destination & 1 & \\
\hline & Tickets and their validity & 3 & $(\Sigma 21)$ \\
\hline \multirow[t]{2}{*}{ Technical Malfunctioning } & Vehicle & 7 & \\
\hline & Equipment & 16 & $(\Sigma 23)$ \\
\hline \multirow[t]{3}{*}{ Vehicle Design and Space } & Crowding & 2 & \\
\hline & Discomfort & 12 & \\
\hline & Embarking and disembarking & 3 & $(\Sigma 17)$ \\
\hline \multirow[t]{2}{*}{ Traffic Planning } & Fare structure & 14 & \\
\hline & Scheduling & 16 & $(\Sigma 30)$ \\
\hline \multirow[t]{4}{*}{ Other } & Traffic accident & 2 & \\
\hline & Traveler thrown off the bus & 1 & \\
\hline & Traveler vomiting & 1 & \\
\hline & Bus out of fuel & 1 & $(\Sigma 5)$ \\
\hline
\end{tabular}

did not remember when it occurred or if it was last week, last month, some time last year, or earlier; how negatively they perceived the incident; and the number of people they had told about it. In addition, respondents were asked if they had 
ever heard about someone else who had encountered a similar incident, a few times, now and then, or frequently. They also rated how negative it was.

\section{Sample}

A random sample of 2,000 respondents was selected consisting of people between 16 and 75 years of age living in Gothenburg (population approximately 450,000 ). Questionnaires were mailed to each respondent's home address with a reply-paid envelope. To increase the response rate, respondents were told that the first 100 respondents would receive a lottery ticket. Two reminders were sent out, the last one with a new copy of the questionnaire.

After three months, 997 usable questionnaires had been received corresponding to a response rate of 49.9 percent. The respondents consisted of 452 men and 545 women, which was slightly more women than living in the area $\left(\mathrm{x}^{2}\right.$ $=5.36, \mathrm{p}<0.05)$. The mean age was 41.6 years old $(\mathrm{SD}=16.2$ years). When compared to the age distribution of people in the area, the ages of 45 to 64 were under-represented, whereas the ages of 25 to 44 were over-represented $\left(x^{2}=\right.$ $24.49, \mathrm{p}<0.01)$. A university degree was held by 31 percent; 60 percent were married or cohabitating; 39 percent had one or more children younger than 18 years old living with them; and 42 percent were employed full-time and 9 percent part- time. Mean family annual income varied between SEK 201,000 and 300,000 ( 1 SEK is approximately equal to $0.15 \mathrm{USD}$ ). Fifty-one percent reported that they used public transport on average more than once a week. ${ }^{4}$

\section{Results}

Table 3 displays the number of respondents who indicated that they had experienced NCIs, mean-rated frequency of experience, and mean-rated degree of negative impact. On average, the NCIs occurred sometime during the last year ( $M=1.0$ on a 0.3 scale). Furthermore, almost all NCIs were experienced, on average, as fairly negative $(M=2.1$ on a $0-3$ scale).

Speaking to the validity of the categories developed in the preceding studies, all NCIs were reported to have been experienced by at least some respondents. However, the correspondence regarding the frequencies was not complete. Assuming that the average reported frequency of incidents in each superordinate 


\section{Table 3}

\section{Recognition Scores Mean Ratings and Standard Deviation in the Mail-Survey Questionnaire}

\begin{tabular}{|c|c|c|c|c|c|}
\hline $\begin{array}{l}\text { Superordinate } \\
\text { Group }\end{array}$ & $\stackrel{\text { Main }}{\text { Category }}$ & Question & Recognition & $M$ & $S D$ \\
\hline \multirow[t]{6}{*}{$\begin{array}{l}\text { Treatment } \\
\text { and Action }\end{array}$} & $\begin{array}{l}\text { Driver refused } \\
\text { to listen }\end{array}$ & $\begin{array}{l}\text { Frequency } \\
\text { Recency } \\
\text { Impact }\end{array}$ & $44(4 \%)$ & $\begin{array}{l}0.1 \\
0.8 \\
2.6\end{array}$ & $\begin{array}{l}0.3 \\
1.0 \\
0.8\end{array}$ \\
\hline & $\begin{array}{l}\text { Not permitted to } \\
\text { enter the vehicle }\end{array}$ & $\begin{array}{l}\text { Frequency } \\
\text { Recency } \\
\text { Impact }\end{array}$ & $676(68 \%)$ & $\begin{array}{l}1.1 \\
1.1 \\
2.6\end{array}$ & $\begin{array}{l}0.9 \\
1.0 \\
0.7\end{array}$ \\
\hline & Careless driving & $\begin{array}{l}\text { Frequency } \\
\text { Recency } \\
\text { Impact }\end{array}$ & $592(59 \%)$ & $\begin{array}{l}0.8 \\
0.8 \\
1.8\end{array}$ & $\begin{array}{l}0.8 \\
0.9 \\
0.9\end{array}$ \\
\hline & $\begin{array}{l}\text { Not permitted to } \\
\text { get off the vehicle }\end{array}$ & $\begin{array}{l}\text { Frequency } \\
\text { Recency } \\
\text { Impact }\end{array}$ & $343(34 \%)$ & $\begin{array}{l}0.4 \\
0.6 \\
2.5\end{array}$ & $\begin{array}{l}0.6 \\
0.9 \\
0.7\end{array}$ \\
\hline & $\begin{array}{l}\text { Driver did not stop } \\
\text { at the bus stop }\end{array}$ & $\begin{array}{l}\text { Frequency } \\
\text { Recency } \\
\text { Impact }\end{array}$ & $329(33 \%)$ & $\begin{array}{l}0.4 \\
0.6 \\
2.6\end{array}$ & $\begin{array}{l}0.6 \\
0.8 \\
0.7\end{array}$ \\
\hline & $\begin{array}{l}\text { Bad treatment } \\
\text { by other employee }\end{array}$ & $\begin{array}{l}\text { Frequency } \\
\text { Recency } \\
\text { Impact }\end{array}$ & $212(21 \%)$ & $\begin{array}{l}0.3 \\
0.8 \\
2.1\end{array}$ & $\begin{array}{l}0.7 \\
0.9 \\
0.9\end{array}$ \\
\hline \multirow[t]{3}{*}{ Punctuality } & Early departure & $\begin{array}{l}\text { Frequency } \\
\text { Recency } \\
\text { Impact }\end{array}$ & $613(61 \%)$ & $\begin{array}{l}0.9 \\
1.0 \\
2.3\end{array}$ & $\begin{array}{l}0.8 \\
1.0 \\
0.8\end{array}$ \\
\hline & Late departure & $\begin{array}{l}\text { Frequency } \\
\text { Recency } \\
\text { Impact }\end{array}$ & $909(91 \%)$ & $\begin{array}{l}1.7 \\
1.5 \\
1.6\end{array}$ & $\begin{array}{l}0.8 \\
1.1 \\
0.9\end{array}$ \\
\hline & $\begin{array}{l}\text { Canceled trip } \\
\text { without notice }\end{array}$ & $\begin{array}{l}\text { Frequency } \\
\text { Recency } \\
\text { Impact }\end{array}$ & $560(56 \%)$ & $\begin{array}{l}0.7 \\
0.7 \\
2.3\end{array}$ & $\begin{array}{l}0.7 \\
0.8 \\
0.8\end{array}$ \\
\hline Information & $\begin{array}{l}\text { Delayed departure } \\
\text { time }\end{array}$ & $\begin{array}{l}\text { Frequency } \\
\text { Recency } \\
\text { Impact }\end{array}$ & $742(74 \%)$ & $\begin{array}{l}1.1 \\
1.0 \\
1.9\end{array}$ & $\begin{array}{l}0.8 \\
1.0 \\
1.9\end{array}$ \\
\hline
\end{tabular}


Table 3 (cont)

\begin{tabular}{|c|c|c|c|c|c|}
\hline $\begin{array}{l}\text { Superordinate } \\
\text { Group }\end{array}$ & $\begin{array}{c}\text { Main } \\
\text { Category }\end{array}$ & Question & Recognition & $M$ & $S D$ \\
\hline & Incorrect display & $\begin{array}{l}\text { Frequency } \\
\text { Recency } \\
\text { Impact }\end{array}$ & $247(25 \%)$ & $\begin{array}{l}0.3 \\
0.6 \\
2.3\end{array}$ & $\begin{array}{l}0.5 \\
0.8 \\
0.9\end{array}$ \\
\hline & $\begin{array}{l}\text { Tickets and their } \\
\text { validity }\end{array}$ & $\begin{array}{l}\text { Frequency } \\
\text { Recency } \\
\text { Impact }\end{array}$ & $64(6 \%)$ & $\begin{array}{l}0.1 \\
0.7 \\
2.3\end{array}$ & $\begin{array}{l}0.3 \\
1.0 \\
0.9\end{array}$ \\
\hline $\begin{array}{l}\text { Technical } \\
\text { Malfunctioning }\end{array}$ & Equipment & $\begin{array}{l}\text { Frequency } \\
\text { Recency } \\
\text { Impact }\end{array}$ & $150(15 \%)$ & $\begin{array}{l}0.2 \\
0.9 \\
1.8\end{array}$ & $\begin{array}{l}0.5 \\
0.9 \\
1.0\end{array}$ \\
\hline \multirow[t]{2}{*}{$\begin{array}{l}\text { Vehicle Design } \\
\text { and Space }\end{array}$} & Crowding & $\begin{array}{l}\text { Frequency } \\
\text { Recency } \\
\text { Impact }\end{array}$ & $929(93 \%)$ & $\begin{array}{l}2.0 \\
1.6 \\
1.2\end{array}$ & $\begin{array}{l}0.9 \\
1.2 \\
0.9\end{array}$ \\
\hline & Discomfort & $\begin{array}{l}\text { Frequency } \\
\text { Recency } \\
\text { Impact }\end{array}$ & $738(74 \%)$ & $\begin{array}{l}1.1 \\
1.0 \\
1.6\end{array}$ & $\begin{array}{l}0.9 \\
1.0 \\
0.8\end{array}$ \\
\hline \multirow[t]{2}{*}{ Traffic Planning } & Fare structure & $\begin{array}{l}\text { Frequency } \\
\text { Recency } \\
\text { Impact }\end{array}$ & $592(59 \%)$ & $\begin{array}{l}1.2 \\
1.5 \\
1.7\end{array}$ & $\begin{array}{l}1.1 \\
1.2 \\
0.9\end{array}$ \\
\hline & Scheduling & $\begin{array}{l}\text { Frequency } \\
\text { Recency } \\
\text { Impact }\end{array}$ & $751(75 \%)$ & $\begin{array}{l}1.3 \\
1.1 \\
2.2\end{array}$ & $\begin{array}{l}0.9 \\
1.1 \\
0.8\end{array}$ \\
\hline Other & Bus stop & $\begin{array}{l}\text { Frequency } \\
\text { Recency } \\
\text { Impact }\end{array}$ & $717(72 \%)$ & $\begin{array}{l}1.1 \\
1.0 \\
1.7\end{array}$ & $\begin{array}{l}0.9 \\
1.1 \\
0.8\end{array}$ \\
\hline
\end{tabular}

Note: Frequency of experience-a similar incident was rated on the scale Never (0), $A$ few' times (1),Occasionally (2), or Regularly (3); Recency of experience-rated on the scale Do not remember, or Further back (0), Some time the last year (1). Last month (2), or Last week (3); Degree of negative impact-rated on the scale Not at all negative (0). Somewhat negative (1). Rather much negative (2), or Very negative (3). 


\begin{tabular}{|c|c|c|}
\hline \multicolumn{3}{|c|}{$\begin{array}{c}\text { Table } 4 \\
\text { Average Rated Frequencies of Incidents } \\
\text { in Each Superordinate Group }\end{array}$} \\
\hline Superordinate Group & Question & $M$ \\
\hline Treatment and Action & $\begin{array}{l}\text { Frequency of experience } \\
\text { Recency of experience } \\
\text { Degree of negative impact }\end{array}$ & $\begin{array}{l}0.5 \\
0.8 \\
2.4\end{array}$ \\
\hline Punctuality & $\begin{array}{l}\text { Frequency of experience } \\
\text { Recency of experience } \\
\text { Degree of negative impact }\end{array}$ & $\begin{array}{l}1.1 \\
1.0 \\
2.1\end{array}$ \\
\hline Information & $\begin{array}{l}\text { Frequency of experience } \\
\text { Recency of experience } \\
\text { Degree of negative impact }\end{array}$ & $\begin{array}{l}0.5 \\
0.8 \\
2.2\end{array}$ \\
\hline Technical Malfunctioning & $\begin{array}{l}\text { Frequency of experience } \\
\text { Recency of experience } \\
\text { Degree of negative impact }\end{array}$ & $\begin{array}{l}0.2 \\
0.9 \\
1.8\end{array}$ \\
\hline Vehicle Design and Space & $\begin{array}{l}\text { Frequency of experience } \\
\text { Recency of experience } \\
\text { Degree of negative impact }\end{array}$ & $\begin{array}{l}1.6 \\
1.3 \\
1.4\end{array}$ \\
\hline Traffic Planning & $\begin{array}{l}\text { Frequency of experience } \\
\text { Recency of experience } \\
\text { Degree of negative impact }\end{array}$ & $\begin{array}{l}1.3 \\
1.3 \\
2.0\end{array}$ \\
\hline Other (bus stop) & $\begin{array}{l}\text { Frequency of experience } \\
\text { Recency of experience } \\
\text { Degree of negative impact }\end{array}$ & $\begin{array}{l}1.1 \\
1.0 \\
1.7\end{array}$ \\
\hline
\end{tabular}

group would correspond to the numbers of complaints (Table 1) or recalled NCIs in the interviews (Table 2), Table 4 shows that NCIs concerning punctuality are among the most frequently experienced, as the results of the preceding studies suggested. However, NCIs related to Treatment and Action are less frequently experienced whereas incidents related to Vehicle Design and Space are more frequently experienced. 


\section{Discussion}

The present results were fairly consistent across three different CIT techniques that may be employed in research on perceived service quality (PSQ) attributes of public transport. Two of the techniques (content analysis of complaints and on-board interviews) are conventional, whereas the third survey-type of technique, to the best of our knowledge, has not been used before in this way to obtain data on critical incidents. Apparently, stronger inferences are possible to make, given that these three complementary techniques demonstrate communality of results.

The main categories in Tables 1, 2 and 3 were used to analyze if attributes identified in previous PSQ research (see Edvardsson 1996) generalize to public transport service. The results from all three techniques seem to warrant the conclusion that PSQ attributes of public transport services involves employee behavior, reliability, and simplicity, as has been found in other service areas (e.g., restaurants, hotels, and banks). A majority of the complaints and negative critical incidents were related to employee behavior (Treatment and Action) and reliability of the service (Punctuality). In particular, the complaints were also frequently concerned with insufficient information (Information). The survey results partly confirmed these findings but also suggested that the design of and space available in vehicles are important.

Consistent with previous findings (e.g., Berry and Parasuraman 1992; Bitner, Booms and Tetreault 1990; Edvardsson 1996; Zeithml, Parasuraman, and Berry 1990), PSQ attributes of public transport services referred to how employees treat the customers. In public transport, the driver is the employee to whom the customer is most frequently exposed. Accordingly, many NCIs were related to driver behavior. These critical incidents may be very important for the customer's overall evaluation of the service. The complaints and interview data suggest that drivers arouse feelings of frustration and sometimes even aggression. For instance, several NCIs attested to the anger some travelers felt when the driver refused to listen or simply ignored them. NCIs related to interaction with other staff did not seem to have the same intensity. It is also natural that the driver 
becomes the target for many complaints that customers may have, for which the driver is not responsible. The driver is furthermore very important since he or she is directly responsible for the passenger's safety and security.

Several studies (Bitner 1990; Grönroos 1990; Zeithaml, Parasuraman, and Berry 1990) have demonstrated that PSQ attributes include reliability and trust. Punctuality is known to be a salient aspect of reliability in public transportation (Borjesson and Kjellgren 1993; Bradley et al. 1989). When the bus departs early or late, or when no bus arrives at all, the travelers are obviously annoyed. If this occurs frequently, customers will eventually loose trust in the service. Critical incidents related to punctuality or reliability sometimes appeared to be due to weather conditions or rush hour. Still, the public transport company was blamed because staff were expected to be responsible for managing such situations. In fact, the company's traffic planning was not perceived to be efficient. For instance, a frequent complaint concerned a lack of coordination of connections.

Furthermore, PSQ attributes have been found to also include simplicity (e.g., information and opening hours) (Edvardsson 1996; Grönroos 1990). As the present complaint data suggested, problems with incomplete or confusing information were prevalent. Complaints concerned missing or difficult-to-access information about times (delays, travel time), destinations, and tickets. It is clearly important for the traveler to know these things. However, frequently they were unable to access relevant information from the driver. Even though this may reflect that drivers act inappropriately, it may also be the case that the means of conveying the information need to be redesigned.

Inconsistent with the hypothesis, no reported incidents were related to recovery when something goes wrong (Albrecht and Zemke 1985; Johnston 1995). Since the three techniques that were used reveal only negative episodes, recovery may still be important, but, in this respect, customers are satisfied with the performance of the public transport company.

In summary, the main sources of NCls were employee behavior and reliability. Also, simplicity was identified as a source of negative critical incidents. This suggests that PSQ attributes of public transport are similar to findings in 
other service areas. Contrary to the hypothesis, vehicle design and space were noted as a cause of negative critical incidents. Furthermore, recovery may not be a PSQ attribute. Thus, inferences made from complaints and negative critical incidents can provide managers with useful information about perceived service quality attributes.

A question that future research should address is whether the PSQ attributes of public transport identified in the present study are exhaustive. As alluded to, it is possible that data on negative critical incidents do not inform about PSQ attributes that play no role for experiencing the service as dissatisfying. Another related question that should be addressed in future research (see Johnston 1995) is the relationship between negative critical incidents, perceived service quality, and satisfaction/dissatisfaction. Although additional research is needed, a clear implication of the current research is that it highlights the important role of employee behavior. This is not frequently realized by public transport companies and motivates more extensive training of employees.

\section{Appendix}

\section{Prototypical incidents included in the mail-survey questionnaire}

Driver refused to listen. You get to the bus/streetcar and let the machine punch your ticket/register your smartcard, which the driver then asks to check. He informs you that the ticket/card is not valid without explaining why. You have to buy a new ticket. A later investigation shows that the ticket/card was, in fact, valid.

Not permitted to embark the vehicle. You are taking a trip which involves getting a connecting bus/streetcar. Both the vehicle you are on and the connecting one arrive simultaneously at the station. Together with several other passengers you get off and run to the connecting bus/streetcar, but the driver closes the doors and drives away. It is not past the listed departure time, and it would not have taken more than 30 seconds for the driver to let you on.

Careless driving. The vehicle is traveling at high speed. Every so often the driver brakes abruptly. Before you want to get off you press the stop button. The 
driver appears not to have noticed and is about to pass your stop. At the last minute he become aware of the signal and brakes abruptly.

Not permitted to get off the vehicle. Just as you are about to get off the bus/ streetcar, the doors suddenly close and the bus takes off before you have a chance to leave. You push on the door but to no avail. Several passengers, including you, shout at the driver to stop. He does not respond and you are forced to stay on until the next stop.

Driver did not stop at the bus stop. You are waiting at the bus stop/streetcar stop where you are clearly visible. You see the half-full vehicle approaching and believe that you have eye contact with the driver. You take a step forward and prepare to get on, but the driver does not stop.

Bad treatment from other staff. You call the public transport company to inquire about a specific bus/streetcar schedule. It takes several minutes before you get an answer, and when you finally do get a response, the information is given in a very unfriendly manner.

Early departure. You decide to take a bus/streetcar and arrive at the stop in plenty of time only to discover that the vehicle has already left well before the scheduled time.

Late departure. You decide to take a bus/streetcar and you get to the stop in plenty of time. You wait for the vehicle to arrive, and when it finally does, it is very late.

Canceled trip without notice. You join other people in good time at the stop. After a long wait, there is still no sign of the bus/streetcar, and you soon realize that none is going to come. You are forced to either wait for the next one or find some other way of reaching your destination.

Delayed departure time. You have checked the timetable for a suitable departure time and wait for the bus/streetcar. At the scheduled time, there is no vehicle in sight. After a while, it turns up, but you get no explanation as to why it was late.

Incorrect display. While you wait at the stop, a bus/streetcar for a destination other than the one you want arrives, stops, and then continues. When it has 
left and no other bus is in sight, you and other passengers begin to suspect that, in fact, that must have been the vehicle you were waiting for. On checking the timetable, you discover that no bus/streetcar going in the direction shown on the vehicle was due to depart from that stop at that time. Thus, the incorrect destination had been displayed. You must now either wait for the next one or find some other means of reaching your destination.

Tickets and their validity. You have already checked the ticket price with the public transport company. When you get on the bus/streetcar, you pay that price. That morning, a ticket inspection is carried out. You are not concerned, but the inspector insists that you have not paid the correct price. You question this, as you know you have paid the quoted fare.

Equipment. You start to suspect that the ticket machine on your bus/streetcar does not always register your smartcard correctly. This means that, in the event of an inspection, you cannot prove that you have paid the correct fare.

Crowding. The arriving vehicle is almost full. The driver stops and allows you and several other passengers onboard. Some of the new passengers find a place to sit, but others, including you, are forced to stand up for the whole trip. During the remainder of the trip, even more passengers are allowed onboard.

Comfort. You get on a bus/streetcar. After a while, you notice how warm/ cold it is in the vehicle. The heating is turned on full/is turned down. The temperature is unpleasant.

Fare structure. You begin to compare the price you pay to what you consider to be a reasonable price - that is, you compare the price you pay to use the public transport system with the service you believe is actually provided.

Scheduling. In order to arrive at your destination, you are required to change buses/streetcars, but the connecting vehicle has already left. This means a long wait for you until the next bus/streetcar departs.

Bus stop. The bus stop/streetcar stop you are waiting at has no shelter/is in a bad condition. 


\section{Notes}

'In previous studies using the CIT (e.g., Edvardsson 1992, Bejou, Edvardsson, and Rakowski 1996), it has been found to be sufficient to analyze between 200 and 300 critical incidents.

${ }^{2}$ One of them also classified the complaints.

${ }^{3}$ Data are reported only for those questions that are directly relevant to the present aim.

${ }^{4}$ Confirming that few complain to the public transport company, only 22 percent stated in the questionnaire that they had ever filed a complaint. More NCIs were remembered by those who had filed complaints than those who had not although the difference did not reach statistical significance $(M=14.1$ vs. 9.4, $\mathrm{p}>0.05$ ).

\section{References}

Albrecht, C., and R. Zemke. 1985. Service America. IL: Dow Jones-Irwin.

Anderson, B., and S. Nilsson. 1964. Studies in the reliability and validity of the critical incident technique. Journal of Applied Psychology 48: 398-403.

Andreassen, W. T. 1995. (Dis)satisfaction with public services: The case of public transportation. Journal of Services Marketing 9:30-41.

Bejou, D., B. Edvardsson, and J. P. Rakowski. 1996. A critical incident approach to examining the effects of service failures on customer relationships: The case of Swedish and U.S. airlines. Journal of Travel Research 1:35-40.

Benister, D. 1992. Demographic structures and social behavior. In Transport Growth in Question, 12th International Symposium on Theory and Practice in Transport Economics, 109-149. Paris: European Conference of Ministers of Transport, OECD.

Berry, L. L., and A. Parasuraman. 1992. Prescriptions for a service quality revolution in America. Organizational Dynamics 20: 5-15.

Bitner, M. J., B. H. Booms, and M. S. Tetreault. 1990. The service encounter: Diagnosing favorable and unfavorable incidents. Journal of Marketing 54 (Jan.): 71-84.

Bitner, M. J. 1990. Evaluating service encounters: The effect of physical surroundings and employee responses. Joumal of Marketing 54 (April): 69-82. 
Bradley, M., E. Kroes., S. Widlert., R. Sheldon., T. Gärling, and S. Uhlin. 1989. Preferences for bus underground services in Stockholm. Paper presented at the Fifth World Conference on Transport Research, July 10-14, Japan: Yokohama.

Börjesson, M., and A. Kjellgren. 1993. Framsteg for kollektivtrafiken. Redovising av TFBs/KFBs forsknings-, utvecklings- och demonstrationsprojeckt om kollektivtrafik [Summaries of results from projects sponsored by Swedish Transport and Communications Research Board]. Stockholm: Kommunikationsforskningsberedningen (KFB).

Cadotte, E. R., and N. Turgeon. 1988. Dissatisfiers and satisfiers: Suggestions for consumer complaints and compliments. Journal of Consumer Satisfaction, Dissatisfaction and Complaining Behavior 1: 74-79.

Day, R. L., K. Grabicke, T. Schaetzle, and F. Staubach. 1981. The hidden agenda of consumer complaining. Journal of Retailing 57 (Fall): 86-106.

Edvardsson, B. 1988. Service quality in customer relationships: A study of critical incidents in mechanical engineering companies. The Service Industries Journal 8: 427-443.

Edvardsson, B. 1992. Service breakdowns: A study of critical incidents in an airline. International Journal of Service Industry Management 3:17-29.

Edvardsson, B. 1996. Tjansteutveckling med inbyggd kvalitet [Service development with in-built quality]. Karlstad: Service Research Center.

Everett, P. B., and B. G. Watson. 1987. Psychological contributions to transportation. Handbook of Environmental Psychology 2:987-1007.

Flanagan, J. C. 1954. The critical incident technique. Psychological Bulletin 51: $327-$ 357.

Folkes, V. S. 1994. How customers predict service quality. What do they expect? In Service quality: New directions in theory and practice, ed. R. T. Rust and R. L. Oliver. California: Sage.

Grönroos, C. 1990. Service management and marketing: Managing the moments of truth in service competition. New York: Lexington Books.

Hartgen, D. T. 1981. Transportation and the behavioral sciences. In Human behavior and environment: Advances in theory and research, ed. I. Altman and J. F. Wohlwill. New York: Plenum.

Johnston, R. 1995. The determinants of service quality: Satisfiers and dissatisfiers. International Journal of Service Industry Management 6: 53-71. 
Johns, N., and P. Tyas. 1997. Customer perceptions of service operations: Gestalt, incident or mythology? The Service Industries Journal 17: 474-488.

Lovelock, C. H. 1983. Classifying services to gain strategic marketing insights. Journal of Marketing 47 (summer): 9-20.

Olsen, Morten J. 1992. Kvalitet $i$ banktjanster-Privatkunders upplevda problem med banktjanster [Quality in banking services-problems in banking services experienced by private customers]. Karlstad: Service Research Center.

Ronan, W. W., and G. P. Lantham. 1974. The reliability and validity of the critical incident technique: A closer look. Studies in Personnel Psychology 6: 53-64.

Stauss, B. 1992. Attribute-based versus incident-based measurement of service quality: Results of an empirical study in the German car service industry. In Quality management in services, ed. P. Kunst and J. Lemmink. Maastricht: Van Gorcum.

Stauss, B. 1993. Using the critical incident technique in measuring and managing service quality. In The Service Quality Handbook, ed. E. E. Scheuing and W. Christopher. New York: American Marketing Association.

Strandvik, T. 1994. Tolerance zones in perceived service quality. Helsinki: Swedish School of Economics and Business Administration.

Youngdahl, W., and D. Kellog. 1996. The relationship between service customer's quality assurance behaviors, satisfaction, and effort: A cost quality perspective. Journal of Operation Management 15: 19-32.

Zeithaml, V., A. Parasuraman, and B. Berry. 1990. Delivering quality service-balancing customer perceptions and expectations. New York: The Free Press.

\section{Acknowledgment}

This research was financially supported by a grant to the Service Research Center from the Swedish Communications and Transport Research Board.

\section{About the Authors}

Margareta Friman is a postgraduate student in psychology at Göteborg University and a researcher at the Service Research Center at the University of Karlstad. Her research focus is on perceived service quality and customer satisfaction in public transport services. 
Bo Edvardsson is a Professor of Business Management and the Director of a Service Research Center at the University of Karlstad. His research interest is in the field of service quality, with an emphasis on service design and development of new services.

Tоммy GärLING is a professor of psychology in the Department of Psychology at Göteborg University. His main research interest is decisionmaking and judgement, including applications in travel behavior. 


\title{
The Value of Having a Public Transit Travel Choice
}

\author{
Xuehao Chu \\ Steven E. Polzin \\ University of South Florida
}

\begin{abstract}
The value of having a public transit travel choice is occasionally acknowledged by planners but never quantified; this paper provides a methodology to quantify it. This value of having a public transit choice is in addition to public transit's benefits to users and non-users as a result of the improved performance of other modes in the transportation system resulting from the public transit investment. The value of choice accrues to the total population that has access to public transit, not just those who chose to use it or those who benefit because others have chosen it. This paper develops a methodology and a crude but plausible estimate of the value of choice for public transit using data describing features of U.S. daily personal travel in 1995. For perspective, this estimate is compared with the total operating and capital expense of providing public transit in the United States. The result indicates that the value of choice alone is comparable in magnitude to the cost of providing public transit in this country.
\end{abstract}

\section{Introduction}

\section{Background}

Over the past several years, the transportation planning and policy analysis communities have spent a great deal of time and effort to better understand and 
quantify the various costs and benefits of transportation investments. The increased attention to intermodal and multimodal transportation has included trying to better compare the relative costs and benefits of these modes. The growth in demand for personal transportation has significantly outstripped the increase in supply, and our greater sensitivities to the physical, community, environmental, social, and economic impacts of transportation are motivating continued research into the relationships and magnitudes of various transportation investment impacts. This paper focuses on public transit as an alternative to continued and growing reliance on an urban passenger travel system increasingly dominated by auto travel, most often single passenger auto travel.

One aspect of transportation impacts receiving increased attention is economic impacts. A full understanding of economic impacts is important in investment evaluation and in making policy decisions regarding investment levels for transportation. This paper provides an initial exploration of an aspect of economic impacts of transportation modes typically characterized by the public and policymakers as "the value of having a choice." It is not uncommon to hear one of the arguments favoring the investment in public transit, pedestrian facilities, or bike facilities being the desire to provide a choice of modes to the traveler. Some modal advocates go so far in valuing the virtue of choice as to treat the availability of access by various modes as an issue of equality. Some media and segments of the public have given the availability of multiple modes a high value in rating the attractiveness of urban areas and neighborhoods. Most certainly, the presence of programs and resources to provide a choice of alternative modes is looked at closely when long range transportation plans are adopted in our urbanized areas.

While we may never be able to unequivocally quantify the value of providing a transit, bikeway, or pedestrian option, decisionmakers do have to make real investment decisions that might benefit from being able to estimate the value of choice. A better understanding og methodologies for estimating the value of choice may also have relevance beyond public transit. We may soon be attempting to value the choice of providing the infrastructure to support an additional system of facilities to handle smart or alternatively fueled vehicles. 


\section{A Classification Scheme for Components of the Value of Public Transit}

What is the total value of having public transit available? Figure 1 provides a categorization scheme for the total value of pubic transit. The total value of public transit may be broken down into components: its transportation value, value of choice, and contingency value. Public transit's transportation value and value of choice comprise the consumer surplus of having public transit available. When there is no uncertainty in modal performance, consumer surplus correctly measures the total value of having public transit available. When there is uncertainty, however, consumer surplus may underestimate the total value of having public transit available by the amount of its contingency value.

The traditional approach to measuring economic impacts has focused on the direct and indirect benefits to travelers as a result of the changes in performance of a transportation system in response to the presence of public transit investment. Public transit clearly offers value in instances where it is a productive element in a transportation system. Public transit can provide value as an efficient mover of people. When well utilized it can offer value in saving travel time and reducing land consumption, energy use, air pollution, and infrastructure investments. This value of public transit that results from changes in modal performance may be called its transportation value.

\begin{tabular}{|llll|}
\hline \multirow{2}{*}{$\begin{array}{l}\text { Type of } \\
\text { Value }\end{array}$} & \multicolumn{3}{c|}{ Total Value } \\
\cline { 2 - 4 } & Transportation Value & Value of Choice & Contingency Value \\
\cline { 2 - 4 } Description & $\begin{array}{l}\text { Consumer surplus } \\
\text { from changes in } \\
\text { performance of } \\
\text { modes other than } \\
\text { public transit due } \\
\text { to the presence } \\
\text { of public transit }\end{array}$ & $\begin{array}{l}\text { Consumer surplus } \\
\text { from the presence } \\
\text { of public transit }\end{array}$ & $\begin{array}{l}\text { Value to non-users } \\
\text { because they may } \\
\text { need to use public } \\
\text { transit in the future } \\
\text { because of uncer- } \\
\text { tainty in the availa- } \\
\text { ability of other modes }\end{array}$ \\
\hline Beneficiaries & $\begin{array}{l}\text { Impacted users } \\
\text { and non-users }\end{array}$ & $\begin{array}{l}\text { Accessible } \\
\text { population }\end{array}$ & Non-users \\
\hline
\end{tabular}

Figure 1. Total economic value of pubic transit. 
Going beyond its transportation value, should public transit be valued for its benefit as a travel choice or its value of choice? As tradeoffs in making transportation investments are weighed, how can all the benefits of public transit investments be accounted for? In American culture, the opportunity to have choices in all of the fundamental elements in our lives-from food, shelter, and clothing to medical care, education, and entertainment—are relished. It is logical that we would pursue having choices in our transportation system. This desire to have choices certainly implies that there is value to having mode choices in travel. While public transit's transportation value is included in conventional cost-benefit analysis, transit's value as a travel choice has been largely ignored.

Similarly, we have begun to appreciate what might be called the contingency value of public transit investments. While the virtues of public transit have been well known to northerners who rely on public transit to avoid having to drive in severe ice or snow storms, the 1990s have shown the value of public transit in post-earthquake and post-hurricane situations. While currently a fading memory, the contingency value of public transit can also be appreciated in energy crisis situations. Finally, the contingency value of transit can be appreciated by those who may lose the use of their primary mode due to situations like auto accidents.

\section{Scope of the Paper}

This paper has three objectives. First, it develops a methodology for estimating the choice value of public transit. This methodology is based on Small and Rosen (1981), who developed a simple way of computing consumer surplus when the choices consumers face are discrete. Mode choice for travel is one example of discrete choices. The result developed by Small and Rosen allows one to compute the consumer surplus to travelers of having public transit available. This paper breaks down the consumer surplus into two components. One measures public transit's transportation value, while the other measures its value of choice.

The second objective of the paper is to apply the methodology to daily personal travel in the United States, using the 1995 Nationwide Personal Trans- 
portation Survey (NPTS). The purpose is to develop a crude but plausible estimate of the value of choice. To simplify the estimation, two-point approximations are used for what really are continuous distributions of generalized costs for various modes.

The third objective is to compare the estimated value of choice with the cost of public transit provision. The estimated value of choice, when combined with an estimate of the transportation value of public transit, can be contrasted with the cost of public transit services to help in evaluating transportation investment policies. Unfortunately, the cost of providing public transit cannot easily be disaggregated between that share intended to provide its transportation value and that share intended to provide its choice value. However, it is possible to compare the total cost of providing public transit services with this newly developed value of choice, one of the components of total value outlined in Figure 1. The total cost of providing public transit includes operating, maintenance, and amortized transit capital investments. The result indicates that public transit's value of choice alone is comparable to the total cost of providing public transit. This result may be attributed partly to the fact that the value of choice exists for every person trip for which public transit is available.

\section{Literature}

The concept that choice has value in itself has never been analyzed in the transportation literature, though it has been implicitly acknowledged (e.g., Weyrich and Lind 1996). The economics literature, however, has a large body of work on the concept. Weitzman (1992) provided a general theory of diversity. Both Sattinger (1984) and Perloff and Salop (1985) studied the value of choice in the context of product diversity in general using non-discrete choice models. Anderson and de Palma (1992) studied product diversity in general using the logit model. Suen (1991) studied the value of choice in general using discrete choice models.

Neither economics nor transportation literature provides any empirical estimate of the value of choice. The economics literature, however, does provide insights on three aspects of the issue: 1) how the value of choice may be defined 
in the context of discrete choice models; 2) why the value of choice exists; and 3) what general characteristics the value of choice has.

Definition. Suen (1991) defined the value of choice for an additional product as the change in consumer surplus without changes in the prices of related products or services.

Why Does the Value of Choice Exist? The value of choice arises from the additional chance that a new product or service gives to an individual to find a service that better suits his or her preferences (Sattinger 1984; Suen 1991). Different individuals' valuations for the same product are rarely the same because of differences in their preferences under typical conditions. Even a single individual's valuation of a given product changes with atypical conditions such as weather, natural disasters, one's state of health, and the flow of new information. People's ability to take advantage of these idiosyncratic factors implies that a large set of alternatives is valuable even if there is no taste for diversity as such. In addition, some individuals do have preferences towards diversity itself (Train 1994).

General Characteristics of the Value of Choice. There are several characteristics of the value of choice (Suen 1991):

- People with low valuations for a new product are more likely to have low valuations of existing products; the value of choice from the new product will be limited. For example, adding red buses to already existing blue buses will have little value.

- The larger the variation in random elements or people's preferences, the larger the value of choice.

- The marginal value of choice from additional diversity is positive but diminishing.

- The value of choice is greater from an excellent product and a poor product than from two mediocre products.

\section{Plan of the Paper}

In the balance of this paper, the methodology developed is discussed first, with details in the Appendix. The methodology shows how the value of choice 
may be measured in the context of the logit mode choice model. Then, the methodology is applied to provide a crude but plausible estimate of the annual choice value of public transit in the United States using data from the 1995 NPTS. Finally, the estimate is compared with the cost of providing public transit. Sensitivity of the results is accessed by making changes in several of the assumptions used.

\section{Methodology}

This section describes the methodology developed in this paper for estimating public transit's value of choice. Details of the methodology development are found in the Appendix.

The initial motivation in developing a methodology for estimating public transit's value of choice was to find a measure of the consumer surplus of having public transit available that can be broken down into two components: the transportation value of having public transit available and the choice value of having public transit available.

Small and Rosen (1981) provided just such a measure. Economists long had had simple ways to measure the consumer surplus of someone consuming a certain amount of goods if the goods can be measured with a continuous variable. Small and Rosen (1981) developed a simple way to do the same for consumer choices that are only measured in discrete terms. We face discrete choices in all aspects of our lives, including which airline to fly, which brand of product to buy, and which mode of transportation to use. Small and Rosen's measure allows one to calculate how consumer surplus changes from changes in price, quality, and the number of options available. The Small and Rosen approach to computing consumer surplus is also recommended by the Transit Cooperative Research Program (Cambridge Systematics 1998).

Their measure of consumer surplus has been widely used in measuring the benefit implications of changes in transportation policies. Such policies include deregulation of the airline industry in the late 1970 s and early 1980 s, road pricing, and improvements to roadways and transit systems. More relevant to this paper are applications of their methodology to estimate the consumer surplus of 
having a particular mode. For example, Morrison (1990) used Small and Rosen's method to compute the consumer surplus of having AMTRAK available in specific corridors.

The methodological contribution of this paper is in breaking down Small and Rosen's measure into two components in the context of mode choice. One component measures consumer surplus purely from having a particular mode available, holding the performance of other modes constant. The other component measures consumer surplus as a result of changes in performance of other modes due to having that particular mode available. The second component is the particular mode's transportation value, while the first component is its value of choice.

For this application, the choice for each one-way person trip is among three modes: private modes (automobiles, vans, and trucks), public transit (bus, trolley, and rail), and other modes (bicycling, walking, taxi, school bus, and others). The value of choice per person trip can then be written as the following:

$$
V=-\frac{1}{\beta}\left[\ln \left(1+e^{\beta\left(G_{O}-G_{C}\right)}+e^{\left.\beta\left(G_{T}-G_{C}\right)\right)}-\ln \left(1+e^{\beta\left(G_{O}-G_{C}\right)}\right)\right]\right.
$$

where $\beta$ is the cost coefficient, In is natural logarithm, $e$ is the natural exponential base, and $G_{C}, G_{r}$ and $G_{0}$ are the generalized costs per one-way person trip for private modes, public transit, and other modes, respectively.

A simplifying assumption is made in applying equation (1), which requires information on the differences in generalized costs. In general, the generalized cost for a given mode follows a continuous distribution across different trips-it is probably moderate for some trips but prohibitive for others. Allowing continuous distributions of the generalized costs, however, would require data far beyond the scope of this paper. Instead, a two-point approximation is used for each mode. Specifically, for each of the three types of mode, the generalized cost is the average value for trips for which a particular mode is available, while it is 
infinity for trips for which the particular mode is unavailable. The average values can be determined using the national modal splits among the three types of mode shown in Table 1. The approximations may give different results than using the true distributions. There is no reason, however, to believe that the approximations would alter the magnitude of measurement.

\section{Estimation}

This section examines the magnitude of the value of choice for public transit nationwide and compares this value with the cost of providing public transit in this country, using readily available information. The following areas are covered:

1) assumptions used in the estimation;

2) annual amount of public transit's value of choice nationwide;

3) annual cost for providing public transit in this country; and

4) comparison between the cost and choice value of public transit.

\section{Assumptions}

Table 1 summarizes the assumptions on the modal splits of person trips, annual number of person trips, modal availability, cost coefficient from mode choice models, discount rate, average lifetime of transit capital investments, annual average amount of transit capital investments, and annual transit operating expenses.

The 1995 NPTS is used to derive the modal splits of all person trips among the private modes (including automobiles, vans, and trucks), public transit (including bus, commuter train, streetcar/trolley, and rail), and other modes (including bicycling, walking, school bus, taxi, airplane, Amtrak, moped, and other modes). Public transit accounted for less than 2 percent of all person trips made by people who were 5 years or older in 1995. The total number of person trips from the 1995 NPTS is about 379,000 million.

The distribution of modal availability shown in Table 1 is derived from the 1995 NPTS. Note that the four categories of modal availability are mutually exclusive. The category that transit is available but neither private modes nor other modes are available is not separately listed because it is likely to be a small percentage. 


\section{Table 1}

Assumptions for Numerical Analysis

Modal Split of Person Trips (1995 NPTS)

Private modes (cars, vans, trucks)

Public transit (bus, commuter train, streetcar, and rail)

Other modes (bicycling, walking, school bus, taxi, and others)

Number of Person Trips (1995 NPTS), millions

Modal Availability (1995 NPTS) ${ }^{2}$

No private modes (but with public transit and other modes available)

No other modes (but with public transit and private modes available)

No public transit

All modes available

Cost Coefficient of Mode Choice Model ( $($ )

Discount Rate (r)

Average Lifetime of Transit Capitals $(\mathrm{N})$, years

Annual Amount of Transit Capital Investments (K), millions in 1995 \$

Annual Public Transit Operating Expenses, millions in $1995 \$$

"Information from the 1995 NPTS comes from a research project in progress at the CUTR, "NPTS Travel Data Analysis," funded by the National Urban Transit Institute.

The number of person trips with both public transit and other modes available but no private modes available is about 5 percent. This is based on several factors. The 1995 NPTS shows that about 8 percent of households have no private modes available. Two other factors are likely to make the percentage of person trips with no private modes smaller than that of households with no private modes. One factor is that some of the households without private modes do not have public transit available either. Another factor is that households with no private modes tend to produce fewer person trips than households with private modes. Without specific numbers on these two factors, 3 percentage points are taken off from the 8 percent of households with no private modes.

The number of person trips with both public transit and private modes available but no other modes available is set to one percent. Recall that other modes 
include bicycling, walking, school bus, taxi, and others. It is hard to think of persons who can use public transit or private modes but cannot walk. Without data available on this issue, it is arbitrarily set to 1 percent.

The number of person trips without public transit available is estimated to be about 80 percent. Public transit is defined as available to a person trip if both its origin and destination are within a quarter mile of the nearest transit stop. This definition of spatial transit availability is widely used in practice. The 1995 NPTS shows that about 30 percent of person trips are made by people living within a quarter mile of transit stops.

This number is adjusted down to account for two other factors. First, transit can be considered as available only for trips when it is available for both their origins and destinations. Second, the measure of availability of public transit service is further modified to reflect that fact that transit services are not available at all time of the day and night. Many urban systems have no late night, evening, or weekend service. Even the largest urban areas have very limited geographic coverage of their "nightowl" services. Without specific numbers to account for these two factors, 10 percentage points are subtracted from the 30 percent of person trips made by people who live within a quarter mile. As a result, it is assumed that 80 percent of all person trips do not have public transit available.

The value of the cost coefficient is about the medium value of a range from a review of previous estimates of mode choice models from the literature. Table 2 shows the estimates from eight selected studies. For each study, the table includes estimates of the cost coefficient, year of data, location of data collected, and type of travel. The review shows a range of the cost coefficient from -0.03 to -0.38 . Only eight are selected from a large number of mode choice models estimated in the literature. First, this is not an exhaustive review. Second, some of these studies used specifications that do not estimate the cost coefficient. Third, some other studies do not report enough information so that the value of the cost efficient can be inferred.

The meaning of the cost coefficient may be better understood in three ways. First, the unit of the cost coefficient is the level of satisfaction per dollar of out- 
of-pocket costs of using various modes. In economic terms, it measures the marginal utility of income. Second, the ratio of the in-vehicle travel time coefficient and the cost coefficient in a mode choice model gives the value of in-vehicle time savings. Third, the magnitude of the cost coefficient affects how changes in the out-of-pocket cost of using a given mode affect the odds of that mode being chosen against any other mode. (The odds of one mode against another is the ratio of the probabilities that they will be chosen.) For example, if the cost coef-

Table 2

Selected Mode Choice Studies

\begin{tabular}{|c|c|c|c|c|}
\hline \multirow{2}{*}{ Study } & \multirow{2}{*}{ Estimates } & \multicolumn{3}{|c|}{ Data } \\
\hline & & Year & Location & Type of trips \\
\hline $\begin{array}{l}\text { Stopher } \\
\text { (1969) }\end{array}$ & -0.03 & $N / A^{2}$ & $N / A^{2}$ & Urban work \\
\hline $\begin{array}{l}\text { Hensher } \\
\text { (1972) }\end{array}$ & -0.03 & N/A & $N / A^{2}$ & Urban work \\
\hline $\begin{array}{l}\text { Parody et al } \\
\quad(1977)\end{array}$ & $-0.06 \sim-0.14$ & $1972-1974$ & Boston & Univ.-related \\
\hline $\begin{array}{l}\text { Galbraith/Hensher } \\
\quad(1982)\end{array}$ & $-0.03 \sim-0.05$ & $1971-1975$ & Australia & Suburban work \\
\hline $\begin{array}{l}\text { Small } \\
(1983)\end{array}$ & $-0.06 \sim-0.14$ & 1972 & San Francisco & Urban work \\
\hline $\begin{array}{l}\text { Dunne } \\
(1984)\end{array}$ & $-0.07 \sim-0.09$ & $N / A^{b}$ & U.K. & Urban work \\
\hline $\begin{array}{l}\text { Morrison/Winston } \\
\text { (1985) }\end{array}$ & $-0.17 \sim-0.38$ & 1977 & U.S. & Intercity \\
\hline $\begin{array}{l}\text { Koppelman/Hirsch } \\
\text { (1989) }\end{array}$ & $-0.17 \sim-0.22$ & 1977 & U.S. & Intercity \\
\hline
\end{tabular}

- The estimates by Stopher (1969) and Hensher (1972) are from a conprehensive review of theory and practice relating to behavioral travel-demand models by Stopher and Meyburg (1976), who do not mention the corresponding years and location of data collection.

${ }^{b}$ Dunne (1984) does not provide information about the year of data collection. 
ficient is -0.1 , then a decrease of one dollar in the out-of-pocket cost of using private modes will increase the odds of private modes being chosen by an individual against any other mode by a factor of $\mathrm{e}^{0.1}=1.11$.

The discount rate is 7 percent, which is required by federal regulations for major transportation investments involving federal funding. The lifetime of transit capital investments varies, depending on the type of investments. Without a distribution of the lifetime of various types of transit investments, an average of 20 years is used. The annual amount of transit capital investments is about $\$ 6$ billion in 1995 dollars. This amount is about the average of the transit capital expenditures for 1992-1995 (APTA 1997: Table 18). These expenditures exclude those made by purchased transportation contractors. Similar data for earlier years are not readily available. The annual amount of transit operating expenses is the nationwide total in 1995 (APTA 1997: Table 27).

\section{The Value of Choice}

Table 3 shows the estimates of public transit's value of choice, based on the methodology described earlier and the assumptions in Table 1. The unit value of choice per person trip varies with modal availability: 0 for trips with no public transit available, about 70 cents for trips with both public transit and other modes available but without private modes, about 10 cents for trips with both public transit and private modes available but without other modes, and about 9 cents for trips with all three types of modes available. Using the distribution of trips by modal availability and the total number of person trips shown in Table 1, these unit values of choice can be aggregated to get a nationwide estimate of about $\$ 18.6$ billion in 1995 . This averages to about 5 cents for every daily person trip in this country.

\section{Cost of Providing Pubic Transit}

The annual total cost of providing public transit includes operating and maintenance expenses and the amortized amount of all transit capital investments that are still within their lifetime. The annual total in the United States in 1995 is about $\$ 26$ billion in 1995 dollars. The annual amount of operating and maintenance expenses is about $\$ 18$ billion, while the annual amount of capital 
Table 3

Resultsa

\begin{tabular}{|c|c|c|c|c|}
\hline \multirow{3}{*}{$\begin{array}{l}\text { Annual } \\
\text { Value of } \\
\text { Choice } \\
\text { (billions } \\
\text { 1995 \$) }\end{array}$} & \multicolumn{4}{|c|}{$\begin{array}{l}\text { Unit Value of Choice by Modal Availabliity } \\
\text { (1995 cents per person trip) }\end{array}$} \\
\hline & \multirow{2}{*}{$\begin{array}{c}\text { No } \\
\text { Public } \\
\text { Transit }\end{array}$} & \multicolumn{3}{|c|}{ Public Transit Available } \\
\hline & & $\begin{array}{l}\text { No Private } \\
\text { Modes }\end{array}$ & $\begin{array}{l}\text { No Other } \\
\text { Modes }\end{array}$ & $\begin{array}{l}\text { All Modes } \\
\text { Available }\end{array}$ \\
\hline 18.6 & 0 & 70 & 10 & 9 \\
\hline
\end{tabular}

'Based on the assumptions in Table 1.

expenses is about $\$ 8$ billion, which is calculated as follows: For a given average lifetime, $\mathrm{N}$, the amortized amount needs to account for all transit capital investments that have been made in the last $N$ years. Given a discount rate, $r$, and an annual average amount of transit capital investments, $\mathrm{K}$, the annual amount of amortized transit capital investments is equal to $\mathrm{N} \mathrm{K} /\left(1-c^{\mathrm{N}}\right)$, where $\mathrm{c}=1 /(1+\mathrm{r})$. The values for $\mathrm{N}, \mathrm{r}$, and $\mathrm{K}$ are shown in Table 1 .

\section{Comparing the Value of Choice and Cost of Public Transit Provision}

The aggregate value of choice and the annual total cost of providing public transit are compared in four ways. First, they are compared, allowing changes in the cost coefficient. Figure 2 shows the results, with changes in the cost coefficient between -0.02 and -0.4 . The annual cost of providing public transit is comparable to the lower estimates but is much lower than the higher estimates of public transit's value of choice. At the median of the range for the cost coefficient suggested by Table $2(-0.2)$, the annual amount of public transit's value of choice in 1995 is about $\$ 18.6$ billion in 1995 dollars, which is slightly more than 70 percent of the annual cost of providing public transit in 1995.

Second, they are compared, allowing changes in the availability of public transit. Figure 2 is drawn with the assumption that public transit is available to 80 percent of all person trips. This estimate of public transit's availability is somewhat uncertain, however. Figure 3 shows the results, with the number of person trips without public transit available ranging between 0 percent and 94 percent. 


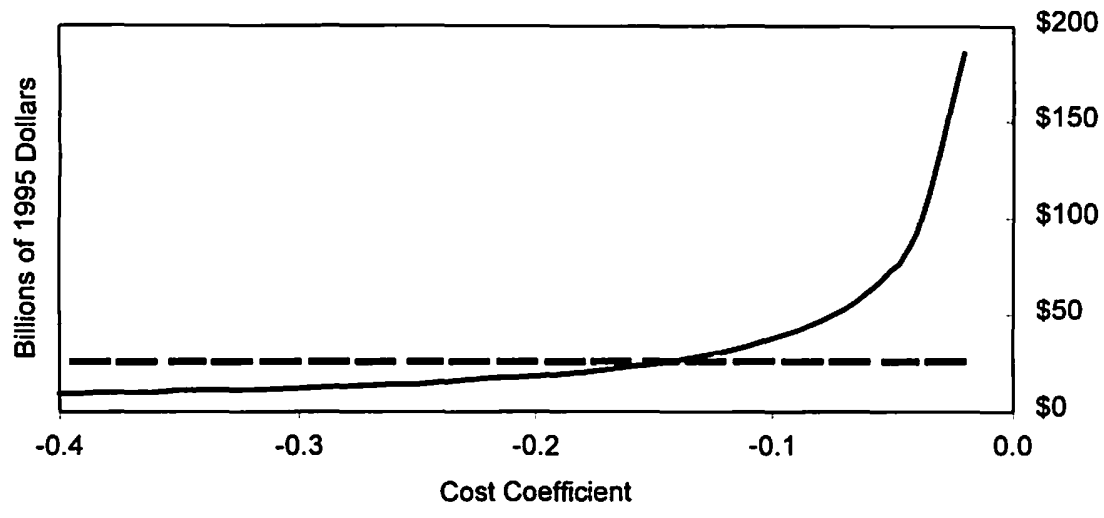

Value of Choice _ _ Cost of Public Transit

Figure 2. Comparison, allowing changes in the cost coefficient, 1995 (based on assumptions in Table 1 except values of the cost coefficient).

The number of person trips with all modes available ranges between 94 percent and 0 percent. The numbers of person trips without private modes available and without other modes available remain at 5 percent and 1 percent, respectively. A value of -0.2 for the cost coefficient is used. For a given value of the cost coefficient, public transit's value of choice decreases linearly with increases in the percentage of person trips without public transit. The value of choice would be about $\$ 46$ billion if public transit were available to all trips and about $\$ 13$ billion if pubic transit were unavailable to any person trips with both private modes and other modes available. The value of choice and cost of providing public transit are comparable in magnitude.

Third, they are compared, allowing hypothetical increases in the modal split of public transit, while the availability of public transit being held constant at 80 percent. Figure 4 shows the results, with the modal split of public transit ranging from 1.8 percent to 50 percent. The calculation for Figure 4 is based on a value of -0.2 for the cost coefficient. The modal split of private modes ranges from 86.3 percent to 38.1 percent, while the modal split of other modes stays constant 


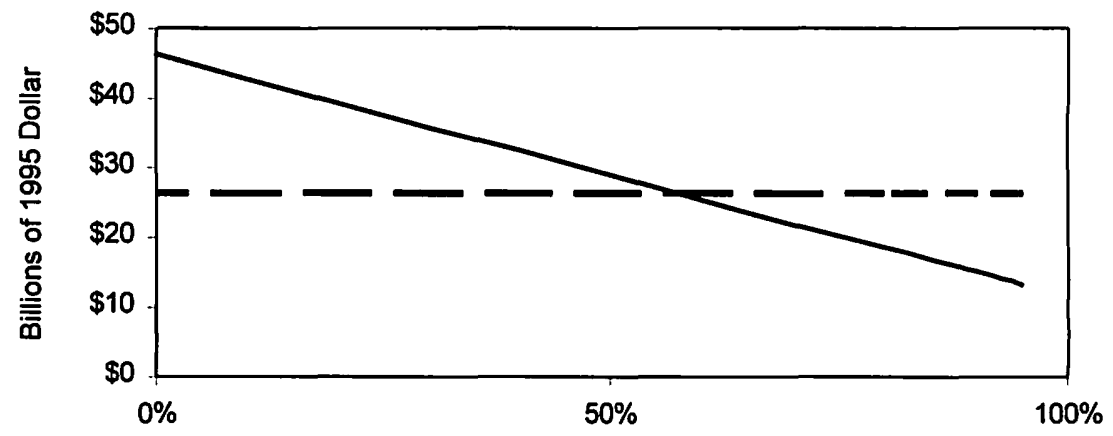

Percent Person Trips without Public Transit Available

Value of Choice - - Cost of Public Transit

Figure 3. Comparison, allowing changes in public transit's availability, 1995 (based on assumptions in Table 1 except percent person trips without public transit available).

at 11.9 percent. The annual cost of providing public transit at each hypothetical modal split of public transit is calculated as follows. First, the cost per trip is computed by dividing the total cost of $\$ 26$ billion by the total number of public transit trips in 1995. Second, this cost per trip is then multiplied by the new number of public transit trips at the increased modal split. Economies or diseconomies of scale in public transit provision are not accounted for in this calculation. The result again indicates that the value of choice and the cost of providing public transit are comparable in magnitude at increased levels of modal split for public transit, especially when transit's modal split is below 20 percent.

Fourth, they are compared, allowing hypothetical increases in the modal split of public transit and changes in the availability of public transit. Figure 5 shows the results. The only difference between Figures 4 and 5 is that public transit's availability is constant in Figure 4 but changes in Figure 5. It is unreasonable to assume that public transit's availability stays constant when its modal split changes. Pubic transit's availability is held constant in Figure 4 because of 
the desire to isolate the effect of increasing public transit's modal split on its value of choice. Public transit's modal split and availability in Figure 5 relate as follows: its availability is 80 percent, 75 percent, 70 percent, 65 percent, 60 percent, 55 percent, and 50 percent when its modal split is 1.8 percent, 5 percent, 10 percent, 20 percent, 30 percent, 40 percent, and 50 percent, respectively. These numbers are somewhat arbitrary because of lack of empirical guidance on how public transit's availability and modal split relate to each other. The result indicates that the value of choice is comparable in magnitude to the cost of providing public transit.

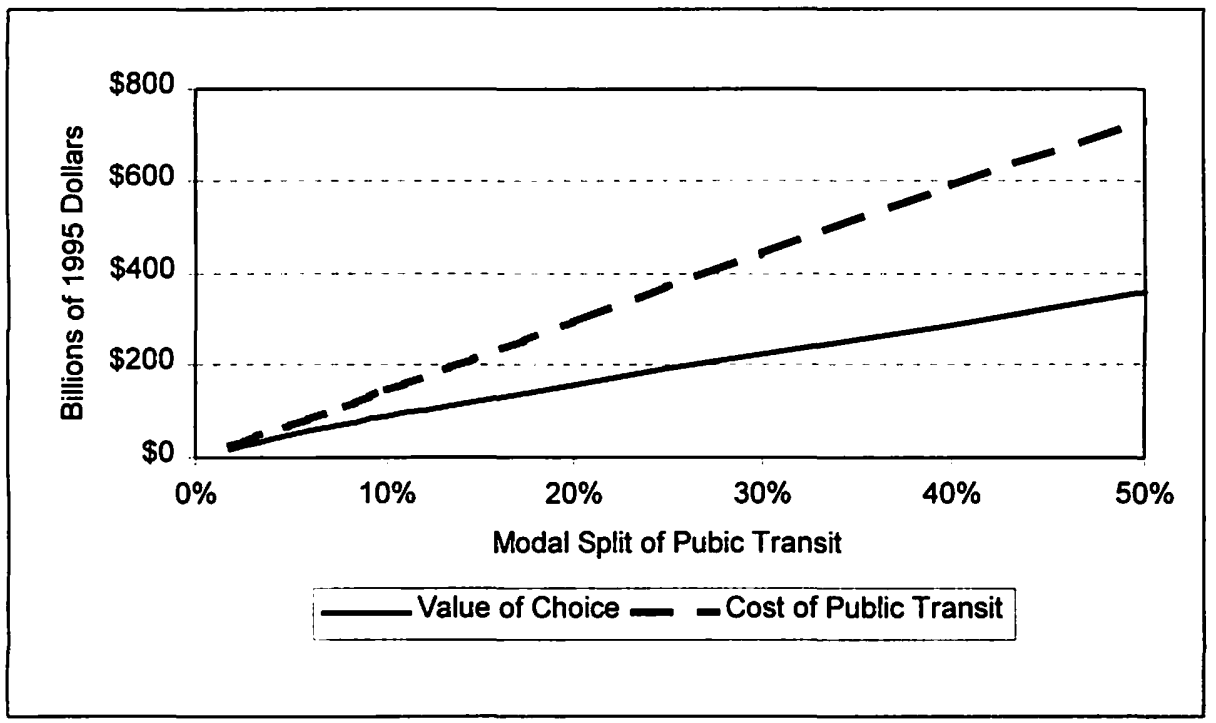

Figure 4. Comparison, allowing increases in public transit's modal split.ab

- The values of choice are based on the following: a value of -0.2 for the cost coefficient; public transit being available to 80 percent of all person trips; modal split of private modes ranging from 86.3 percent to 38.1 percent; and modal split of other modes being constant at 11.9 percent.

- The annual cost of providing public transit at each hypothetical modal split of public transit is calculated as follows. First, the cost of per trip is computed by dividing the total cost of $\$ 26$ billion in 1995 by the total number of public transit trips in 1995. Second, this cost per trip is then multiplied by the new number of public transit trips at the increased modal split. Economies of scale in public transit provision are not accounted for in this calculation. 


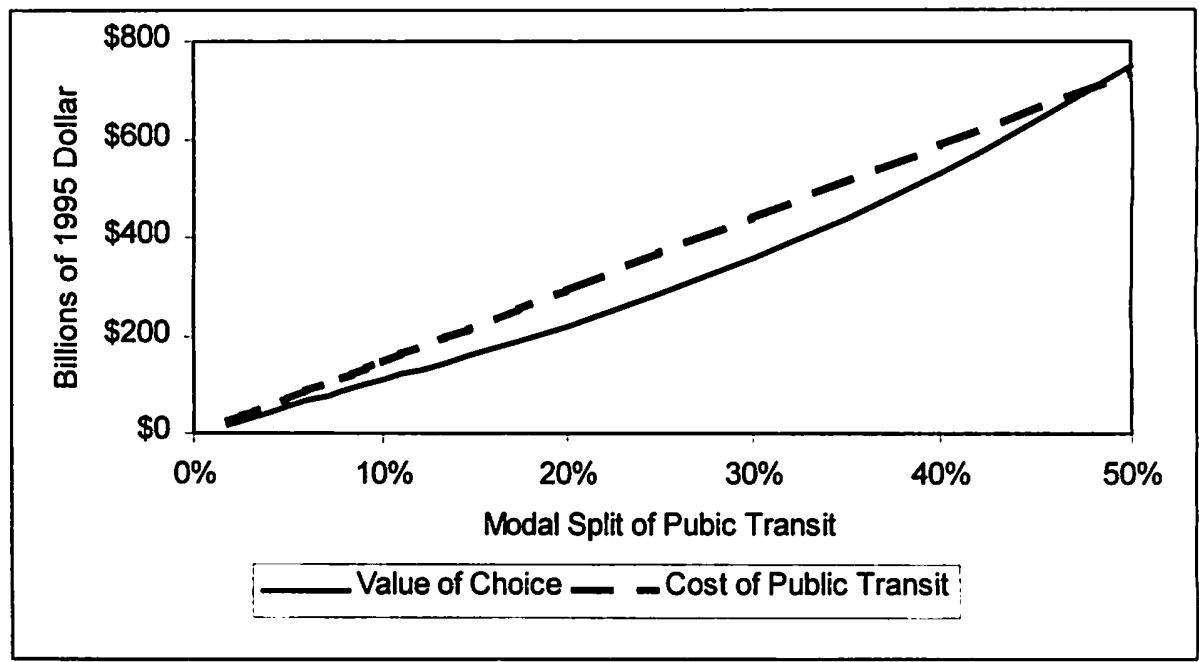

Figure 5. Comparison, allowing changes in transit's modal split and availability.:

- Figure 5 differs from Figure 4 in the following way. In Figure 4, the availabliity of public transit is held constant at 50 percent, while it changes with the modal split of public transit in Figure 5. Specifically, public transit's availability is 80 percent, 75 percent, 70 percent, 65 percent, 60 percent, 55 percent, and 50 percent when its modal split is 1.8 percent, 5 percent, 10 percent, 20 percent, 30 percent, 40 percent, and 51 percent, respectively. These numbers are somewhat arbitrary because of lack of empirical evidence on how public transit's availability and modal split relate to each other.

\section{Conclusion}

The paper has developed a methodology to estimate the value of having a public transit choice. This value is in addition the user and non-user benefits that result from improved performance in the transportation system due to the presence of public transit. A variety of approaches to quantifying the user and nonuser benefits of public transit exist, which result from performance changes. This methodology allows a means of quantifying the value of choice in supplementing the user and non-user benefits for public transit.

This paper has also applied this methodology to provide a plausible though crude estimate of the value of having a public transit choice. Interestingly, the value of choice is comparable in magnitude to the total cost of providing public transit services under a variety of scenarios in this country. In the most reasonable scenario presented, the value of choice nationally was estimated at $\$ 18.6$ 
billion annually. This value alone exceeds 70 percent of the total U.S. cost of pubic transit provision at $\$ 26$ billion annually.

Future research might take two directions. The strategy provides one possible set of estimates for valuing the national presence of transit as a choice. In any given urban area, the planner can use this methodology to develop localized estimates of this value for use in local policy analysis. Second, this paper has estimated the value of choice for public transit through a plausible though crude application of a well-funded methodology. Specifically, the application uses a two-point approximation to what really is a continuous distribution of generalized costs. Future work may explore more refined applications. For example, an application to a metropolitan area may use a mode choice model estimated specifically for this area, which allows one to use the true distribution of generalized costs. Finally, additional exploration of the quantification of contingency value can support efforts to quantify the total value of providing public transit services.

\section{Appendix}

This appendix develops the methodology applied in this paper. The logit mode choice model is first described, followed by the measure of consumer surplus from Small and Rosen (1981). This measure of consumer surplus is then broken down to develop a measure of the value of choice of having a public transit choice.

\section{The Logit Mode Choice Model}

The logit model is widely used in modeling mode choices (Ben-Akiva and Lerman 1985). One behavioral assumption of the model is that an individual chooses among those available to him the mode that would give him the highest level of satisfaction. The level of satisfaction an individual would get from a mode depends a number of things: 1) observed characteristics of the mode, including monetary costs and time spent traveling and waiting; 2 ) observed characteristics of the individual, such as household income and life-cycles; 3 ) unobserved, systematic factors; and 4) unobserved, random factors.

The observed components and unobserved, systematic factors may be summarized as: 


$$
U_{m}=\alpha_{m}+\beta c_{m}+\alpha_{1} i v t_{m}+\alpha_{2} w t_{m}+\alpha_{3} s
$$

where:

$$
\begin{aligned}
& c_{m} \quad=\text { monetary cost of trip making per unit of time via mode } \\
& i v t_{m} \quad=\quad \text { in-vehicle-time of trip making per unit of time via mode } \\
& m \\
& w t_{m} \quad=\quad \text { waiting time of trip making per unit of time via mode } \\
& m \\
& \mathrm{~s} \quad=\text { characteristics of the individual } \\
& \beta, \alpha_{m}, \alpha_{p}, \alpha_{z} \alpha_{3}=\text { coefficients to be estimated. } \alpha_{m} \text { is a mode-specific con- }
\end{aligned}
$$

Each variable in equation (A1) may vary with individuals. A superscript to indicate individuals is not used for simplicity. The unobserved, random factors are captured in an error term not shown in equation (A1). Some of the unobserved factors are random to the analyst but not to the individuals. Examples of such factors include personal characteristics not included in the model, such as crime rates in where an individual lives. Others are random to both the analyst and the individuals, such as weather conditions.

Alternatively, $U_{m}$ may be written as

$$
U_{m}=\beta\left(c_{m}+\frac{\alpha_{m}}{\beta}+\frac{\alpha_{1}}{\beta} i v t_{m}+\frac{\alpha_{2}}{\beta} w t_{m}+\frac{\alpha_{3}}{\beta} s\right)
$$


The terms in the parentheses give the generalized cost of making one trip via mode $m$ :

$$
G_{m} \equiv c_{m}+\frac{\alpha_{0}}{\beta}+\frac{\alpha_{1}}{\beta} i v t_{m}+\frac{\alpha_{2}}{\beta} w t_{m}+\frac{\alpha_{3}}{\beta} s
$$

The probability of an individual choosing mode $m$ is given by:

$$
P_{m}=\frac{e^{\beta G_{m}}}{\sum_{k} e^{\beta G_{k}}}
$$

where $k$ sums over all modes available to the individual and $e$ is the exponential base.

\section{Consumer Surplus Measure}

The denominator in equation (A4) gives the maximum satisfaction an individual can get from the choice situation. Assuming that only one trip is made per unit of time, this maximum satisfaction can be used to measure the consumer surplus to the individual as follows (Small and Rosen 1981):

$$
C S=-\frac{1}{\beta} \ln \sum_{m} e^{\beta G_{m}}
$$

where $-\beta$ is the marginal utility of income, In is the logarithmic function, and $\mathrm{m}$ sums over all modes available to the individual.

The economic benefits of a policy change to the individual per unit of time would be changes in $C S$ because of the policy change. In the case of this paper, the economic benefits of having public transit available is measured by the difference between the amount of consumer surplus with public transit as it is today 
and the amount of consumer surplus without public transit. This measure of benefits applies to users of all modes even if the policy is specific to a particular mode.

\section{The Value of Choice for Public Transit}

For this analysis, it is assumed that the choice for each one-way person trip is among three modes: private modes (automobiles, vans, and trucks), public transit (bus, trolley, and rail), and other modes (bicycling, walking, taxi, school bus, and others). Let $G_{C}, G_{T}, G_{O}$ be the generalized costs per one-way person trip for private modes, public transit, and other modes, respectively. Using equation (A5), consumer surplus per person trip is the following:

$$
C S=-\frac{1}{\beta} \ln \left[e^{\beta G_{O}}+e^{\beta G_{C}}+e^{\beta G_{T}}\right]
$$

The absence of public transit would result in a change in $G_{T}$ from the current value $\mathrm{G}_{\mathrm{T}}$ to an infinitely large value $G^{A}$ (an infinitely large value is equivalent to services not being available), where superscript " $\mathrm{A}$ " indicates the case without public transit available. The absence of public transit may also result in changes in $G_{C}$ and $G_{C}$ from current values $G_{o}$ and $G_{C}$ to $G^{A}{ }_{o}$ and $G^{A}$, respectively. Equation (A6) gives the current amount of consumer surplus per person trip, while the amount of consumer surplus per person trip would be $C S_{\mathrm{A}}=-\ln$ $\left[e^{\beta G_{0}^{A}}+e^{\beta G} \hat{c} / \beta\right.$ without public transit. The difference in consumer surplus per person trip between with and without public transit, i.e., $\triangle C S=C S-C S_{\mathrm{A}}$, gives the total per-trip value of having public transit available.

This value can be broken down into two parts:

$$
\Delta C S=\left[C S-C S^{0}\right]+\left[C S^{0}-C S_{A}\right] \text {, where } C S^{0}=-\ln \left[e^{\beta \mathcal{Q}}+e^{\beta G} \mathrm{c}\right] / \beta
$$

The first component measures changes in consumer surplus without changes in performance of other modes. The second component measures changes in consumer surplus as a result of changes in performance of other modes due to 
having public transit available. The first component is interpreted as the value of choice for public transit, which can be rewritten as:

$V_{\text {all }}=-\frac{1}{\beta}\left[\ln \left(1+e^{\beta\left(G_{o}-G_{C}\right)}+e^{\left.\beta\left(G_{T}-G_{c}\right)\right)}-\ln \left(1+e^{\beta\left(G_{o}-G_{c}\right)}\right)\right]\right.$

Several characteristics of this value are important to point out. First, this value is to individual person trips when the generalized costs are measured for individual person trips. Second, the value applies to all person trips. Third, the formula gives the value of choice for individual trips. For each of the modes, there is a distribution of generalized costs facing different trips. Allowing this variation in generalized costs, however, goes beyond the scope of this paper. Instead, a two-point approximation is used. For each of the three modes, the generalized cost is the average value for trips to which a particular mode is available, while the generalized cost is infinity for trips to which the particular mode is unavailable.

Specifically, if all three modes are available, the value is given by equation (A7). If public transit is unavailable, the value becomes zero: $V_{T}=0$. If private modes are unavailable, the value becomes:

$$
\left.V_{C}=-\frac{1}{\beta} \ln \left[1+e^{\beta\left(G_{r}-G_{O}\right)}\right)\right]
$$

If other modes are unavailable, the value becomes:

$$
V_{O}=-\frac{1}{\beta} \ln \left[1+e^{\beta\left(G_{T}-G_{c}\right)}\right]
$$


Calculating the unit values would require first specifying a value for the cost coefficient from the logit mode choice model, $B$, and then determining the exponential values that appear in equations (A7), (A8), and (A9). In fact, if we let $P_{c} P_{r}$ and $P_{o}$ represent the current modal splits of the private modes, public transit, and other modes, respectively, the above exponential values are equal to the corresponding odds ratios:



Once the unit values for different levels of modal availability are computed, they can be aggregated over all person trips with the distribution of modal availability. Let $D$ be the annual number of person trips nationwide and $M_{C}, M_{r}, M_{o}$. and $M_{a l l}$ be the shares of person trips that have no private modes available, no public transit available, no other modes available, and all modes available, respectively. Then the annual value of choice may be measured by $V=D\left(M_{c} V_{c}+\right.$ $\left.M_{T} V_{T}+M_{O} V_{O}+M_{u l l} V_{u l l}\right)$, where $V_{C}, V_{r}, V_{O}$ and $V_{u l l}$ are the unit values for the four levels of modal availability.

\section{References}

American Public Transit Association (APTA). 1997. Transit fact book. Washington, D.C.: APTA.

Anderson, S. P., and A. de Palma. 1992. The Llgit as a model of product differentiation. Oxford Economic Papers 44: 51-67.

Ben-Akiva, M., and S. R. Lerman. 1985. Discrete choice analysis: Theory and application to travel demand. Cambridge, Massachusetts: the MIT Press.

Cambridge Systematics, Inc. 1998. Economic impact analysis of transit investments: Guidebook for practitioners. Washington, D.C.: Transit Cooperative Research Program, Report 35, Transportation Research Board.

Dunne, J. P. 1984. Elasticity measures and disaggregate choice models. Journal of Transport Economics and Policy 18(2): 189-203.

Galbraith, R. A., and D. A. Hensher. 1982. Intra-Metropolitan transferability of mode choice models. Journal of Transport Economics and Policy 16(1): 7-29. 
Hensher, D. A. 1972. The consumer's choice function: A study of traveler behavior and values. Unpublished Ph.D. dissertation, School of Economics, University of New South Wales, Australia.

Koppelman, F. S., and M. Hirsch. 1989. Intercity travel behavior: Theory and empirical analysis. In Travel Behavior Research, ed. Brookfield. The International Association for Travel Behavior, USA: Avebury.

Morrison, S. A., and C. Winston. 1985. An econometric analysis of the demand for intercity passenger transportation. In Research in Transportation Economics, Vol. 2, ed. T. E. Keeler. Greenwich, Connecticut: JAI Press: 213-237.

Morrison, S. A. 1990. The value of AMTRAK. Journal of Law and Economics 33: 361-382.

Parody, T. E. 1977. Analysis of predictive qualities of disaggregate modal-choice models. Transportation Research Record 637: 51-57.

Perloff, J. M, and S. C. Salop. 1985. Equilibrium with product differentiation. Review of Economic Studies 52: 107-120.

Sattinger, M. 1984. Value of an additional Firm in monopolistic competition. Review of Economic Studies 51: 321-332.

Small, K. A, and H. S. Rosen. 1981. Applied welfare economics with discrete choice models. Econometrica 49: 105-130.

Small, K. A. 1983. Bus priority and congestion pricing on urban expressways. In Research in Transportation Economics, Vol. 1, ed. T. E. Keeler. Greenwich, Connecticut: JAI Press: 27-74.

Stopher, P. R. 1969. A probability model of travel mode choice for the work journey. Highway Research Record 283.

Stopher, P. R., and A. H. Meyburg. 1976. Behavioral travel-demand models. In Behavioral travel demand models, Proceedings of the Second International Conference on Behavioral Travel Demand, Asheville, N.C., 1975.

Suen, W. 1991. The value of product diversity. Oxford Economic Papers 43(2): $217-$ 223.

Train, K. E. 1994. Self-selecting tariffs under pure preferences among tariffs. Journal of Regulatory Economics 6(3): 247-64.

Weisbrod, B. A. 1964. Collective-consumption services of individual-consumption goods. Quarterly Journal of Economics 78: 471-477. 
Weitzman, M. L. 1992. On diversity. Quarterly Journal of Economics 107: 363-405. Weyrich, P. M., and W. S. Lind. 1996. Conservatives and mass transit: Is it time for a new look? Washington, D.C.: APTA.

\section{Acknowledgment}

We are grateful to F. Ron Jones and three anonymous referees for their comments and suggestions on earlier versions. The research was partially funded by the National Urban Transit Institute (NUTI) at the Center for Urban Transportation Research (CUTR). The content of the paper reflects the views of the authors, not necessarily those of NUTI or CUTR.

\section{About the Authors}

Xuehao Chu, Ph.D., is a Research Associate at the Center for Urban Transportation Research at the University of South Florida in Tampa.

Steve Polzin, Ph.D., P.E., is Deputy Director for Institutes at the Center for Urban Transportation Research at the University of South Florida in Tampa. 